\title{
An Investigation of Tunnel-Soil-Pile Interaction in Cohesive Soils
}

by

JOE MATTAR
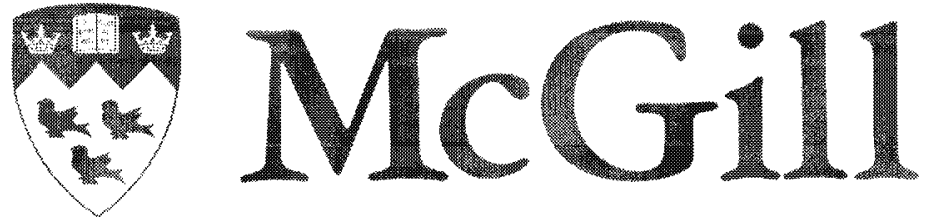

Department of Civil Engineering and Applied Mechanics

McGill University

Montreal, Canada

December 2007

\begin{abstract}
A Thesis Submitted to the
Graduate and Postdoctoral Studies Office

in partial fulfillment of the requirements of the degree of

Masters of Engineering
\end{abstract}

(C) Joe Mattar, 2007 
Library and

Archives Canada

Published Heritage

Branch

395 Wellington Street

Ottawa ON K1A 0N4

Canada
Bibliothèque et

Archives Canada

Direction du

Patrimoine de l'édition

395 , rue Wellington

Ottawa ON K1A ON4

Canada

Your file Votre référence

ISBN: 978-0-494-51468-9

Our file Notre référence

ISBN: 978-0-494-51468-9

NOTICE:

The author has granted a nonexclusive license allowing Library and Archives Canada to reproduce, publish, archive, preserve, conserve, communicate to the public by telecommunication or on the Internet, loan, distribute and sell theses worldwide, for commercial or noncommercial purposes, in microform, paper, electronic and/or any other formats.

The author retains copyright ownership and moral rights in this thesis. Neither the thesis nor substantial extracts from it may be printed or otherwise reproduced without the author's permission.
AVIS:

L'auteur a accordé une licence non exclusive permettant à la Bibliothèque et Archives Canada de reproduire, publier, archiver, sauvegarder, conserver, transmettre au public par télécommunication ou par l'Internet, prêter, distribuer et vendre des thèses partout dans le monde, à des fins commerciales ou autres, sur support microforme, papier, électronique et/ou autres formats.

L'auteur conserve la propriété du droit d'auteur et des droits moraux qui protège cette thèse. $\mathrm{Ni}$ la thèse ni des extraits substantiels de celle-ci ne doivent être imprimés ou autrement reproduits sans son autorisation.
In compliance with the Canadian

Privacy Act some supporting forms may have been removed from this thesis.

While these forms may be included in the document page count, their removal does not represent any loss of content from the thesis.
Conformément à la loi canadienne sur la protection de la vie privée, quelques formulaires secondaires ont été enlevés de cette thèse.

Bien que ces formulaires aient inclus dans la pagination, il n'y aura aucun contenu manquant.

\section{Canada}




\section{ACKNOWLEDGEMENTS}

The author would like to thank all persons who have been involved in this research project. I am particularly grateful to Professor Mohamed Meguid for his supervision and guidance throughout the execution of this project.

My warmest thanks to my collaborator Miguel Nunes who helped make the project a success even in doubt.

Special thanks to John Bartczak, Damon Kiperchuk, Ronald Shepherd, Marek Przykorski, William Cook, Jorge Sayat, Joe Colaciello, Robert Wolak, Frank, and all technicians and specialists for their expertise, and sense of humour.

I cordially thank Cheehan Leung, Zach Veaner, Nisreen Balh, Charlotte Chow, Shoshanna Saxe, Sean Monkman, Merouane, Kaveh, and many others for their help and encouragements.

I specially thank Maggie Wolfe for her patience.

My dearest thanks to Nabil Saliba for his invaluable counsel and advice, to which I am very grateful.

And last but not least, a big thank you to my parents and my family for the love and support. 


\begin{abstract}
Underground tunnels are considered to be a vital infrastructure component in most cities around the world. Careful planning is always necessary to ensure minimum impact on nearby surface and subsurface structures. This thesis describes the experimental and numerical investigations carried out at McGill University to examine the effect of existing pile foundation on the stresses developing in a newly constructed tunnel supported by a flexible lining system. A small scale testing facility was designed and built to simulate the process of tunnel excavation and lining installation in the close vicinity of pre-installed piles. Lining stresses were measured for different separation distances between the tunnel and the existing piles. Significant decrease in circumferential stresses was observed when the lining was installed at a distance that ranges between one to three times the tunnel diameter from the piles. Two-dimensional finite element analyses were also conducted to investigate the different aspects of the pile-soil-lining interaction including lining deformation, axial forces and bending moments. The measured lining stresses agreed with those obtained using finite element analysis. The results presented in this study provided an insight into understanding an important aspect of this soil-structure interaction problem.
\end{abstract}




\section{RÉSUMÉ}

Les tunnels souterrains jouent un rôle vital au niveau de l'infrastructure urbaine moderne dans le monde. Une planification minutieuse est nécessaire afin de garantir un impact minimal sur les structures souterraines se situant à proximité. Cette étude présente les recherches expérimentales et numériques qui se sont effectuées a l'Université McGill pour étudier l'influence de la présence de pieux sur les contraintes qui se développent au niveau d'un tunnel nouvellement construit et d'un système de doublure flexible. Un modèle réduit a été construit afin de simuler la construction de tunnels et l'installation de doublures a proximité de pieux existants. Les contraintes se développant au niveau de la doublure ont été mesures à différentes distances de séparation entre le tunnel et les pieux. Une baisse importante des contraintes sur la doublure a été observée quand le tunnel était situé à une distance des pieux de un à trois fois le diamètre du tunnel. Des analyses 2D par éléments finis ont été également effectuées pour étudier les différents aspects de l'interaction pieu-soil-doublure, comme par exemple la déformation de la doublure, les forces normales et les moments de flexion. Les contraintes mesurées dans les doublures ont été validées par l'analyse par éléments finis. Les résultats présentés dans cette étude ont permis de mieux comprendre l'important problème de l'interaction sol-structure. 


\section{TABLE OF CONTENT}

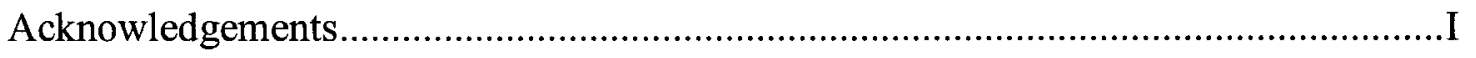

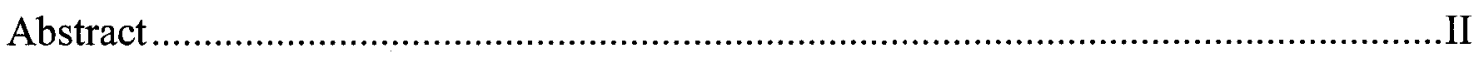

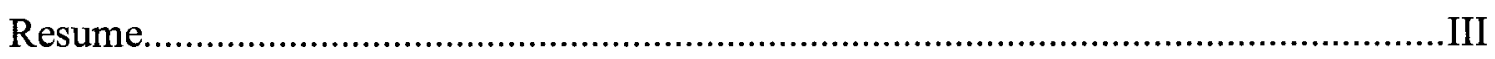

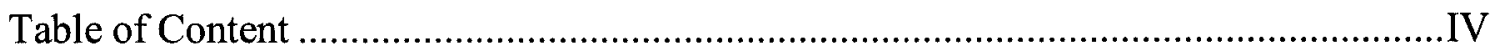

List of Figures and Tables ...................................................................................

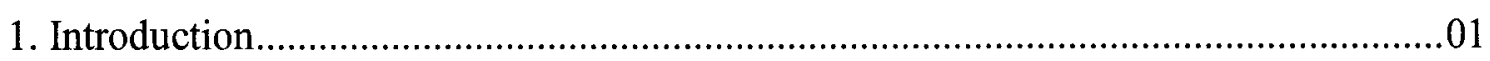

1.1 The Need for More Physical Modeling ....................................................01

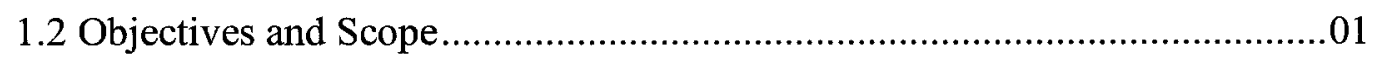

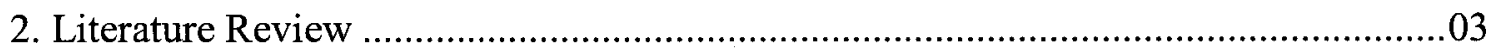

2.1 Soil Movements and Lining Stresses Induced by Tunnelling ......................03

2.2 Physical Modeling of Tunnels in Soft Ground ...........................................10

2.2.1 Gravity vs. Centrifuge Modeling ............................................10

2.2.2 Tunnel Modeling Techniques .................................................12

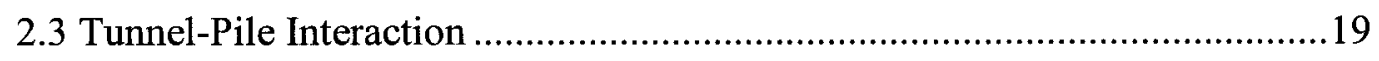

2.3.1 Pile Response to Tunnelling ..................................................20

2.3.2 Effects of Existing Surface Structures on Tunnelling ..................26

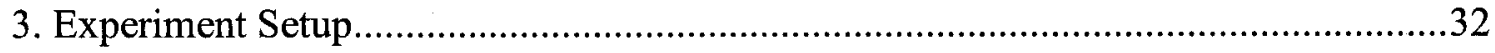

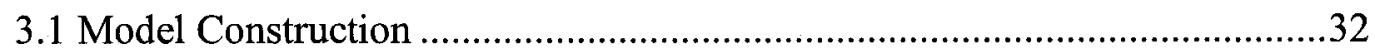

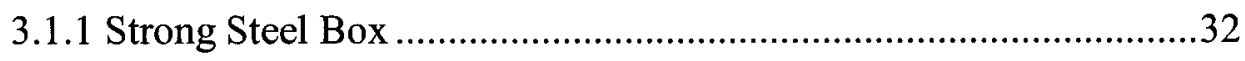

3.1.2 Circular Plexiglas Flanges ....................................................33

3.1.3 Wooden Feed Hopper .............................................................35

3.1.4 Tunnel Excavation Procedure ......................................................36

3.1.5 Tunnel Lining (Monitoring Pipe) ..............................................37

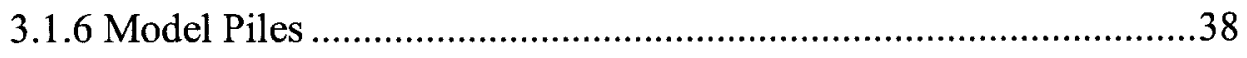

3.2 Tunnel Excavation ......................................................................... 40

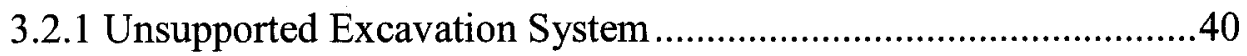

3.2.2 Thin Rods Shield System........................................................41

3.2.3 Fully Shielded Excavation ................................................... 42

3.3 Soil Preparation and Characterization ..................................................45 


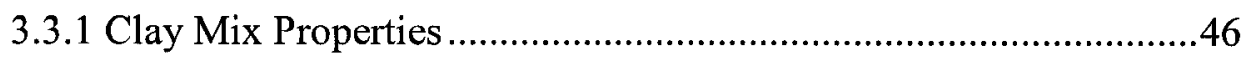

4. Testing Procedure and Data Acquisition ..................................................................

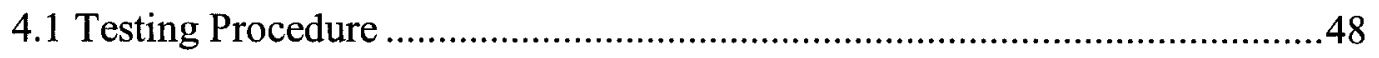

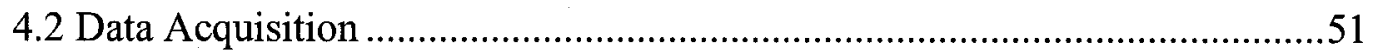

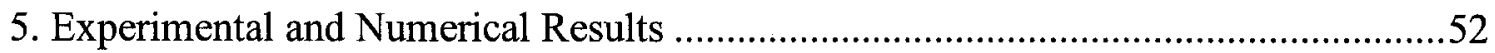

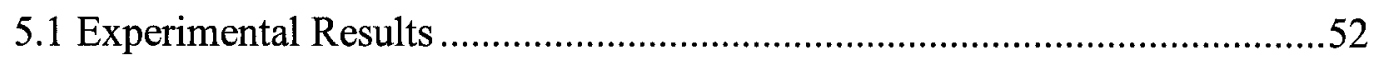

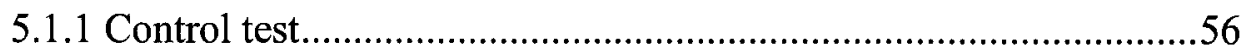

5.1.2 Piles located at 3D away from the tunnel centerline ……...............56

5.1.3 Piles located at 2.5D away from the tunnel centerline ...................57

5.1.4 Piles located at 1D away from the tunnel centerline ......................57

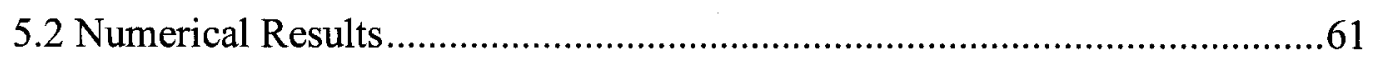

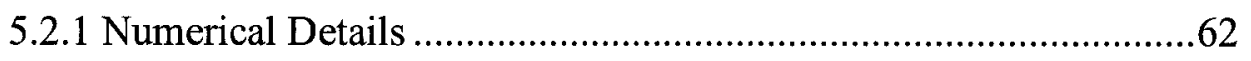

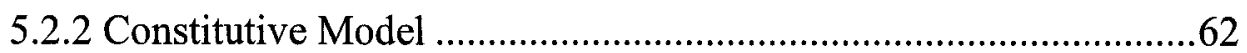

5.2.3 Two-Dimensional Approximation of the Pile Group ......................67

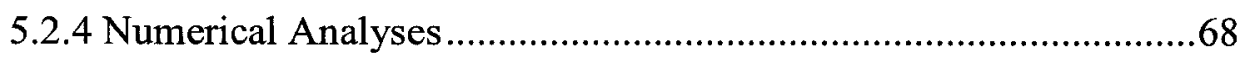

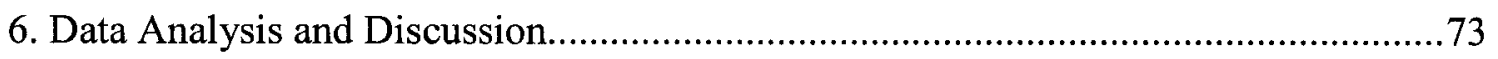

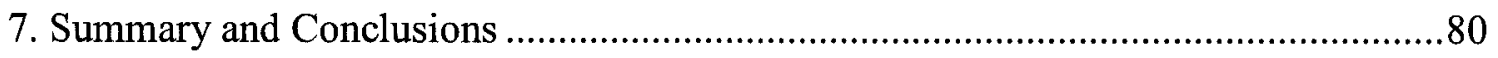

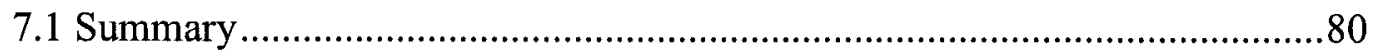

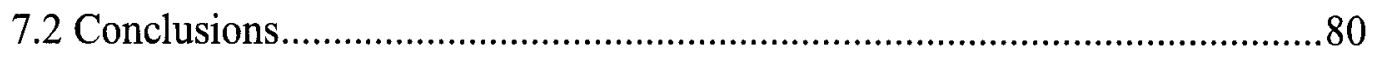

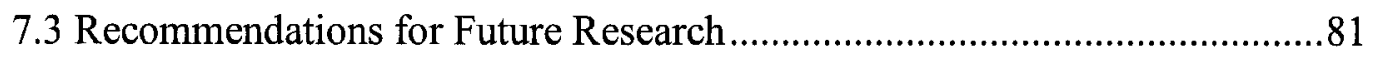

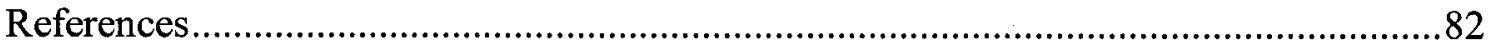

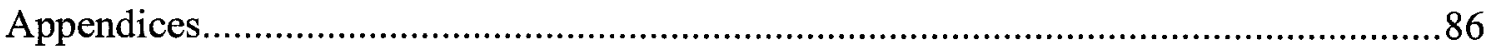




\section{LIST OF FIGURES AND TABLES}

Figure 1.1 - Representation of Pile-Tunnel Interaction

Figure 2.1 - Pressures Against and Deflections of Hypothetical Linings (Peck, 1969).05

Figure 2.2 - Thrust (Left) and Bending Moment (Right) Distributions in a Typical Lining

Figure 2.3 - Shallow Tunnel Problem (Bobet, 2001) .09

Figure 2.4 - Centrifugal Acceleration (Atkinson, Potts and Schofield, 1977)...............11

Figure 2.5 - Typical Trap Door Problem (Meguid et al., 2007) ..................................12

Figure 2.6 - Bury and Cover Model .................................................................. 13

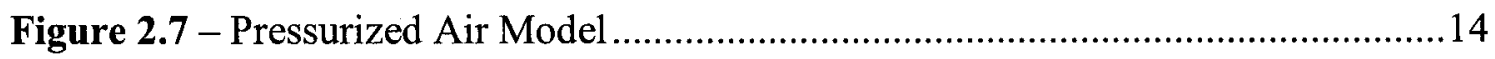

Figure 2.8 - Fluid Pressure Model (Chambon and Corte, 1994) ................................15

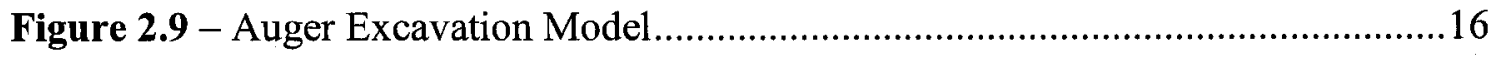

Figure 2.10 - Miniature TBM (Nomoto et al., 1999) …............................................17

Figure 2.11 - Problem Definition (Chen et al., 1999) ..............................................20

Figure 2.12 - Bending Moments in the Pile at a Distance $\mathrm{x}$ from Tunnel Centerline for

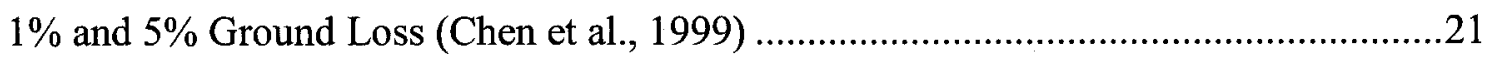

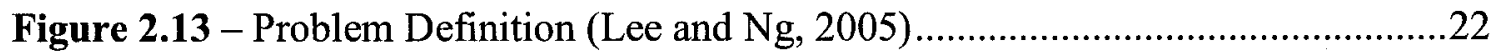

Figure 2.14 - Tunnelling Induced Bending Moments along a Pile at Various Stages of Excavation: a) About $\mathrm{x}$-Axis and b) About $\mathrm{y}$-Axis (Lee and $\mathrm{Ng}, 2005)$.........................23

Figure 2.15 - Problem Definition (Kitiyodom, 2005) ...........................................24

Figure 2.16 - Computed Responses of Single Piles Located at Different Distances, $\mathrm{x}$, from the Tunnel Centerline: a) Lateral Deflection, b) Bending Moment, c) Vertical Movement, and d) Axial Force (Kitiyodom, 2005) ..................................................25

Figure 2.17 - Problem Geometry (Potts and Addenbrooke, 1997) ............................26 
Figure 2.18 - Surface Settlement Trough (Potts and Addenbrooke, 1997)...................28

Figure 2.19 - Model Tunnel Device (Lee and Yoo, 2006)......................................29

Figure 2.20 - Centerline Movements of the Model Tunnel during the Development of

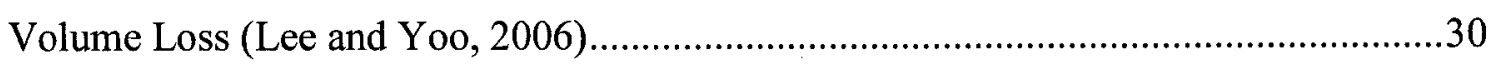

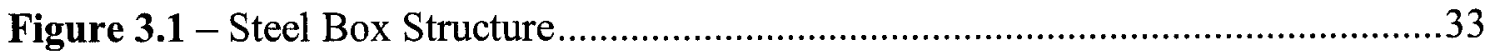

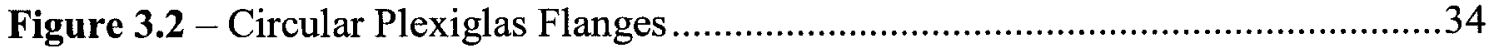

Figure 3.3 - 1/4 inch Threaded Rods around Plexiglas' Face Hole ...............................34

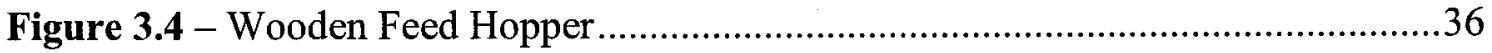

Figure 3.5 - Tunnel Excavation Mechanism (Front View and Back View) ..................36

Figure 3.6 - Monitoring Pipe (Assembled and Open) ….........................................

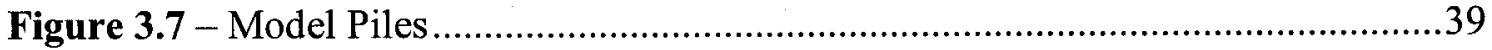

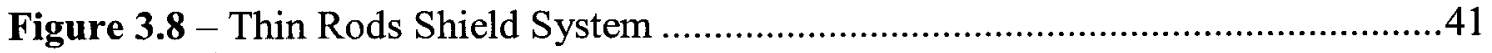

Figure 3.9 - Preliminary Sand Test with Metal Rods...............................................42

Figure 3.10 - Fully Shielded Excavation ............................................................43

Figure 3.11 - Pile Groups Installed around the Tunnel .........................................44

Figure 3.12 - Location of Shear Vane Tests...........................................................47

Figure 3.13 - Grain Size Distribution of the Sand.................................................4

Figure 4.1 - Left: Single Batch Mixing - Right: Unloading Clay with Hopper .............48

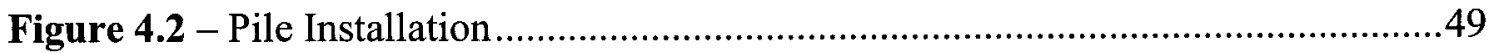

Figure 4.3 - Insertion and Extraction of Shield ..................................................50

Figure 4.4 - Pre- and Post-Extraction of the Shield ................................................50

Figure 4.5 - Complete Data Acquisition Setup ................................................51

Figure 5.1 - Typical Lining and Strain Gauges Locations ......................................52

Figure 5.2 - Typical Strain Gauge Readings ......................................................53 
Figure 5.3 - Layout of Strain Gauge Locations on Lining

Figure 5.4 - Strain Gauge Readings before Correction ..........................................55

Figure 5.5 - Corrected Strain Gauge Readings .................................................55

Figure 5.6 - Strain Gauge Readings for the Control Test.........................................59

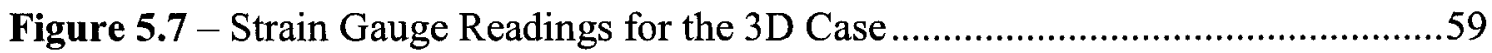

Figure 5.8 - Strain Gauge Readings for the 2.5D Case ..........................................60

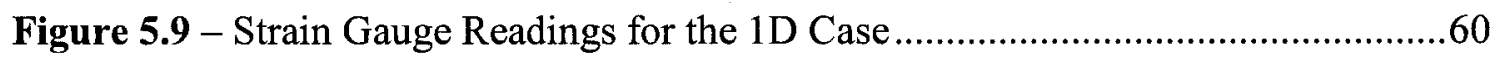

Figure 5.10 - Finite Element Mesh: Control Test ..............................................61

Figure 5.11 - Hyperbolic Stress-Strain Relationship in Primary Loading for a Standard

Drained Triaxial Test (Adapted from Plaxis User Manual, 2004) ................................63

Figure 5.12 - The Variation of the Modulus of Elasticity with Confining Pressure under

CID Test Condition (Kempfert and Gebreselassie, 2006) ..........................................65

Figure 5.13 - Equivalent Two-Dimensional Pile-Soil Section..................................67

Figure 5.14 - Finite Element Mesh: Piles Located 2.5D Away from Tunnel Centerline

Figure 5.15 - Deformed Shape of the Lining: Control Test...................................... 70

Figure 5.16 - Normalized Bending Moments Distribution: Control Test .....................71

Figure 5.17 - Normalized Axial Force Distribution: Control Test..............................72

Figure 6.1 - Bending Moment Ratios at the Crown and the Springline (Control Test).74

Figure 6.2 -Bending Moment Ratios at the Crown and the Springline.........................76

Figure 6.3 -Bending Moments Ratios and Trend at the Tunnel Crown ........................77

Figure 6.4 - Bending Moments Ratios and Trend at the Tunnel Springline ..................77

Figure 6.5 - Trend Comparison: Bending Moments in Lining (Top Chart) vs. Piles

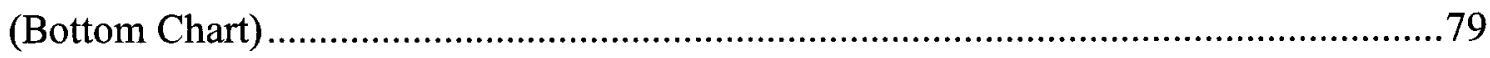


Table 2.1 - Comparison of Various Model Tunnelling Techniques (Adapted from

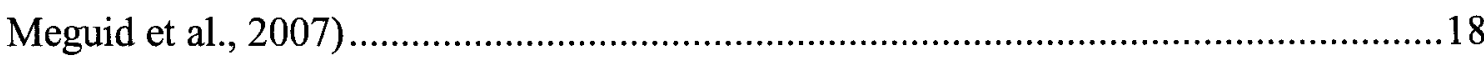

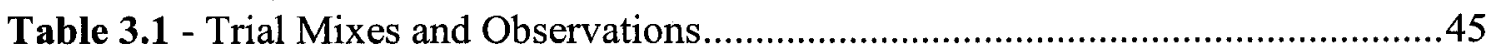

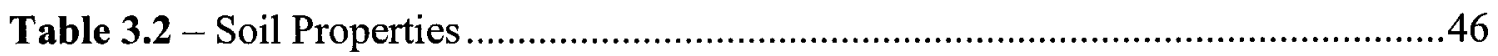

Table 5.1 - Soil Properties in the Numerical Model .................................................66

Table 5.2 - Tunnel/Lining Properties ..............................................................66

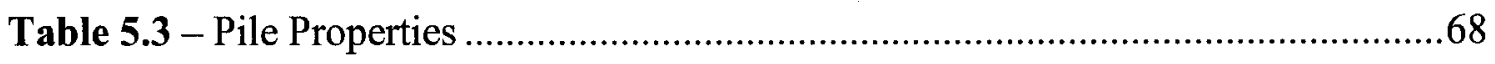

Table 6.1 - Experimental Strain and Stress Values for Crown and Springline...............73

Table 6.2 - Experimental and Numerical Bending Moment Ratios at the Crown and

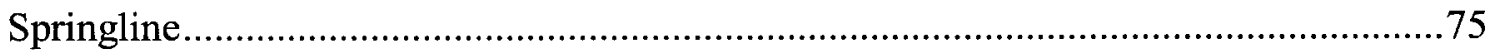

Appendix A - AutoCad Drawing of Steel Box Structure and Flange Components .......86

Appendix B - Pile Grid Dimensions (Top View) ................................................90 


\section{INTRODUCTION}

Tunnels have become an attractive option for sewer, transportation, and other infrastructure, especially in urban areas. Compared to the open trenched methods, they cause less traffic disruption and damage to roads and other surface utilities.

The construction of tunnels, within the broader field of geotechnical engineering, is not an exact science. However, the accumulated experience over the years and abundance of research allowed for more tunnels to be built in different challenging geological conditions. In modern cities, the excavation of tunnels near existing surface and subsurface structures is inevitable and requires more knowledge of the interaction between the newly built tunnel and the existing structures.

\subsection{The need for more physical modeling}

Several studies have been conducted (e.g. Attewell et al., 1986, Chen et al., 1999, Lee and $\mathrm{Ng}, 2005$, Kitiyodom et al., 2005) to investigate the effect of tunnel excavation on the surrounding shallow and deep foundations. However, few attempts have been made to examine the inverse problem of the effect of existing deep foundation on the lining stresses during tunnel construction.

\subsection{Objectives and scope}

The objective of this thesis is to investigate the effect of an existing pile foundation system on circumferential stresses developed in a flexible lining during the construction of a tunnel in the close vicinity of the piles (Figure 1.1). 


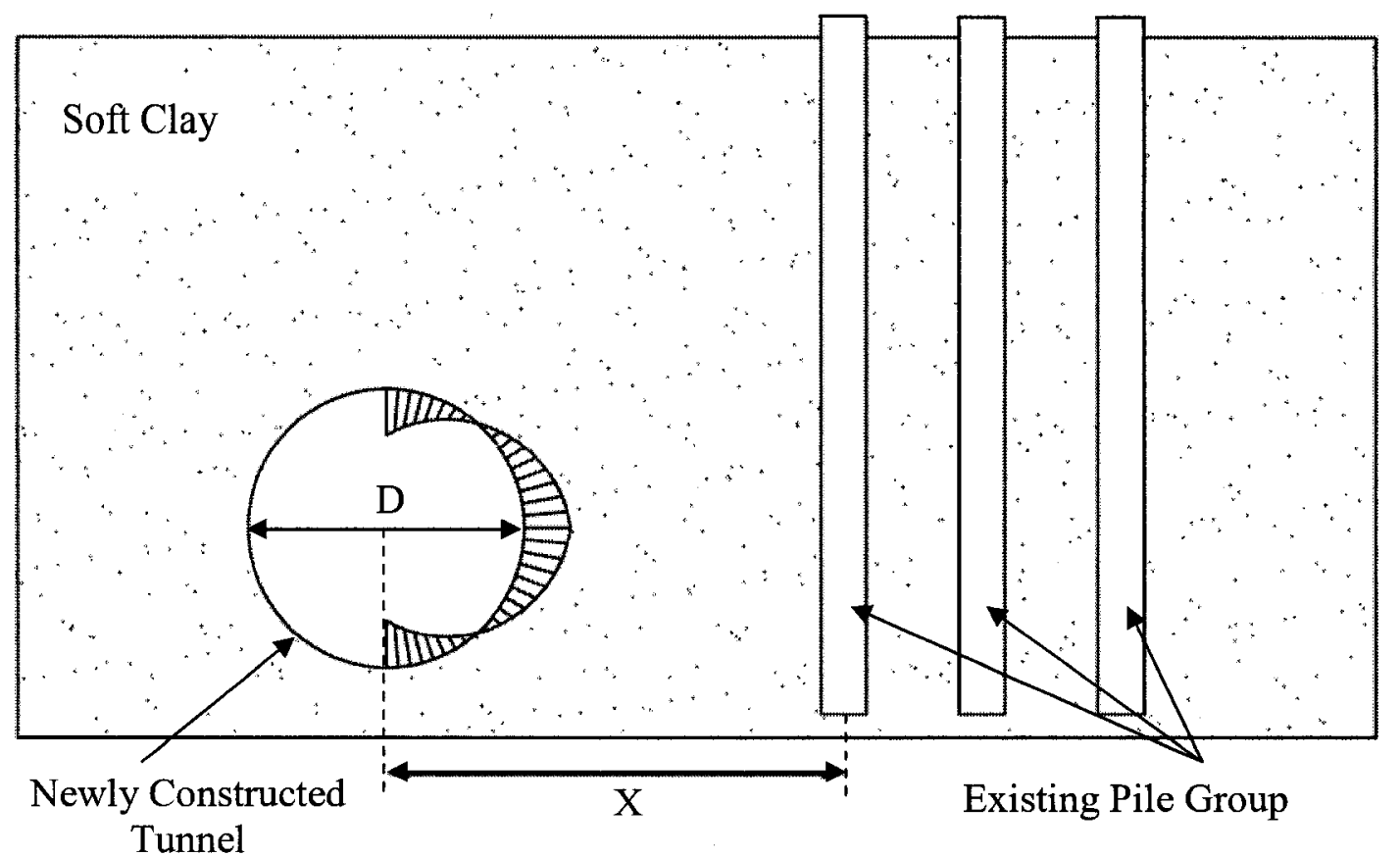

Figure 1.1 - Representation of Pile-Tunnel Interaction

The thesis consists of seven chapters:

Chapter 2 consists of a literature review that summarizes various methods used to calculate stresses in the tunnel lining, a background of the physical modeling techniques, and an examination of the previous research related to pile-tunnel interaction.

Chapter 3 explains the model construction and provides the properties of different materials used to build the model.

Chapter 4 describes the experimental procedures, followed by Chapter 5 which presents the experimental and numerical results, and Chapter 6 that presents a discussion of these results and their practical implications.

Conclusions and recommendations are presented in Chapter 7 of the thesis. 


\section{LITERATURE REVIEW}

This chapter provides a background review of different empirical, semi-empirical and analytical solutions used to calculate ground movements from tunnelling in soft ground and the stresses developing in the tunnel lining. In addition, a review of the different physical modeling techniques used to simulate the process of tunnel excavation and lining installation will be presented. Finally, a brief review of relevant research related to the interaction between tunnels and nearby pile foundation systems will be summarized.

\subsection{Soil movements and lining stresses induced by tunnelling}

The construction of tunnels in soft ground is associated with a change in the state of stress in the ground and with corresponding strains and displacements. Some degree of settlement of the overlying ground surface accompanies ground loss around the tunnel excavation and onto the lining. If such settlement, or subsidence, is excessive, it may cause damage to structures, roads and services located above and next to the tunnel.

The designer is obliged to judge the extent of surface movement or lost ground that would be considered tolerable, and to specify or to grant his approval to construction procedures that will meet the requirements. These obligations cannot be fulfilled unless reliable predictions of the inevitable settlement associated with every construction procedure are made. Proper consideration has to be paid to the type of soil, groundwater conditions, geometry and depth of tunnel, and to any deviations from the best techniques and workmanship for a given construction procedure. 
Peck (1969) provided methods to determine surface settlement and lining stresses induced by tunnelling based on field measurements and empirical data. Analytical solutions for similar problems were also provided by a number of studies (Zurabov and Bugaeva, 1962, Muir Wood, 1975, Curtis et al., 1976, Chou and Bobet, 2002, etc.)

In his state-of-the-art report, Peck (1969) emphasized that strains and deformations are not necessarily undesirable consequences of tunnelling. They constitute part of the mechanism whereby the strength of the soil surrounding the tunnel can be mobilized to improve the stability of the tunnel face during excavation and to reduce the structural demands on the lining.

He also reviewed the basic concepts of lining design by examining the case of a tunnel placed in soil with no disturbances or excavation of the soil within. This initial state of stress is shown in Figure 2.1a, where the vertical pressure at the crown is $p_{z}$ which is equivalent to $\gamma$ (unit weight of soil) times z (depth of cover), and horizontal pressure at the springline equivalent to $K_{o}$ (at rest earth pressure coefficient) times $p_{z}$. If the soil is suddenly removed from inside the flexible but incompressible lining, a new state of equilibrium must be attained as the soil pressures are redistributed and the lining deforms to an elliptical shape as shown in Figure 2.1b.

Had the shape of the lining initially been of a horizontal over vertical diameter ratio of $\mathrm{K}_{\mathrm{o}}$, it would've been in equilibrium after excavation and no deformation are required to achieve the distribution of pressure compatible with the absence of bending stresses in the lining (Figure 2.1-c). 

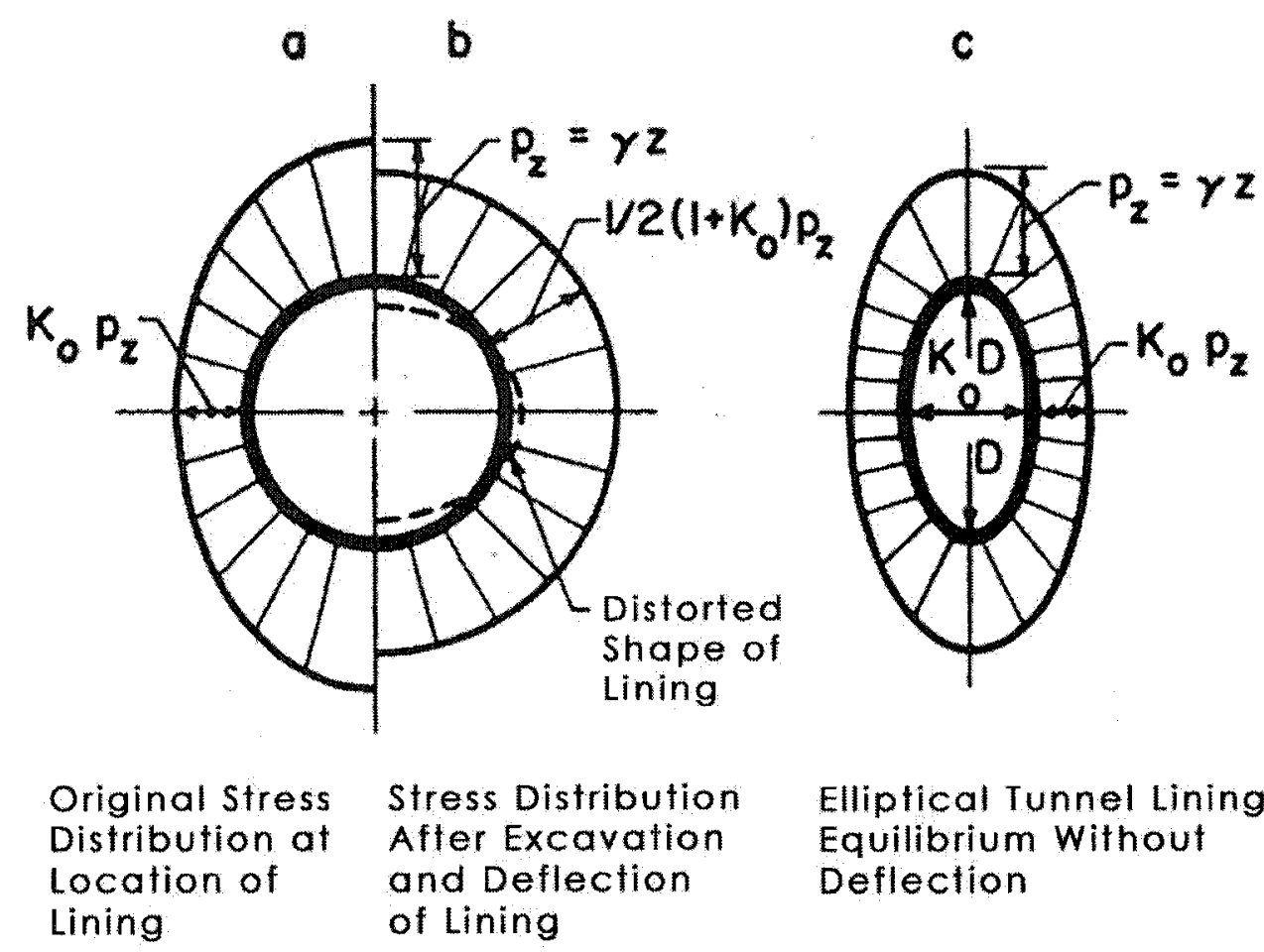

Elliptical Tunnel Lining, Equilibrium Without Deflection

Figure 2.1 - Pressures Against and Deflections of Hypothetical Linings (Peck, 1969)

If instead of a flexible lining there was a rigid and infinitely strong circular lining, the initial pressure would've been the same but after excavation no deformation would occur and therefore preventing any redistribution of soil pressures. In this case, the lining would be subjected to bending moments. These idealized scenarios can greatly assist in visualizing the behaviour and requirements of real tunnel linings.

Peck (1969) also found that in all tunnels, irrespective of the rigidity of the lining, and even in soft clays and silts, the change in diameter have rarely exceeded $0.5 \%$. The findings demonstrated that distortions of more than a few tenths of a percent of the diameter of a lining are effectively prevented by the strength mobilized in the surrounding ground. It was also shown that the rate of distortion in such soils decreases with time. 
Analytical solutions for the normal forces and bending moments in a tunnel lining have also been developed by several researchers considering the relative flexibility of the soillining system. A typical distribution of thrust forces and moments is shown in Figure 2.2.

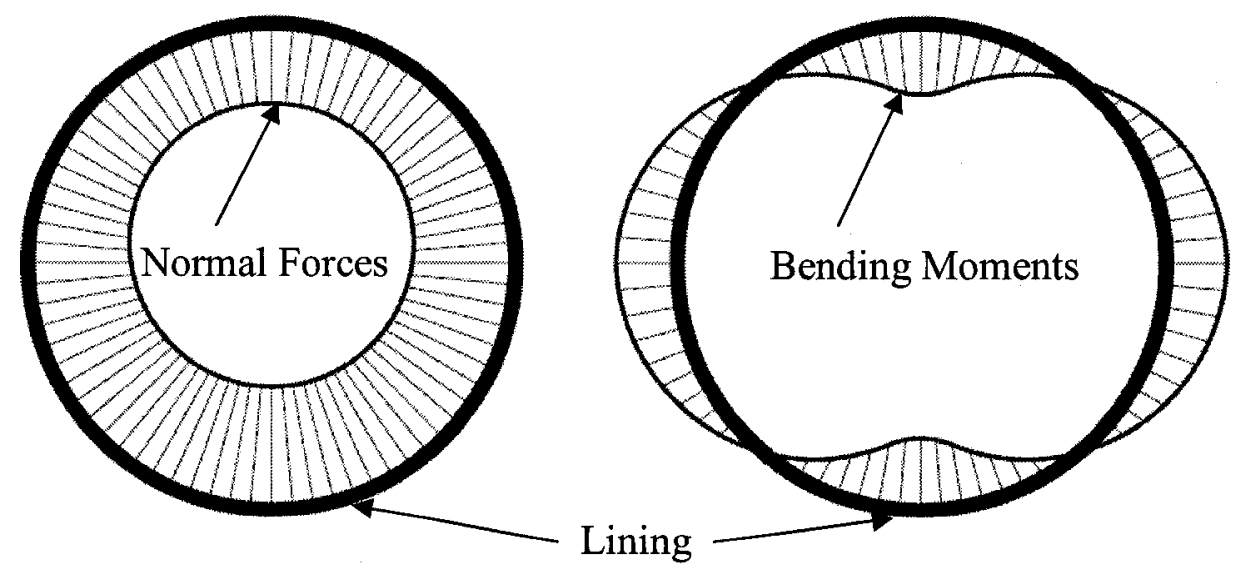

Figure 2.2 - Thrust (Left) and Bending Moment (Right) Distributions in a Typical Lining.

A solution for bending moments in the lining is developed by Zurabov and Bugaeva (1962) as follows:

$M_{M A X}=p_{\nu} r_{o}^{2}\left(0.25-\frac{0.014}{0.06416+\frac{E I(1+\mu)}{E_{c} r_{o}^{3}}}\right)$

Where,

$\mathrm{p}_{\mathrm{v}}=$ vertical pressure at the crown

$r_{o}=$ radius to the extrados of the lining

$\mu=$ Poisson's ratio of the ground

$E_{c}=$ Young's modulus of the soil

$E=$ Young's modulus of the lining 
$I=$ second moment of area of lining per unit length of tunnel.

Muir Wood (1975) proposed a solution to determine the maximum bending moments in linings based on the assumption that the circular lining deforms into an elliptical mode in elastic ground ignoring the shear stresses between the lining extrados and the ground:

$$
M_{M A X}= \pm p_{v}\left(1-K_{o}\right) r_{o}^{2} \cdot \frac{(5-6 \mu)}{6(5-6 \mu)+\frac{2}{(1+\mu)} \cdot \frac{E_{c} r_{o}^{3}}{E I}}
$$

Where $M_{M A X}$ is the maximum bending moment at the crown, $K_{0}$ is the at rest earth pressure coefficient and all other factors are similar to those defined previously.

Curtis et al. (1976) developed another solution to calculate bending moments in tunnel lining, and it is as follows:

$$
M_{M A X}= \pm \frac{p_{v} r_{o}^{2}}{4}\left(1+\frac{E_{c} r_{o}^{3}}{12 E I(1+\mu)} \cdot \frac{(3-2 \mu)}{(3-4 \mu)}\right)
$$

Bobet (2001) proposed a solution for shallow tunnels in dry and saturated ground; lining compressibility and flexibility ratios ( $\mathrm{C}$ and $\mathrm{F}$ respectively) were first introduced:

$$
\begin{aligned}
& C=\frac{E r_{o}\left(1-v_{s}^{2}\right)}{E_{s} A_{s}\left(1-v^{2}\right)} \\
& F=\frac{E r_{o}^{3}\left(1-v_{s}^{2}\right)}{E_{s} I_{s}\left(1-v^{2}\right)}
\end{aligned}
$$

The solution for shallow tunnels in saturated ground becomes: 


$$
\begin{aligned}
& T=\frac{1}{2} \frac{\left[2 E \frac{w}{r_{o}}-\gamma h(1+K)(1+v)\right](C+F)}{(C+F)(1+v)+\left(1-v^{2}\right) C F} r_{o} \\
& -\frac{3}{2} \frac{1}{(1-v) F+6} \gamma h(1-K) r_{o} \cos 2 \theta+\frac{1}{(1-v) F+24} \gamma(1-K) r_{o}^{2} \sin 3 \theta \\
& M=-\frac{3}{2} \frac{1}{(1-v) F+6} \gamma h(1-K) r_{o}^{2} \cos 2 \theta+\frac{1}{(1-v) F+24} \gamma(1-K) r_{o}^{3} \sin 3 \theta
\end{aligned}
$$

Where,

$\mathrm{T}=$ thrust in the lining

$\mathrm{M}=$ bending moment in the lining

$\theta=0^{\circ}$ at springline and $90^{\circ}$ at crown

$\mathrm{w}=$ volume loss

$v=$ Poisson's ratio of the soil

$\gamma=$ unit weight of soil

$h=$ depth of cover to centre of tunnel

$\mathrm{K}=$ at rest earth pressure coefficient

$r_{0}=$ radius of tunnel

$E=$ Young's modulus of the soil

$v_{\mathrm{s}}=$ Poisson's ratio of the lining

$\mathrm{E}_{\mathrm{s}}=$ Young's modulus of the lining

$\mathrm{A}_{\mathrm{s}}=$ cross-sectional area of the lining

$I_{s}=$ second moment of area of the lining per unit length of tunnel.

The problem geometry and definitions of different parameters are shown in Figure 2.3. 


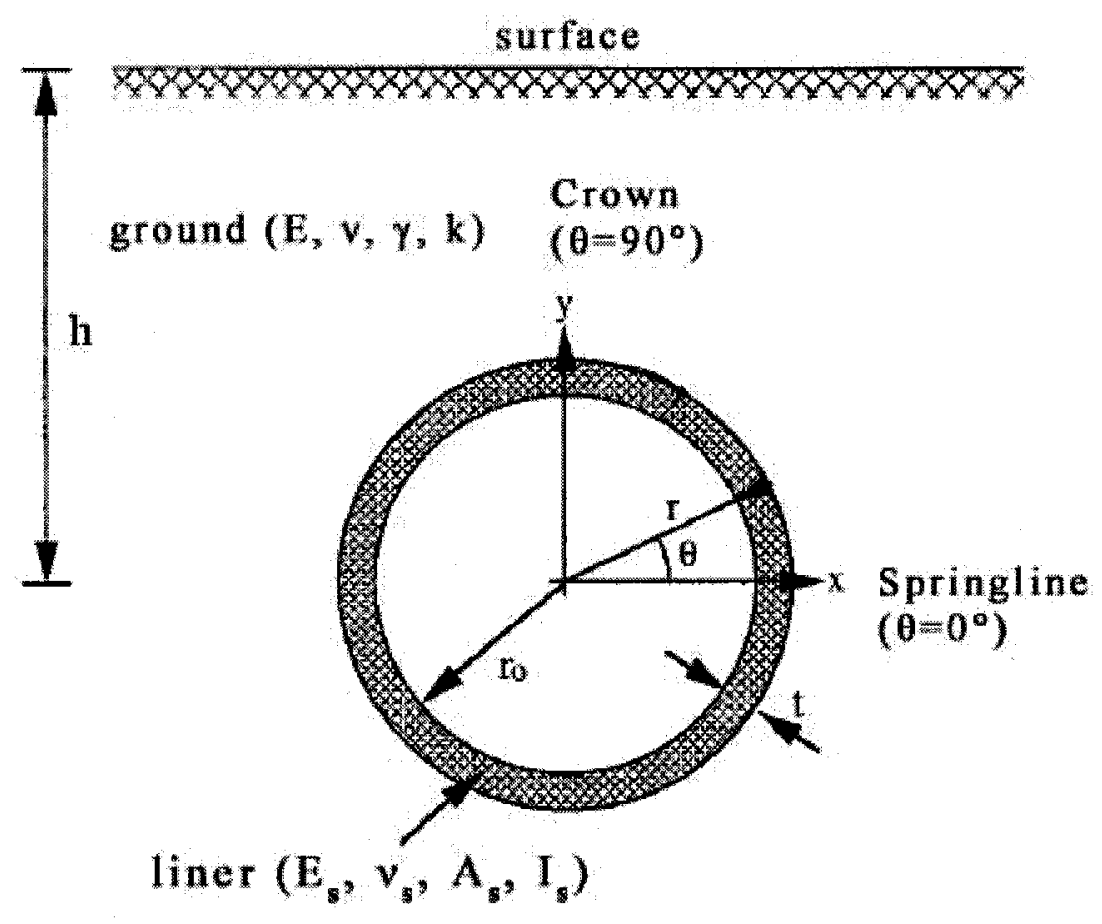

Figure 2.3 - Shallow Tunnel Problem (Bobet, 2001)

The different theoretical methods presented so far provide an approximate estimate of the ground movement as well as forces and moments in the lining. Empirical and semiempirical methods are still used to provide preliminary estimates for tunnelling problems assuming an idealized soil condition. Analytical methods, on the other hand, are particularly useful for the analysis of tunnel lining in elastic ground under Greenfield conditions (i.e. no structures present in the area of influence of the tunnel). For soft soils and non-homogeneous ground conditions, the above methods do not provide accurate results and the use of physical or numerical methods is necessary. 


\subsection{Physical modeling of tunnels in soft ground}

Full-scale modeling or the analysis of onsite conditions during tunnel construction can yield useful information. However, onsite investigation is limited by instrument placement restrictions (e.g. depth restrictions), and safety concerns that prevent access to tunnels near collapse. Full-scale experiments are very expensive, difficult to run, and are hard to repeat (Chambon and Corte, 1994). Therefore, ground response to tunnelling is often studied using reduced scale physical models.

The construction of a tunnel is a complex three-dimensional process that involves many different events, therefore, exact physical or numerical modelling of the tunnelling process is quite difficult and simplifications are usually necessary (Sharma et al., 2001). Laboratory model tests conducted under gravity, or in a centrifuge seem more suitable for this purpose. In fact they can single out the most relevant factors influencing the overall behaviour of the tunnel and provide valuable data for refining the chosen numerical model.

\subsubsection{Gravity vs. centrifuge modeling}

Gravity scale models (GSM) are investigated under normal $1 \mathrm{~g}$ condition. They provide the flexibility of carrying out the test under controlled environment, whereas in centrifuge testing the actual self-weight of the ground and the corresponding in-situ stresses are accounted for.

GSM are much more economical compared to centrifuge, full scale, or onsite investigations. However, for a successful GSM testing, correlations between the model 
and the prototype are necessary; at a minimum, they have to follow the same physical laws (Atkinson and Potts, 1977). The usefulness of GSM is limited by the fact that in-situ stresses are not fully established. Despite this limitation GSM have long been successfully used in soft ground tunnelling research.

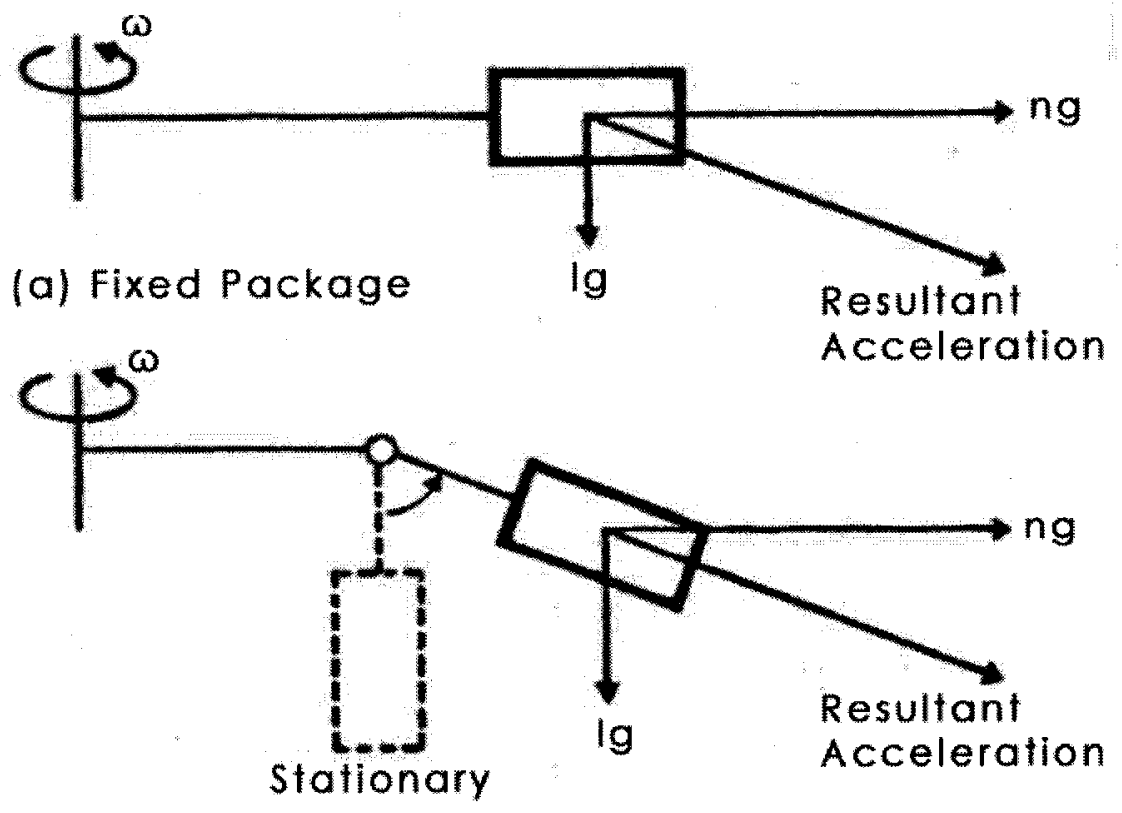

(b) Swinging Package

Figure 2.4 - Centrifugal Acceleration (Atkinson, Potts and Schofield, 1977)

On the other hand, with centrifuge models (CM) testing, the in-situ stress state can be accurately simulated as compared to a $1 \mathrm{~g}$ test. In a centrifuge the model is rotated with an angular velocity, $\omega(\mathrm{rad} / \mathrm{s})$, at a radius $\mathrm{R}$ (see Figure $2.4-\mathrm{a})$. This causes the model to experience an acceleration of $\mathrm{a}=\mathrm{ng}=\omega^{2} \mathrm{R}$, where $\mathrm{g}$ is the acceleration due to the earth's gravity $\left(\mathrm{g}=9.81 \mathrm{~m} / \mathrm{s}^{2}\right)$ and $\mathrm{n}$ is the scaling factor. This means that centrifuge model experiences $\mathrm{n}$ times the gravity, with the value of $\mathrm{n}$ depending on the speed of rotation. This effectively, as far as the values of in-situ stresses are concerned, makes the model $n$ times larger (Atkinson, Potts and Schofield, 1977). 


\subsubsection{Tunnel modeling techniques}

Several modeling techniques have been developed to investigate different aspects of ground response to tunnelling. A summary of some of these techniques is given below.

\section{Trap door models}

Trap door tests have been used to study the mechanics of 2D and 3D ground movements near the face of an advancing tunnel in different soils (Murayama et al., 1968, 1971, Adachi et al., 1995, 1997, 2003, Xu et al., 1995, Sakai, 1996, Nakai et al., 2000). When a trap door that supports a granular material is lowered the earth pressure acting on the trap door decreases and the earth pressure acting around the trap door increases. Trap door models are considered to be an approximate method to simulate tunnel excavation process by controlling the ground volume loss induced by the process of lowering the trap door (see Figure 2.5). It facilitates the evaluation of the surface settlement and the corresponding earth pressure on and around the trap door resulting from soil movement.

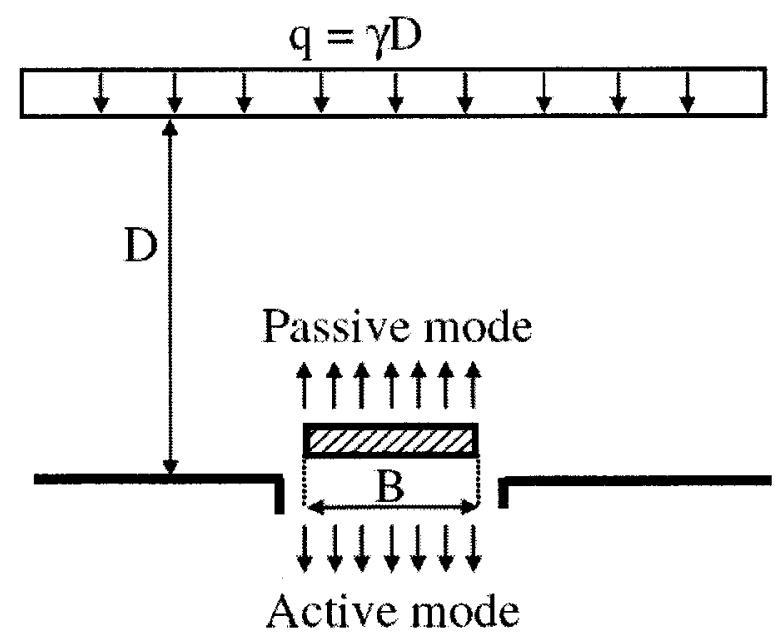

Figure 2.5 - Typical Trap Door Problem (Meguid et al., 2007) 
Bury and Cover is a simple method for simulating the pressure acting around tunnels.

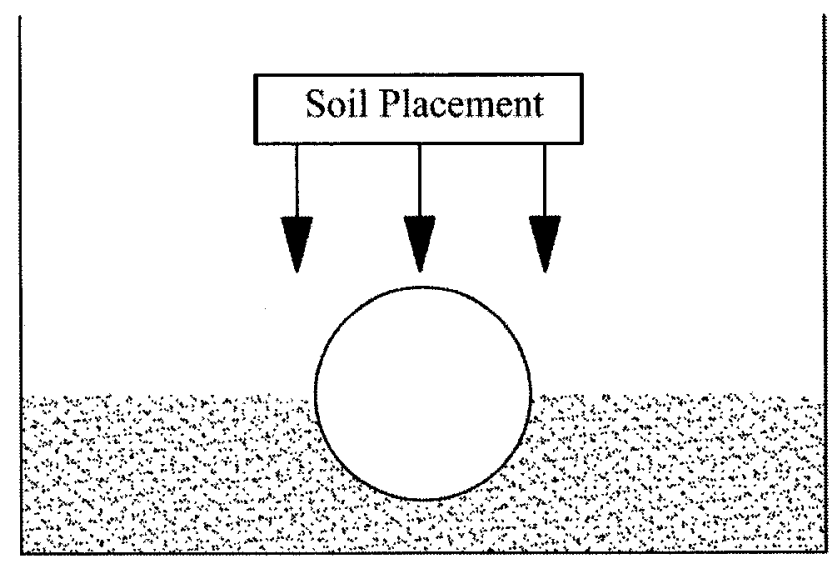

Figure 2.6 - Bury and Cover Model

A tube (representing the lining) is buried in a container and soil (usually granular material) is added over the lining (see Figure 2.6). This method does not simulate the process of tunnel excavation and is therefore very limited in its application (Chambon and Corte, 1994, Nomoto et al., 1999).

\section{Pressurized air model}

Pressurized air in a rubber bag of negligible strength has been widely used in tunnel modeling (see Figure 2.7). A tube is pushed through the soil or buried during soil placement to create a tunnel; a rubber bag is then inserted into the simulated tunnel and pressurized. The tube is usually removed from the soil (unlined tunnels), or left in place (lined tunnels). In the initial stress conditions, the air pressure is equal to the overburden pressure. The air pressure is then lowered incrementally to simulate stress reduction 
experienced by the soil during tunnel excavation until complete failure is achieved (Mair, 1982).

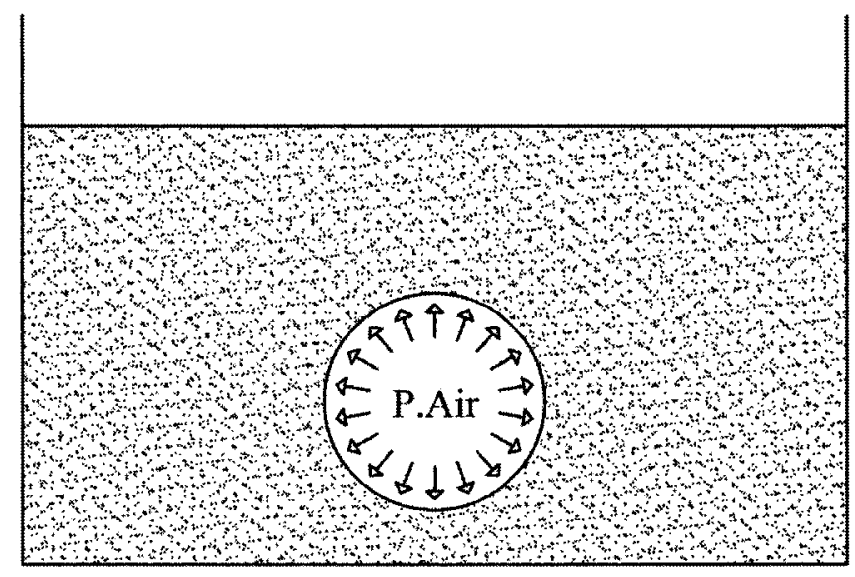

Figure 2.7 - Pressurized Air Model

\section{Heavy liquid drainage}

Another approach similar to using air is using Heavy Liquid Drainage. It consists of filling the tunnel with a heavy liquid such as zinc chloride and then slowly draining it (Sharma et al., 2001). This approach requires that both ends of the tunnel be plugged. It does not account for the directional reduction of stresses experienced during tunnel advancement.

\section{Fluid pressure}

The stability of tunnel face in cohesionless soils has been investigated by Chambon and Corte (1994). Fluid Pressure models usually consist of a rigid metallic tube with one end covered with a thin latex membrane as shown in Figure 2.8. A hydrostatic pressure is, then, used to simulate the pressure induced by a slurry shield. 


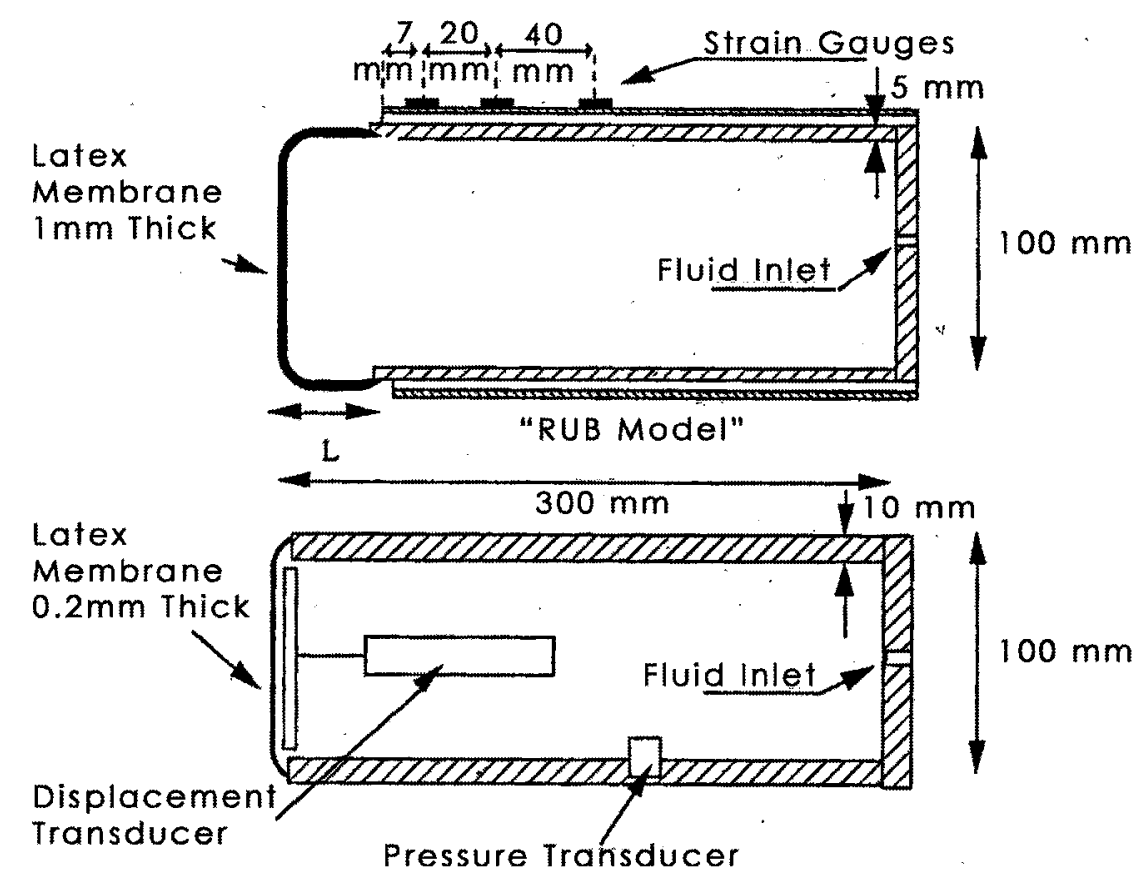

Figure 2.8 - Fluid Pressure Model (Chambon and Corte, 1994)

\section{Polystyrene foam and organic solvent}

In this method, a stiff tube of polystyrene foam is buried in the soil (Sharma et al., 2001). In the initial state (pre-dissolution) the foam simulates the soil to be excavated and is subjected to in-situ stresses that would be applied to the surrounding soil before tunnel excavation. Once exposed to an organic solvent the foam dissolves quickly. The reduction of stresses applied to the surrounding soil as the foam dissolves models the stress reductions experienced during tunnel excavation.

\section{Soil augering method}

This method involves the use of a small soil auger to excavate an opening in reconstituted or natural clay material (Chapman et al., 2006). Soil is typically consolidated in a tank under a specified pressure. An auger is then used to bore through the soil material in 
order to simulate the excavation process. Lining segments can be installed as the auger excavates to further model the tunnel construction process (see Figure 2.9).

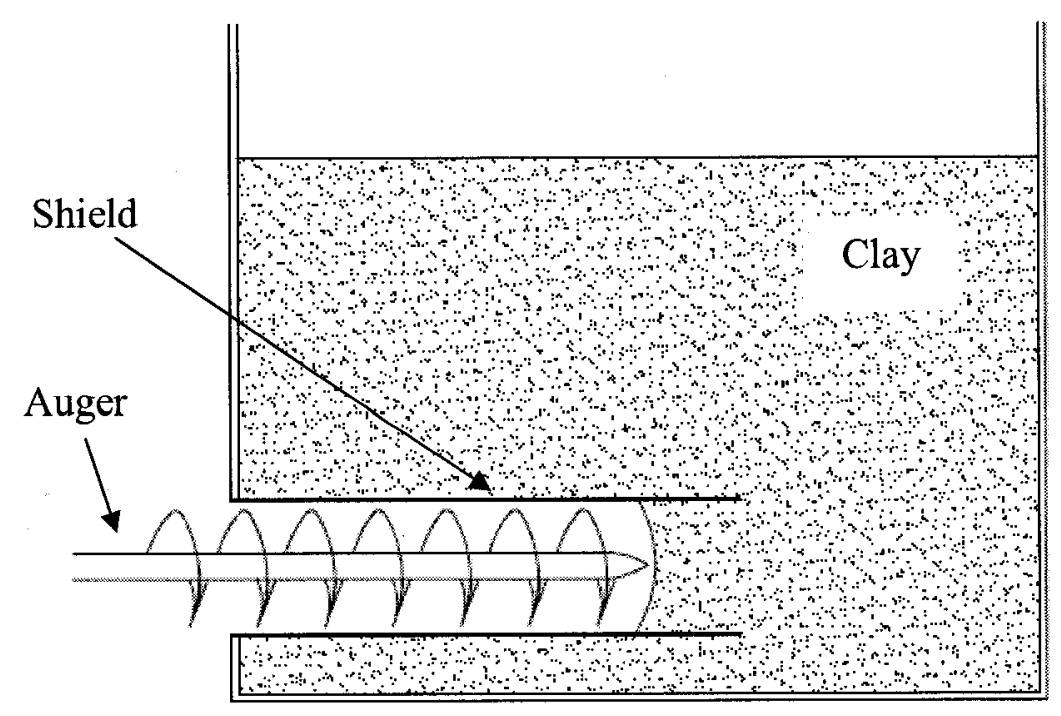

Figure 2.9 - Auger Excavation Model

\section{Miniature tunnel boring machine}

This method was developed by Nomoto et al. (1999) (Figure 2.10). This machine was designed to simulate the actual process of shield tunnelling as closely as possible. The machine is made up of the following three main components:

The Shield: is made up of three tubes, a $100 \mathrm{~mm}$ diameter stainless steel tube houses a spiral conveyer with a cutting head to excavate and carry out intake soils, a middle tube of diameter $96 \mathrm{~mm}$ and $98 \mathrm{~mm}$ that serves as the tunnel lining (a series of load cells are inlaid on this middle tube), and a $100 \mathrm{~mm}$ diameter stainless steel pipe for simulating the tail void formation (this tube is removed after the complete advancement of the tunnel.) 
The driving component: is made up of two motors, one for the forward advancement of the shield part and for removing the tail void tube, the other for driving the excavation cutter.

The strong box: is a $240 \times 700 \times 700 \mathrm{~mm}$ of stainless steel that houses the model and displacement measurement system.

The miniature tunnel boring machine took four years to be designed and developed, which is a time and financial investment that very few others, if anyone, could repeat. In addition, the machine is limited to tests using only one specific tunnel diameter, $100 \mathrm{~mm}$, and can only be tested up to $25 \mathrm{~g}$, meaning that this method can only be used to model prototype tunnels with a maximum diameter of $2.5 \mathrm{~m}$.

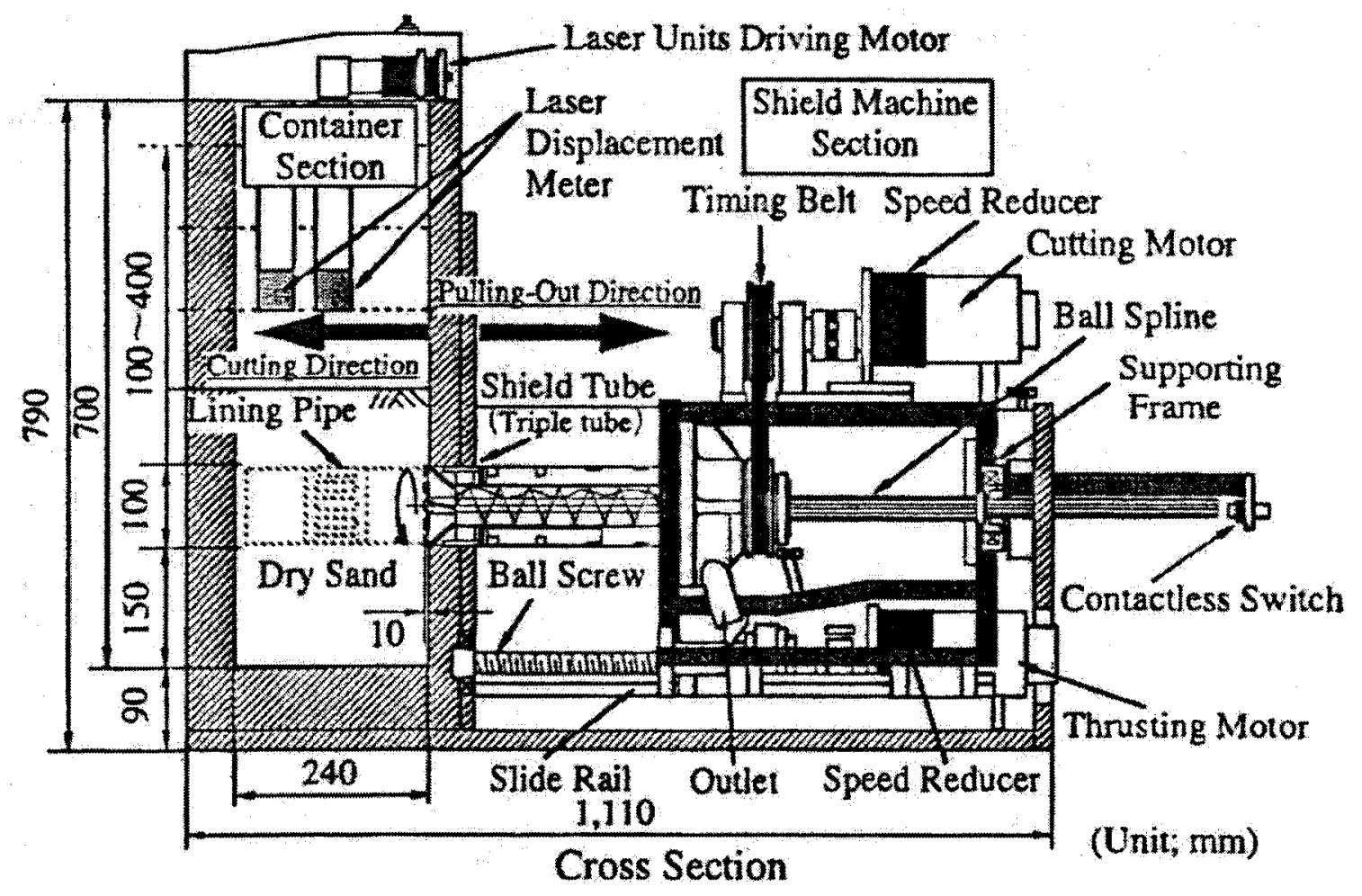

Figure 2.10 - Miniature TBM (Nomoto et al., 1999) 
The physical modeling techniques reviewed in this section were studied for feasibility and similarity to real tunnelling to help choose an adequate procedure for the experiments to be conducted in this study. The "Bury and Cover", "Pressurized Air" and "FoamSolvent" methods require that a shield is installed before soil placement. "Fluid Pressure" and "Heavy Liquid Drainage" are best suited to investigate the tunnel stability.

"Augering" and "Miniature TBM" methods closely simulate tunnel excavation and the model developed in this study will fall in between. A comparison of different model tunnelling techniques adapted from Meguid (2007) is shown in Table 2.1.

\section{Table 2.1 - Comparison of Various Model Tunnelling Techniques (Adapted from Meguid et al., 2007)}

\begin{tabular}{lll}
\hline Method & Advantages and Application & Disadvantages \\
\hline Trap Doors & -Used to evaluate surface settlement & -Does not simulate the actual \\
& and pressure on the trap door & tunneling process \\
& simulating tunneling induced & -Only approximate estimations \\
& movement and lining stresses & of surface settlements and lining \\
& -2D and 3D ground movements can & stresses \\
& be evaluated under 1g and centrifuge & \\
& conditions & \\
\hline Rigid Tube - & -Used to study face stability of & -Does not provide information \\
Flexible Face & shallow tunnels & on the surface settlement behind \\
& -Tests can be conducted under 1g and & the tunnel face \\
& centrifuge conditions & \\
\hline Pressurized & -2D and 3D tests that can be & -Used mostly for unlined \\
Air & conducted under both 1g and & tunnels \\
& centrifuge conditions & -Does not simulate the tunnel \\
& -Used to study tunnel stability and & face advance \\
& ground movements around tunnels & \\
\hline & & \\
& &
\end{tabular}




\begin{tabular}{|c|c|c|}
\hline $\begin{array}{l}\text { Foam and } \\
\text { Solvent }\end{array}$ & $\begin{array}{l}\text {-Can be conducted in a centrifuge } \\
\text { Simulates the tunnel advance process }\end{array}$ & $\begin{array}{l}\text {-Results were less satisfactory } \\
\text { when the excavation was } \\
\text { simulated under water }\end{array}$ \\
\hline $\begin{array}{l}\text { Soil } \\
\text { Augering }\end{array}$ & $\begin{array}{l}\text {-Simulates the tunnel advance } \\
\text { process } \\
\text { Easy to operate }\end{array}$ & $\begin{array}{l}\text {-Used mostly for cohesive soils } \\
\text {-Insertion of a shield is usually } \\
\text { required } \\
\text {-1g only, not easily mechanized } \\
\text { for a centrifuge }\end{array}$ \\
\hline $\begin{array}{l}\text { Miniature } \\
\text { TBM }\end{array}$ & $\begin{array}{l}\text {-Conducted in a centrifuge } \\
\text {-Simulates the complete tunneling } \\
\text { process }\end{array}$ & $\begin{array}{l}\text {-Expensive } \\
\text {-Limited gravitational } \\
\text { acceleration (up to } 25 \mathrm{~g} \text { ) }\end{array}$ \\
\hline $\begin{array}{l}\text { Adjustable } \\
\text { Tunnel } \\
\text { Diameter }\end{array}$ & $\begin{array}{l}\text {-Simulates the 2D tunnel excavation } \\
\text { process } \\
\text {-Simple to operate }\end{array}$ & $\begin{array}{l}\text {-Manually controlled } \\
\text {-Limited to 2D models under } 1 \mathrm{~g} \\
\text { condition }\end{array}$ \\
\hline
\end{tabular}

\subsection{Tunnel-pile interaction}

A major concern during tunnelling is potential damage that might occur to surrounding buildings and structures. The subsidence caused by the ground lost during excavation provokes redistribution of stresses in the soil and usually negatively affects the nearby structures, such as foundations, piles, and other buried structures. This is attributed to the fact that the tunnel construction was understandably not taken into account in the design of these existing structures.

Several studies investigated the effect of tunnel construction on nearby deep foundation (Breth and Chambosse, 1974, Morton and King, 1979, Attewell et al., 1986, Rankin, 1988, Vermeer and Bonnier, 1991, Burland, 1995, Mroueh and Shahrour, 1999, 2002, Coutts and Wang, 2000, and Cheng et al., 2006), however the reverse of the problem (the 
effect of pile foundation on the stresses developing in the tunnel lining) has not received enough research attention. Selected studies investigating this interaction are summarized below.

\subsubsection{Pile response to tunnelling}

Chen et al. (1999) studied the lateral and axial pile response induced by tunnelling using a two-stage approach. They first analyzed the ground movements free from structures caused by tunneling using the analytical approach of Loganathan and Poulos (1998). They then proceeded to impose these soil movements on the pile in a boundary element analysis to compute the bending moment, lateral deflection, compressive and tensile axial force in the pile. The factors shown to influence this response ranged from tunnel geometry, ground loss ratio, soil strength and stiffness, pile diameter and ratio of pile length to tunnel cover depth. Figure 2.11 illustrates the problem definition $(\mathrm{h}=20 \mathrm{~m}, \mathrm{R}=$ $3 \mathrm{~m}, \mathrm{~L}_{\mathrm{p}}=25 \mathrm{~m}, \mathrm{~d}=0.50 \mathrm{~m}$, and ground loss $=\epsilon \mathrm{R}^{2}=1 \%$ and $5 \%$ ).

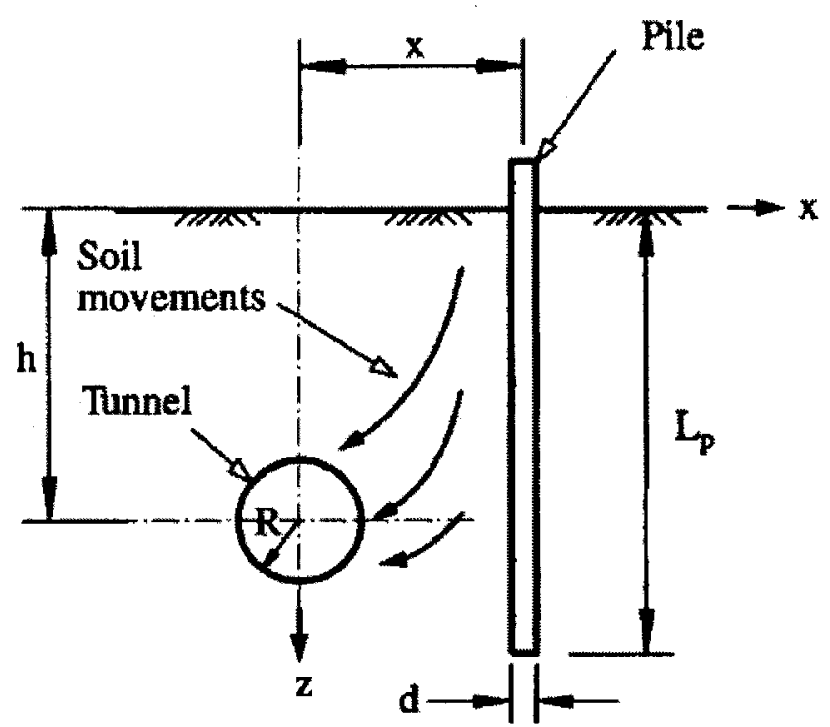

Figure 2.11 - Problem Definition (Chen et al., 1999) 
Figure 2.12 illustrates the pile response at different separating distances from the tunnel centerline for two different values of ground loss. Bending moments in the pile increased as the separating distance became smaller. The pile response to a $5 \%$ ground loss as opposed to a $1 \%$ ground loss produced a faster rate of increase in bending moments.

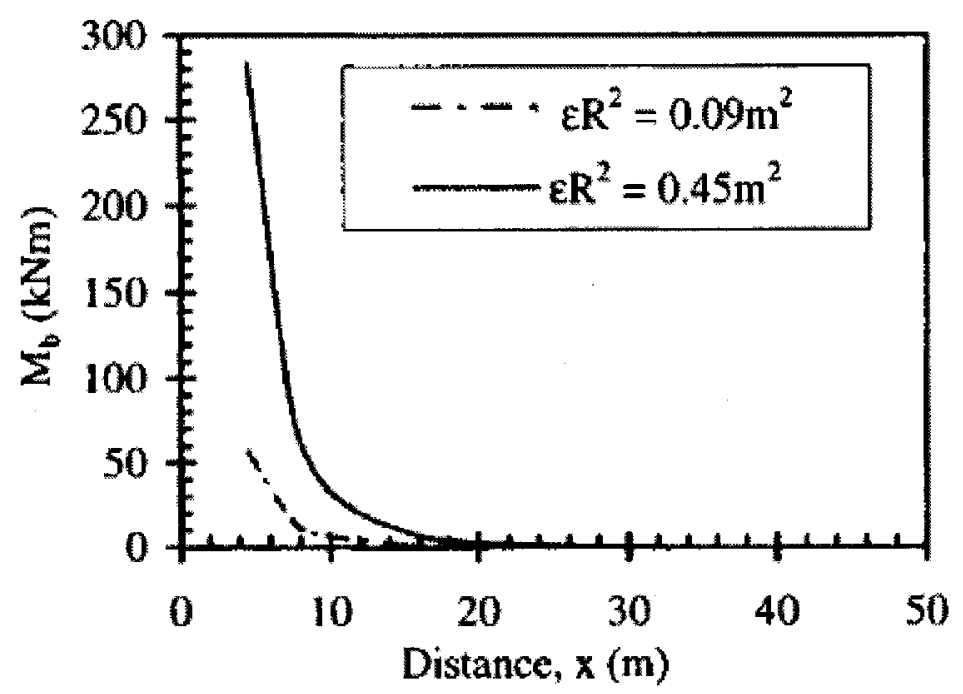

Figure 2.12 - Bending Moments in the Pile at a Distance $x$ from Tunnel Centerline for $1 \%$ and $5 \%$ Ground Loss (Chen et al., 1999) 
Another study by Lee and $\mathrm{Ng}(2005)$ numerically investigated a loaded pile's response to a nearby advancing open face tunnel using a finite element model. The Problem definition is shown in Figure 2.13.

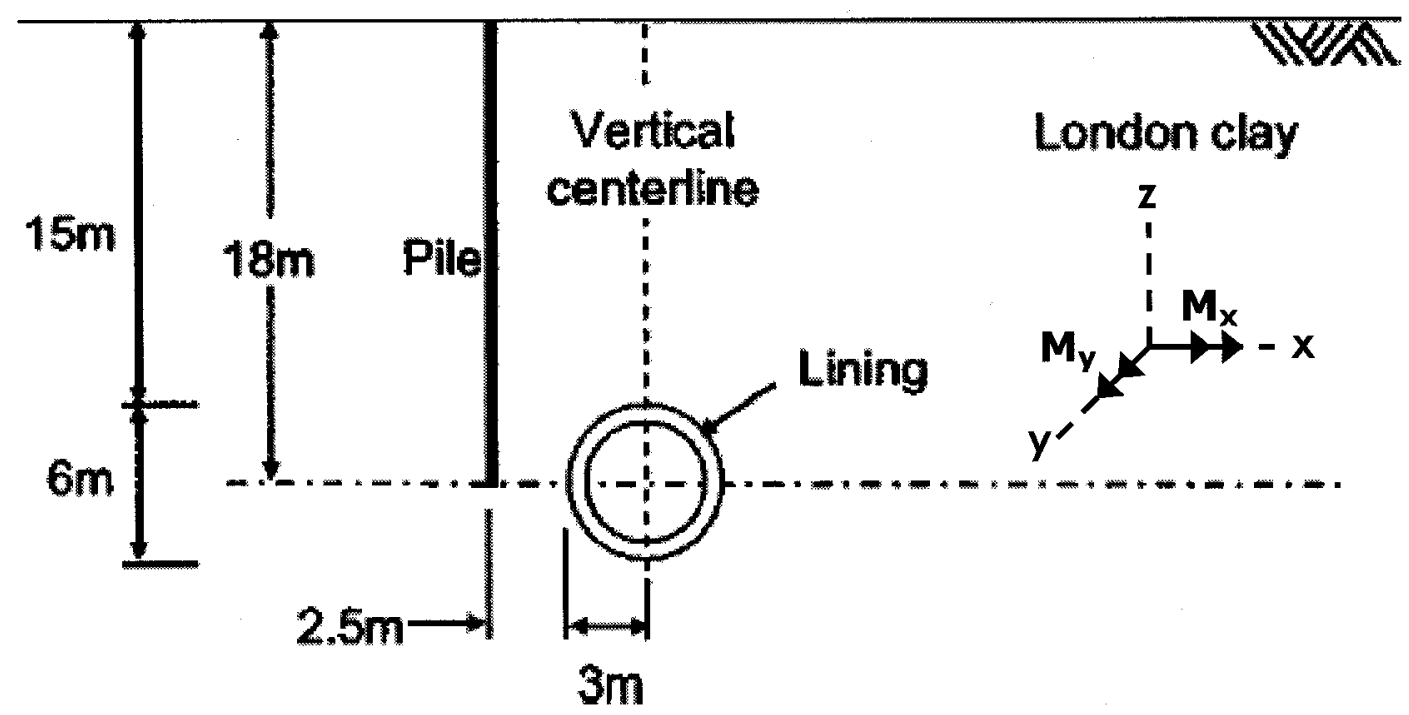

Figure 2.13 - Problem Definition (Lee and Ng, 2005)

A zone of influence (one tunnel diameter behind the pile and one ahead) was defined, in which an excess pile settlement was found to develop, which corresponded to an increase in loading in the pile.

Other responses were also measured, such as the variation in bending moments in the pile about the $\mathrm{x}$ axis and the $\mathrm{y}$ axis as the tunnel face advanced (see Figure 2.14). Bending moments in both directions increased when the tunnel advanced from a distance of 3 diameters behind the pile to a distance of 3 to 5 diameters past the location of the pile. As expected, the moments about the $y$ axis increased more dramatically as compared to the moments about the $\mathrm{x}$ direction especially in the zone of influence. 

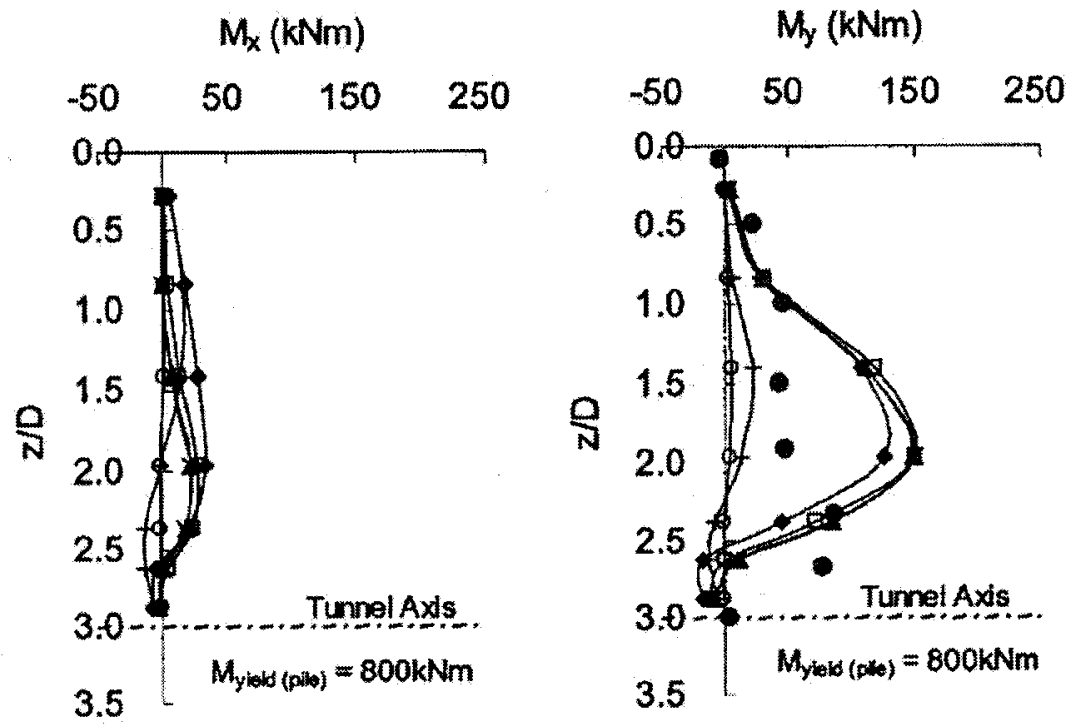

(a)

(b)

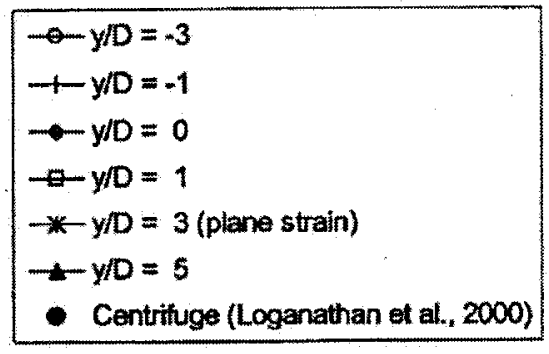

Figure 2.14 - Tunnelling Induced Bending Moments along a Pile at Various Stages of Excavation: a) About $\mathrm{x}$-Axis and b) About $\mathrm{y}$-Axis (Lee and $\mathrm{Ng}$, 2005) 
Kitiyodom et al. (2005) investigated the response of a single pile as well as piled raft to tunnelling. Analytical methods such as Loganathan and Poulos (1998) were used to model the pile-raft-soil interaction.

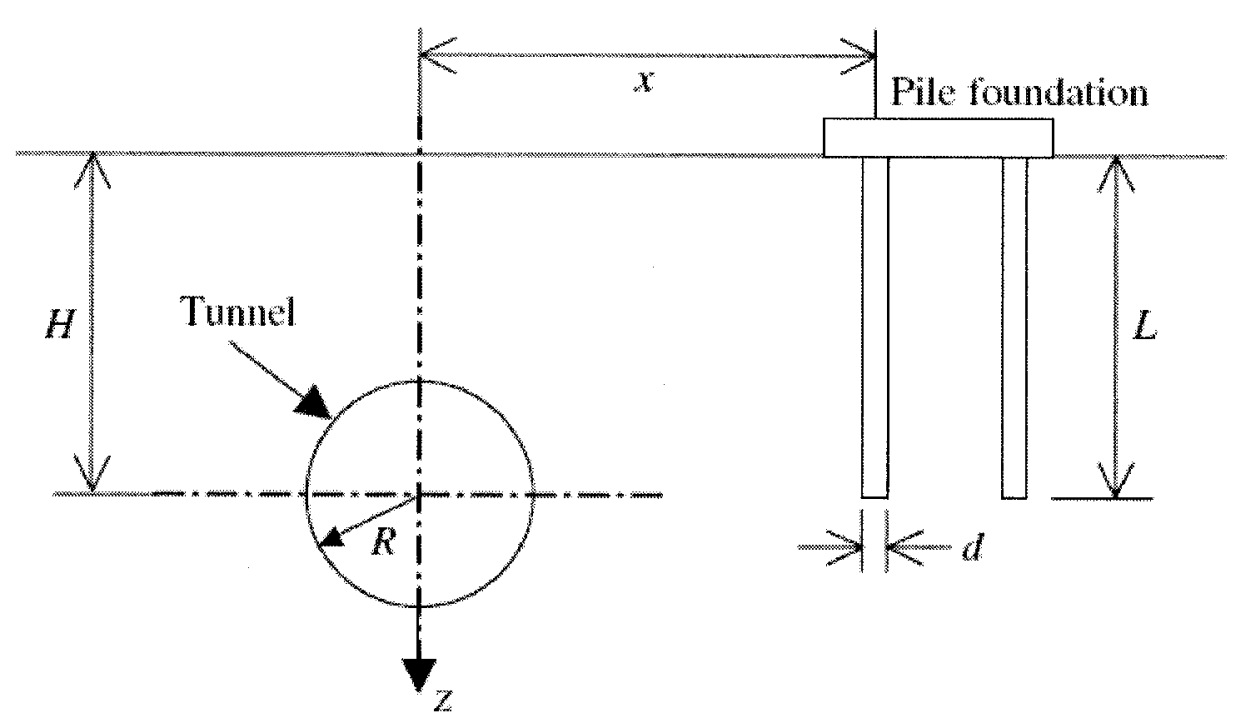

Figure 2.15 - Problem Definition (Kitiyodom et al., 2005)

Figure 2.15 illustrates the problem definition $(H=20 \mathrm{~m}, \mathrm{R}=3 \mathrm{~m}, \mathrm{~L}=25 \mathrm{~m}$, and $\mathrm{d}=0.50$ m). This model was first validated using analytical solutions and then investigated using finite difference analysis. Results indicated that single piles experienced an increase in lateral deflection, bending moment, vertical movement and axial force when the pile is closer to the tunnel advance. For piled raft foundation the closest piles in the group experienced greater movement as compared to the farthest with respect to the tunnel advance.

Figure 2.16 shows the different pile responses. These were measured for various distances to tunnel centerline which ranged from $4.50 \mathrm{~m}$ to $13.00 \mathrm{~m}$. An increase in the pile response such as maximum axial force or vertical settlement was noted. The increase 
in lateral pile deflection or bending moment almost doubled when comparing the pile at $6.75 \mathrm{~m}$ away from the tunnel centerline versus the pile at $4.50 \mathrm{~m}$ away.
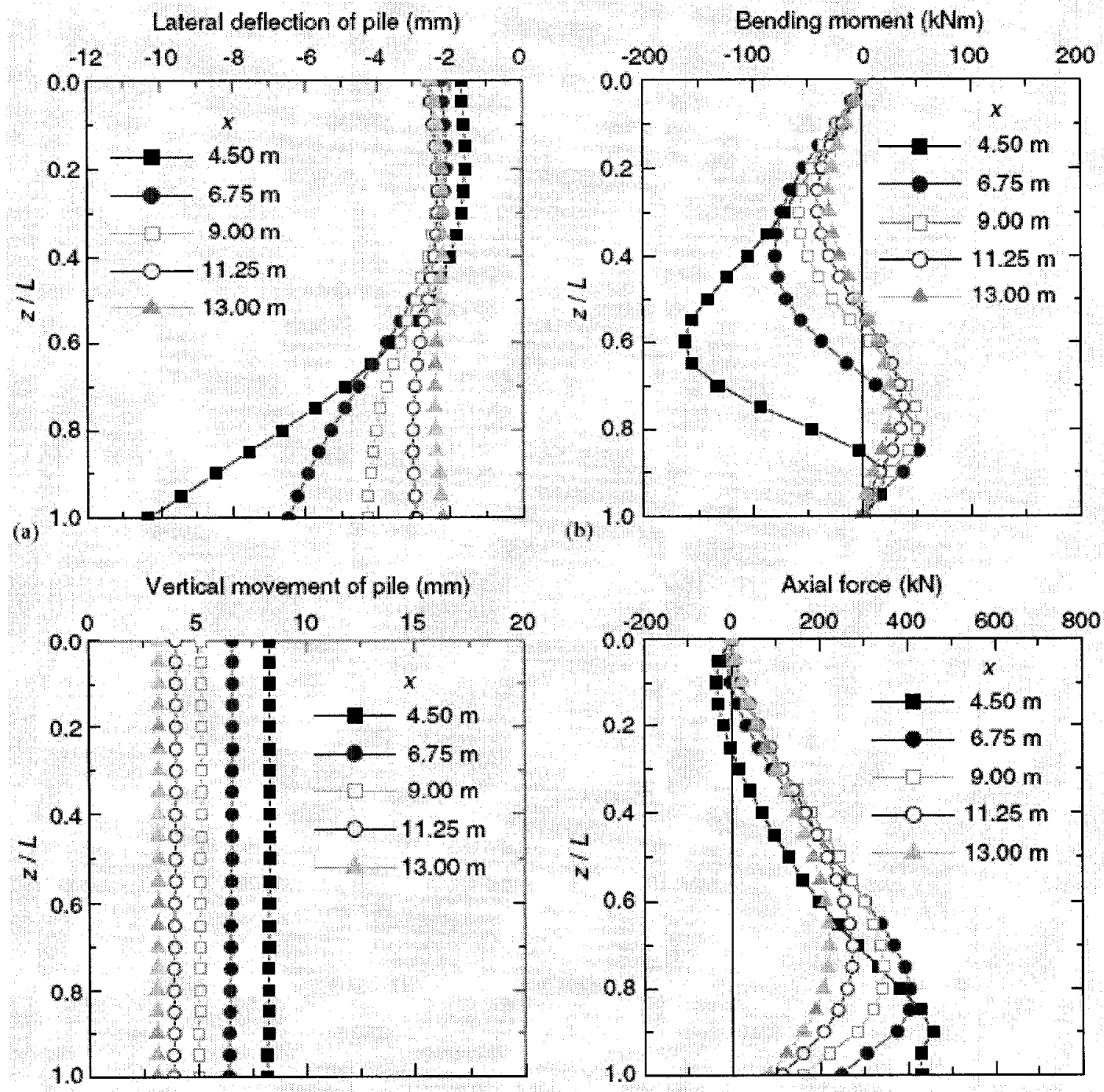

(c)

(d)

Figure 2.16 - Computed Responses of Single Piles Located at Different Distances, $x$, from the Tunnel Centerline: a) Lateral Deflection, b) Bending Moment, c) Vertical Movement, and d) Axial Force (Kitiyodom et al., 2005) 


\subsubsection{Effects of existing surface structures on tunnelling}

Potts and Addenbrooke (1997) investigated the effect of existing surface structures on subsidence induced by tunnel construction using finite element analysis (see Figure 2.17):

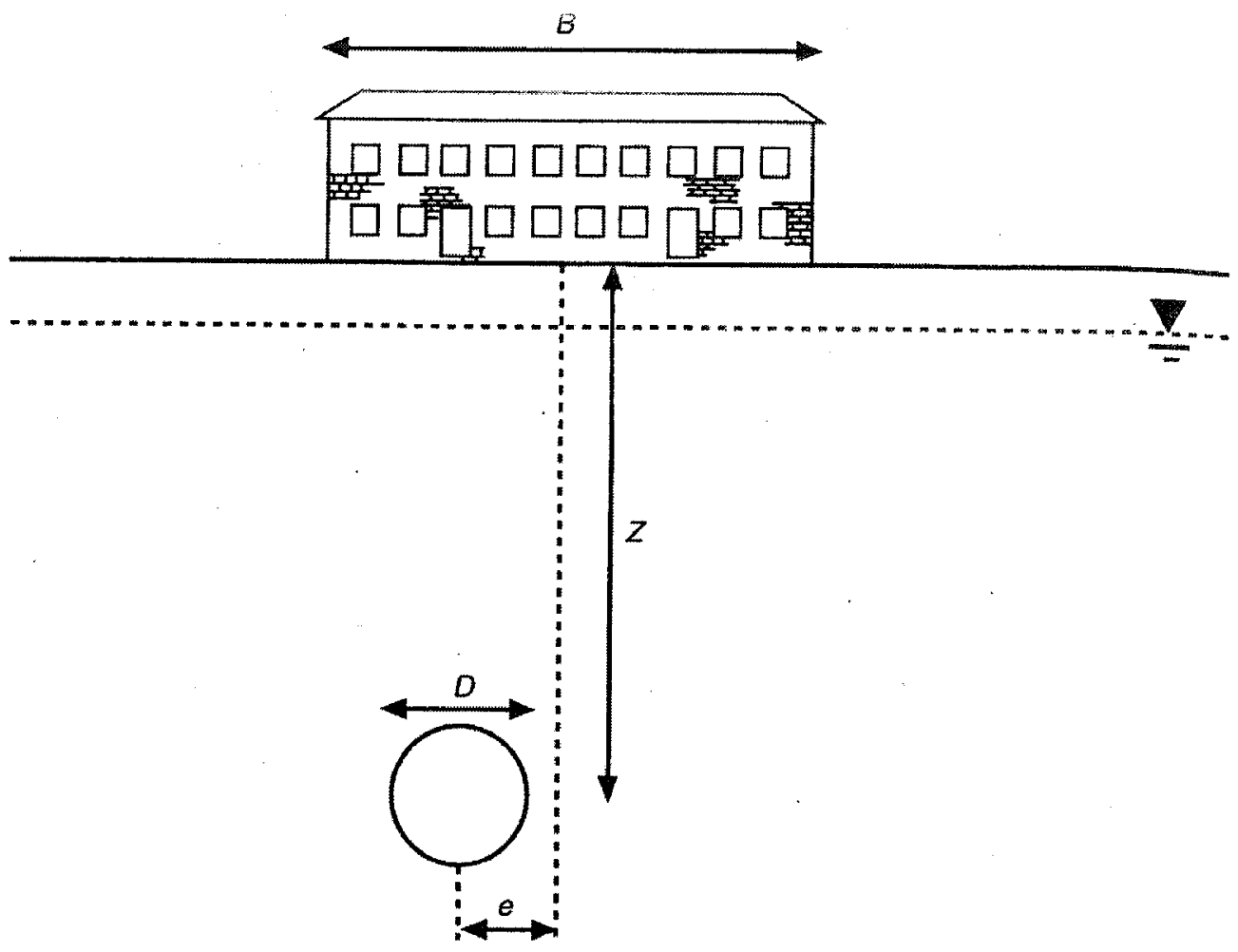

Figure 2.17 - Problem Geometry (Potts and Addenbrooke, 1997)

The problem's geometry was as follows: a tunnel diameter of $4.146 \mathrm{~m}(\mathrm{D})$, the depth from the surface to tunnel axis varied between $20 \mathrm{~m}$ and $34 \mathrm{~m}(\mathrm{Z})$. The surface structure was represented by a beam of width $\mathrm{B}$ and eccentricity $e$, axial stiffness (EA) and bending stiffness (EI) were the main variables considered in the parametric study. The soil properties were: a clay with saturated bulk unit weight of $20 \mathrm{kN} / \mathrm{m}^{3}$ and a hydrostatic 
pore water pressure profile with a water table at $2 \mathrm{~m}$ below ground surface. Since only short-term response was investigated, the soil was assumed to behave undrained.

The results of the analysis were presented in terms of $\rho^{*}$ and $\alpha^{*}$, respectively representing the relative bending and axial stiffnesses as follows:

$$
\begin{aligned}
& \rho^{*}=\frac{E I}{E_{s} H^{4}} \\
& \alpha^{*}=\frac{E A}{E_{s} H}
\end{aligned}
$$

$\mathrm{E}_{s}$ is a representative soil modulus, and $\mathrm{H}$ is equal to $\mathrm{B} / 2$. These parameters were similarly used in other studies (Fraser and Wardle, 1976 and Potts and Bond, 1994 for $\rho^{*}$, Boscardin and Cording, 1989 for $\alpha^{*}$ ). The tunnel excavation was modeled by incrementally removing elements from within the tunnel boundary. A typical value of $1.5 \%$ ground loss was used in the analysis. The result obtained from the finite element analysis showed that the presence of a structure $60 \mathrm{~m}$ wide with zero eccentricity affected the Greenfield settlement trough (settlement profile with no surface structure) proportionally to any of the relative axial or bending stiffnesses.

Figure 2.18 illustrates how increasing the relative axial stiffness (Figure 2.18-a) decreases the maximum settlement in the Greenfield curve but widens it at the same time. A similar effect was achieved when increasing the relative bending stiffness (Figure 2.18-b). The effect of the structure however, is only restricted to a limited extent beyond its edge. 
Distance from Centerline: $\mathrm{m}$

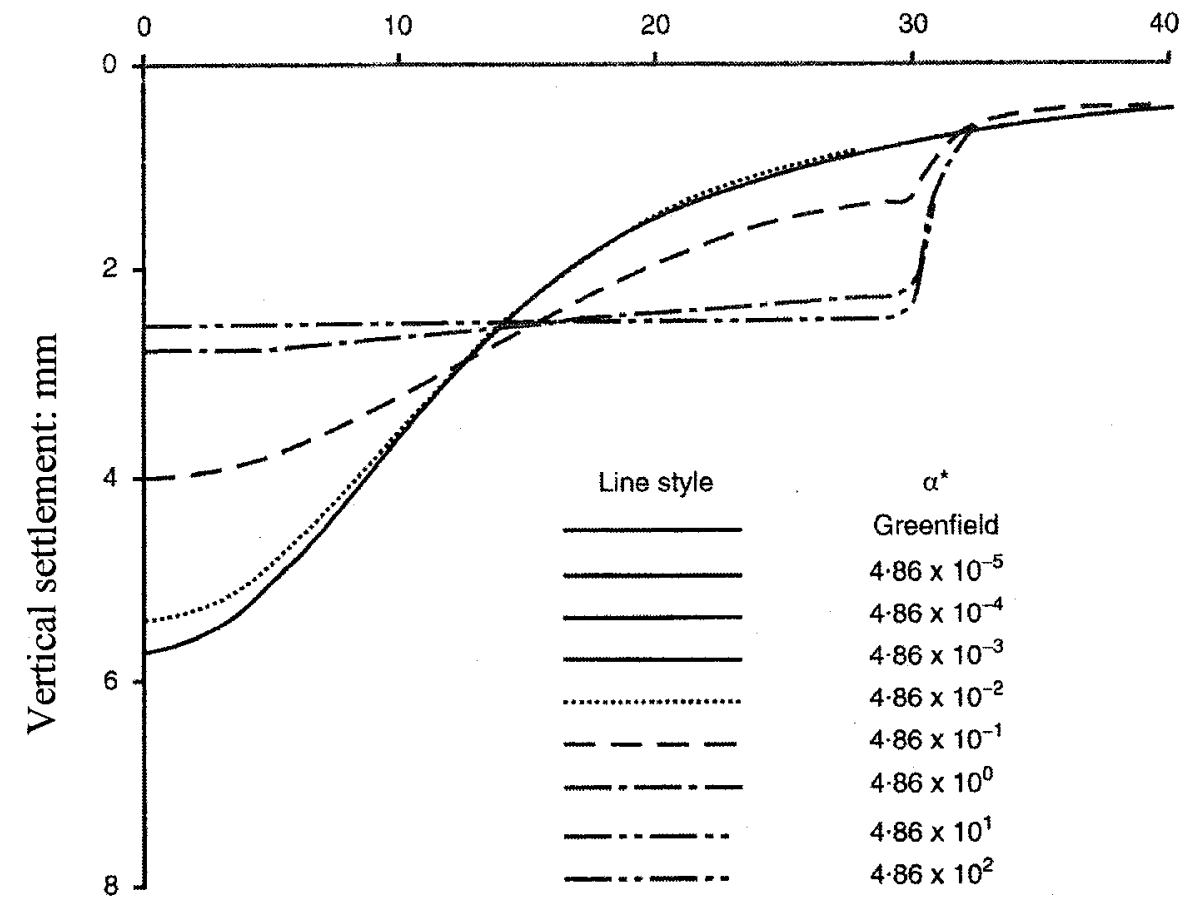

(a)

Distance from Centerline: $\mathrm{m}$

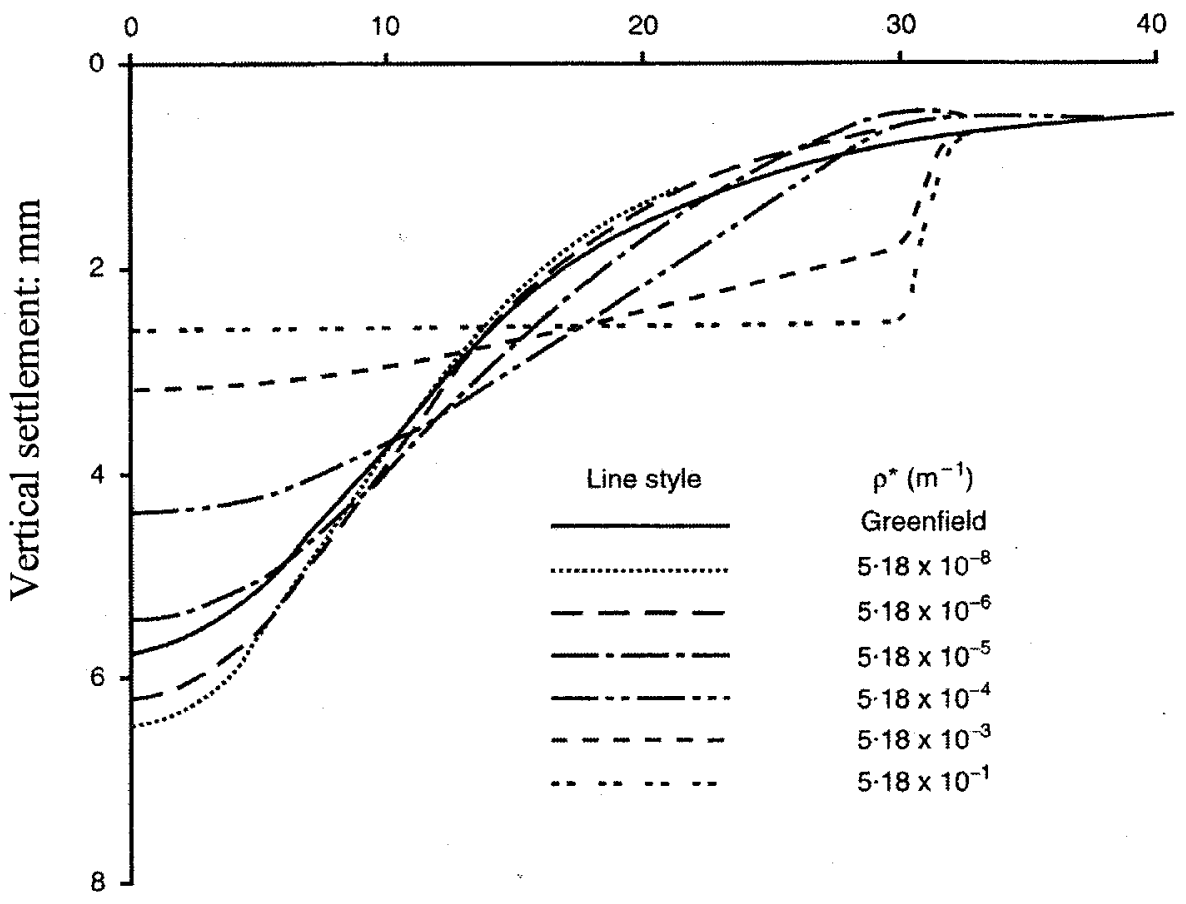

(b)

Figure 2.18 - Surface Settlement Trough (Potts and Addenbrooke, 1997) 
Lee and Yoo (2006) investigated a somewhat different type of pile-soil-tunnel interaction. A two-dimensional physical scale model (910 mm x $720 \mathrm{~mm}$ x $75 \mathrm{~mm})$ was used to quantify the tunnel centerline movements during excavation in the vicinity of preinstalled rectangular piles $(75 \mathrm{~mm} \times 25 \mathrm{~mm})$ installed in aluminium rod mixture that represented an idealized 2D granular material.

Tunnel excavation was modeled using a cylindrical shaped apparatus that could be reduced in diameter by turning two knobs located at each side of the cylinder (see Figure 2.19).

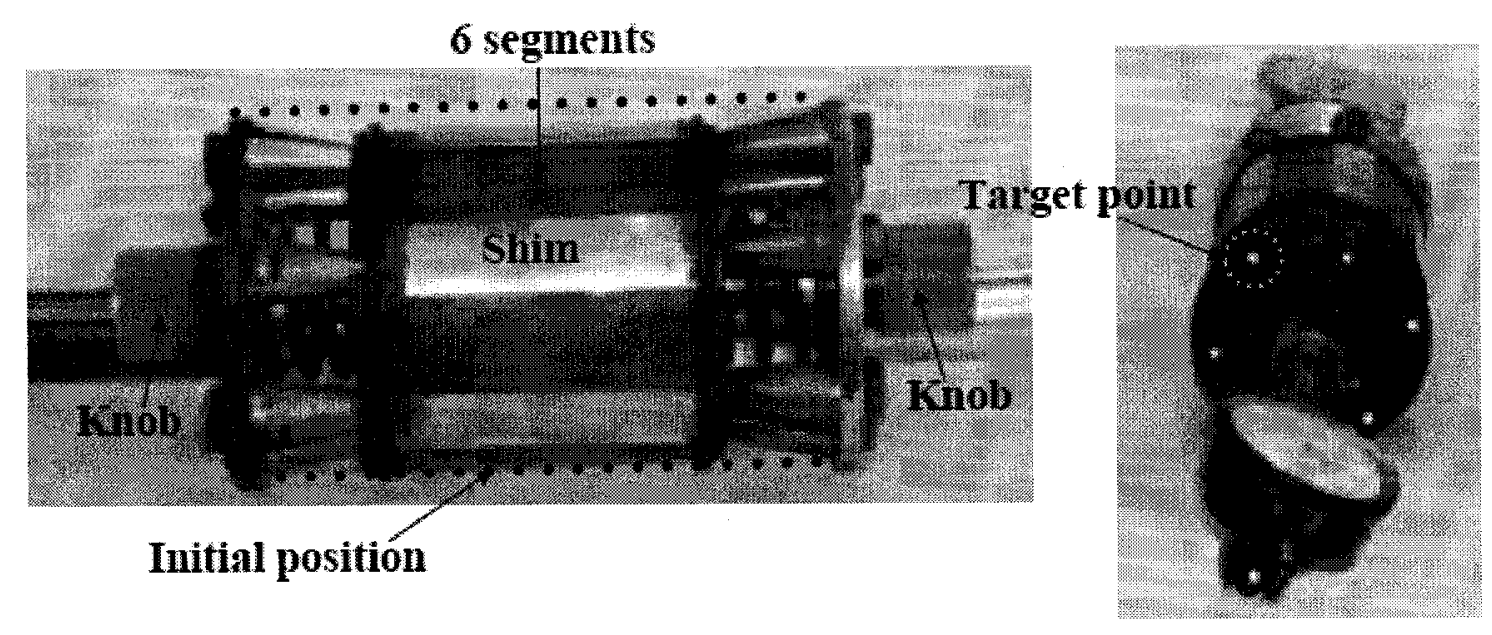

Figure 2.19 - Model Tunnel Device (Lee and Yoo, 2006)

Measurements of movements were performed using a photogrammetric technique that involves taking several high resolution digital images. The results obtained indicated that horizontal and vertical shifting tunnel movements occurred during excavation and were generally higher in magnitude when pre-installed piles were located closer to the tunnel centerline. This is illustrated in Figure 2.20: horizontal and vertical shifting movements of the model tunnel were measured when a staged reduction in diameter is applied; the 
four different curves represent different locations of the pile from the tunnel centerline (A0 at 1 diameter away from tunnel centerline, $\mathrm{B} 0$ at 1.5 diameters, $\mathrm{C} 0$ at 2 diameters and $\mathrm{D} 0$ at 3 diameters).

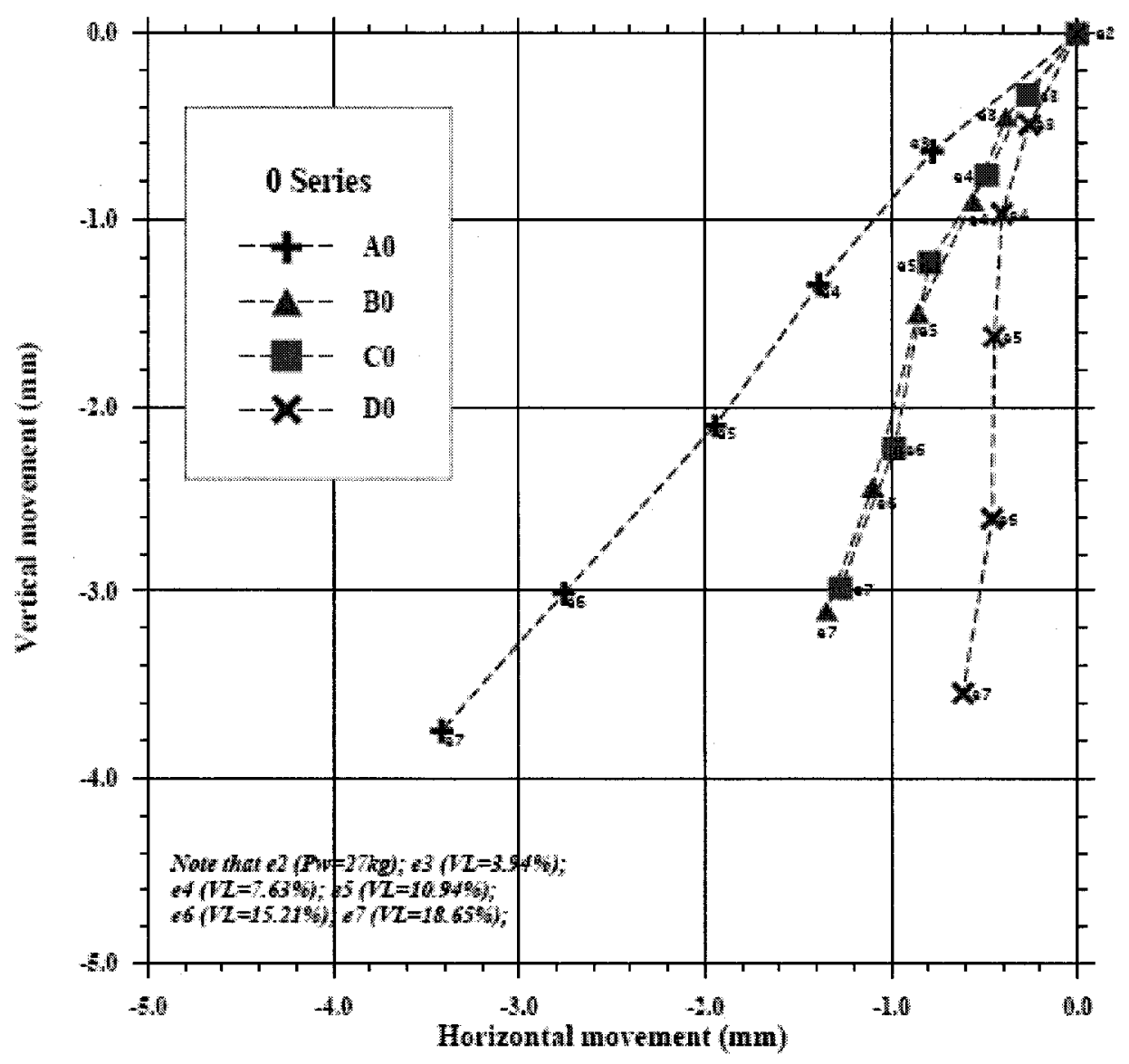

Figure 2.20 - Centerline Movements of the Model Tunnel during the Development of Volume Loss (Lee and Yoo, 2006)

The above studies indicate that the presence of pre-installed structures in soils has an influence on nearby tunnels. This influence can be in the form of changes in settlement troughs as suggested by Potts and Addenbrooke (1997) or movements of the tunnel itself as suggested by Lee and Yoo (2006) or strains/stresses in the tunnel lining as set to be demonstrated within the scope of this study. 
This chapter provided a review of the literature relevant to the experiments that were conducted in the present thesis.

The first portion of the chapter listed a number of different important empirical, semiempirical and analytical methods that are used to determine stresses and strains in linings due to tunnelling excavation. These methods were meant as a guide for a preliminary estimation of lining behaviour.

The second part of the chapter consisted of a comparison between different methods used be researchers for the physical modelling of tunnels including the pros and cons of each model. As a result of this examination and in the scope of this research, a physical model based on the "Augering" method was designed and constructed.

The last part of the chapter focused on the literature pertaining to soil-structure interaction and more specifically to the tunnel-soil-pile interaction. A sample of the large number of studies that investigated piles response to tunnelling was reviewed. The other side of the problem, tunnel's behaviour in the presence of piles, was subject to a smaller number of studies. The present thesis aimed at shedding more light on the latter side of the problem and the physical model was adjusted accordingly. 


\section{EXPERIMENT SETUP}

This chapter provides a description of the steps taken to develop the experimental setup used in the laboratory investigation and shows how the physical model evolved to the final design that has been used in this study. The last section of this chapter focuses on the composition and geotechnical properties of the soil used throughout the experiments.

\subsection{Model Construction}

The construction of the physical model was based on a "build/validate/refine" process. The following section describes the different components used in building the model.

\subsubsection{Strong steel box}

The design dimensions of the box were chosen such that it facilitates two-dimensional simulation of the tunnel construction. The box is approximately 1 foot $(0.30 \mathrm{~m})$ thick $\mathrm{x}$ 4.5 feet $(1.35 \mathrm{~m})$ wide $\mathrm{x} 4$ feet $(1.20 \mathrm{~m})$ high (see Appendix A). The box was made of 4 steel sides and 1 detachable Plexiglas face. The steel sides were attached together via steel angles and bolts, and then welded.

The Plexiglas face was also attached to the rest of the box with bolts but a thin rubber layer separated them to ensure the tightness of the connections during the repeated removal and installation of the Plexiglas. The full structure was stiffened from both sides with three 4-inch $(0.10 \mathrm{~m})$ Hollow Steel Sections (HSS) that were attached together with threaded rods (See Figure 3.1). A 6-inch $(0.15 \mathrm{~m})$ diameter hole was drilled in the Plexiglas face and the opposite side steel plate to represent the location of the tunnel. 


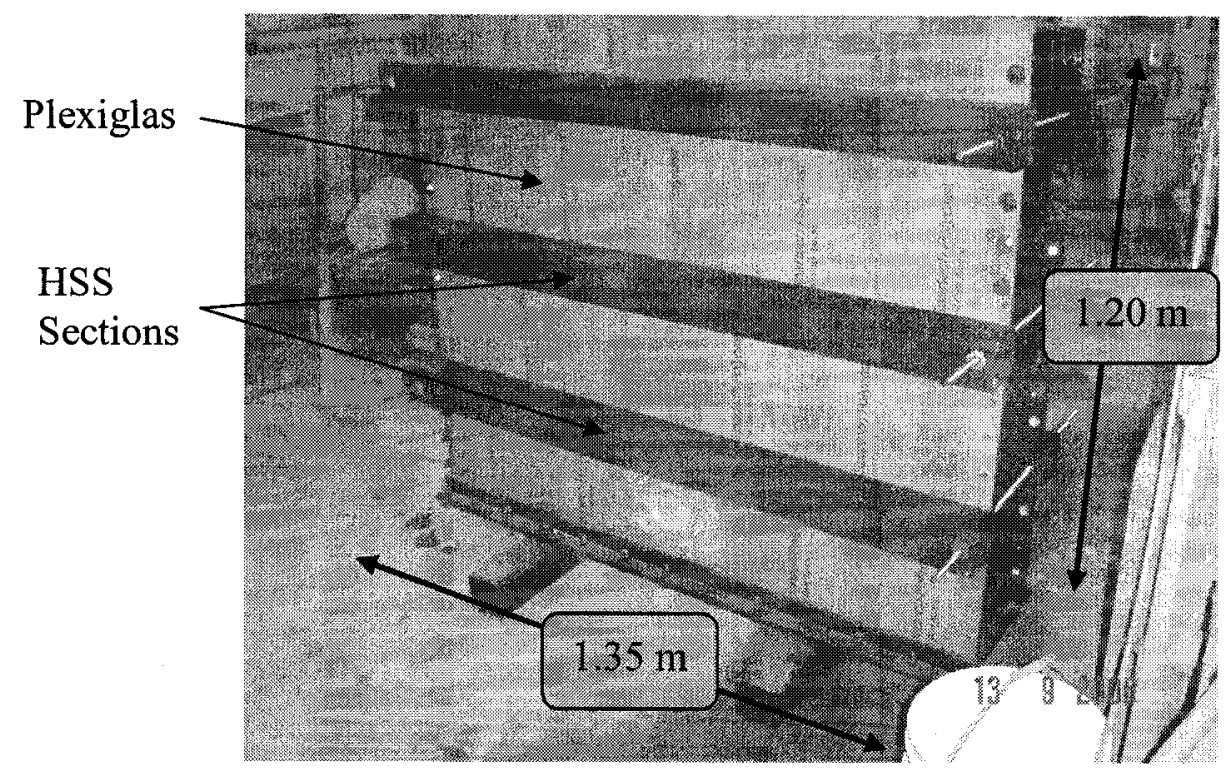

Figure 3.1 - Steel Box Structure

\subsubsection{Circular Plexiglas flanges}

Two circular Plexiglas flanges were constructed to serve multiple purposes: (1) to prevent leakage as the soil is poured into the tank, (2) to provide a track for the thin metal rods shield system. Each flange is composed of a ring component and a plug component (See Figure 3.2). The ring has an inner diameter of 5 inches $(0.13 \mathrm{~m})$, and an outer diameter of 8 inches $(0.20 \mathrm{~m})$. The plug has an inner diameter of 5 inches $(0.13 \mathrm{~m})$ to fit perfectly in the ring and an outer diameter of 8 inches $(0.20 \mathrm{~m})$. Details are provided in Appendix A. The rings and plugs outer diameters are larger than the holes on the sides of the steel box to provide a mean to attach them. This was achieved by drilling the flanges with eight $1 / 4$ inch $(0.006 \mathrm{~m})$ holes that allowed them to be fixed to the box's steel face via welded $1 / 4$ inch $(0.006 \mathrm{~m})$ threaded rods, and to the box's Plexiglas face via resin glued threaded rods (See Figure 3.3). 


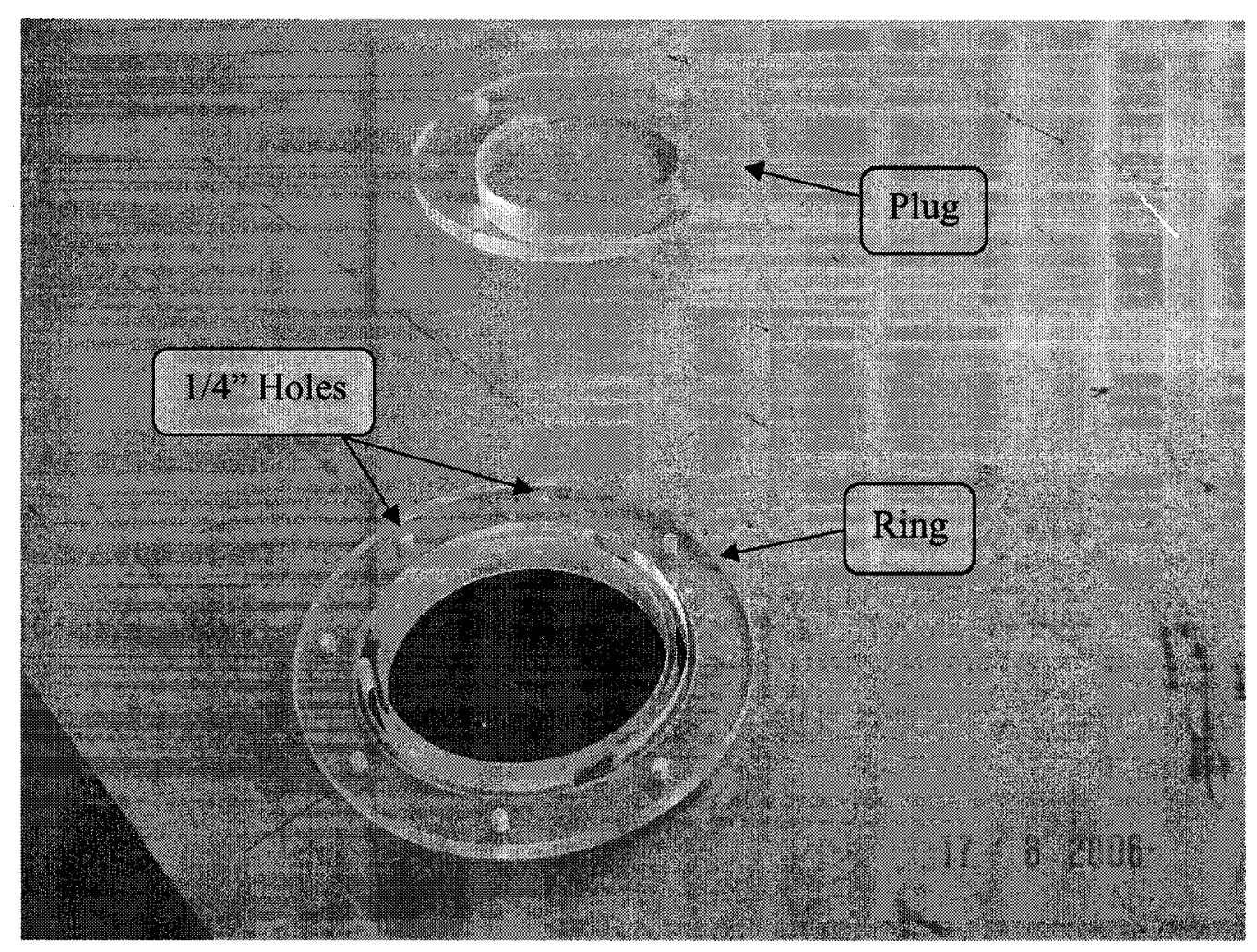

Figure 3.2 - Circular Plexiglas Flanges

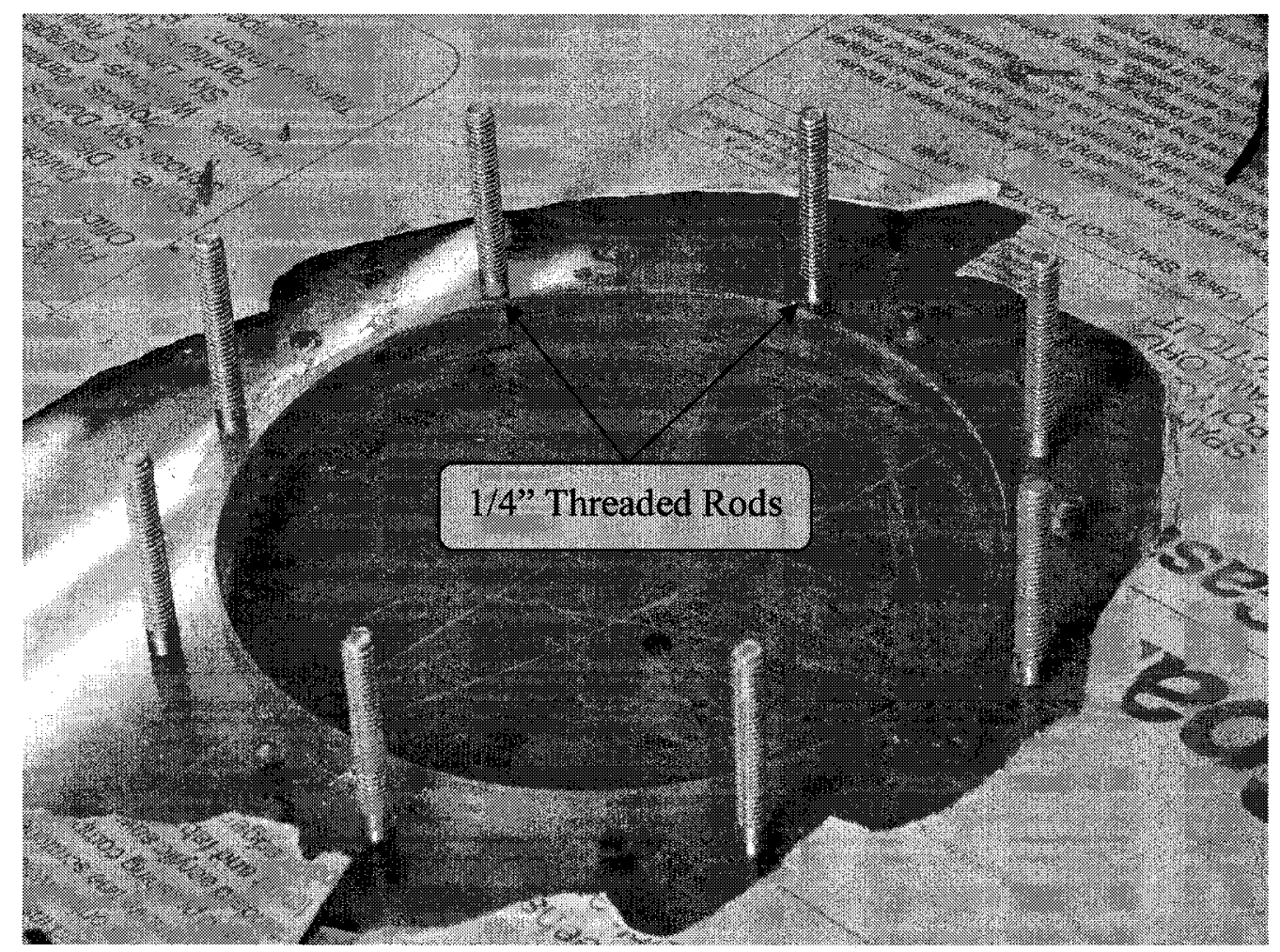

Figure $3.3-1 / 4$ inch Threaded Rods around Plexiglas' Face Hole 
To prevent leakage from any orifices that may have existed between the flanges and any of the faces, circular rubber gaskets were custom fitted in these specific locations. Similar to the rubber seals between the edges of the Plexiglas face and the steel sides of the box. It is important to note that the ring components of the flanges were drilled with 3 arcshaped holes of approximately 2.9 inches $(0.07 \mathrm{~m})$ in radius (See Appendix A). These were used in preliminary testing using the thin metal rods shield system described in section 3.2.1. In a latter stage, the plug components of the flanges were drilled with a $1 / 2$ inch $(0.013 \mathrm{~m})$ hole in the centre to accommodate the threaded rod of the shield used in the final excavation technique. The flanges were completely removed after soil placement and before the tunnel excavation, to allow the insertion of the 6 inch $(0.15 \mathrm{~m})$ diameter shield pipe.

\subsubsection{Wooden feed hopper}

The approximate volume of soil material needed in a single test was 15 cubic feet $(0.45$ $\left.\mathrm{m}^{3}\right)$ and the capacity of a single mixing batch was approximately 3 cubic feet $\left(0.09 \mathrm{~m}^{3}\right)$. It entails a total number of 5 batches per experiment. Due to the large volume of material per experiment, a hopper was constructed in an inverted pyramidal shape, with an approximate volume equal to that of one mixing batch, i.e.: 3 cubic feet $\left(0.09 \mathrm{~m}^{3}\right)$. It was supported by a steel frame to allow for the use of a forklift (See Figure 3.4).

The unloading of the hopper was achieved by rotating a semi-cylindrical door operated by an aluminium bar. It was supplemented with rubber and foam gaskets and lined with a plastic bag that was replaced on a batch-to-batch basis. 


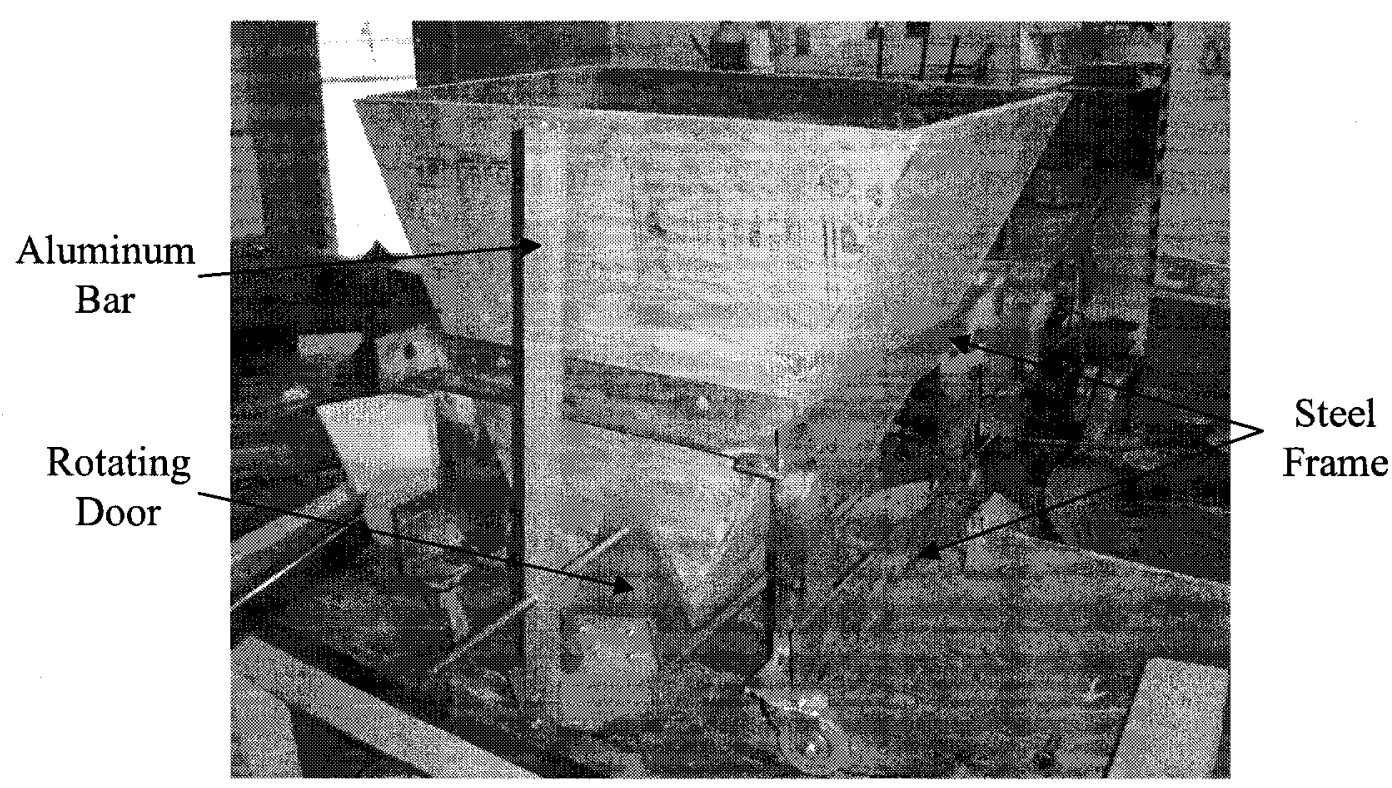

Figure 3.4 - Wooden Feed Hopper

\subsubsection{Tunnel excavation procedure}

The tunnelling was simulated using a system composed of a hydraulic jack, a 6 inch $(0.15$ $\mathrm{m}$ ) diameter steel cylinder and a connecting threaded rod of $1 / 2$ inch $(0.013 \mathrm{~m})$ diameter and 3 feet $(0.9 \mathrm{~m})$ long. A long steel I-beam was set up behind the model's box to act as a track and fix the location of the hydraulic jack during testing (See Figure 3.5).
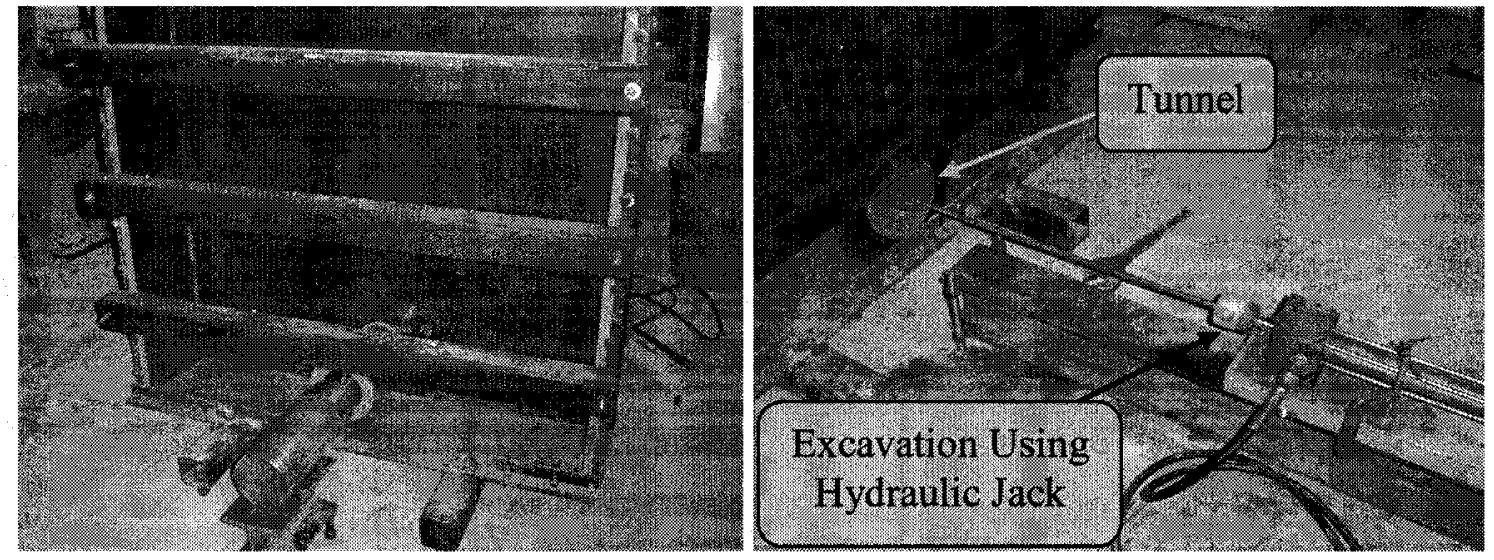

Figure 3.5 - Tunnel Excavation Mechanism (Front View and Back View) 
As mentioned previously, the shield cylinder was connected to the hydraulic jack via a long threaded rod that was attached to the jack from one side and to the cylinder from the other side via 4 spokes welded with a nut.

A hydraulic pump was connected to the jack with two hoses to facilitate the shield advance. The approximate time to fully extend or retract the jack was about 3 minutes. The shield was pulled into the model in two stages: first, the insertion of the shield cylinder into the soil; and second, pulling the shield out of the soil in the same direction through the other side of the box.

\subsubsection{Tunnel lining (monitoring pipe)}

One of the most delicate components of the model, the lining consisted of an aluminium pipe that was equipped with strain gauges to measure positive and negative strains induced by soil movements. The pipe assembly was done by rolling a 1 foot $(0.30 \mathrm{~m})$ wide by 1.3 feet $(0.40 \mathrm{~m})$ long aluminium sheet of $1 / 100^{\text {th }}$ of an inch $(0.00025 \mathrm{~m})$ thickness around a 5 inch $(0.013 \mathrm{~m})$ diameter pipe, then closing it with a series of $1 / 8^{\text {th }}$ inch $(0.003 \mathrm{~m})$ nuts and bolts (See Figure 3.6 Left).

The selection of aluminium as the pipe material was based on laboratory testing of different materials. Aluminium provided the necessary flexibility and elasticity to maximize strain detection. A calculation of compressibility and flexibility factors for the chosen lining according to Bobet (2001) (see Equation 2.4) gave values of 0.00889 and 6894 respectively which translates into minimal compressibility and high flexibility. 
The installation of strain gauges required several steps. After marking the locations and cleaning the surface with fine sandpaper and a proper cleaning agent, the strain gauges were attached with super-strength glue, their wirings properly isolated and then soldered to electrical wires which were fitted to pin connectors (See Figure 3.6 Right).
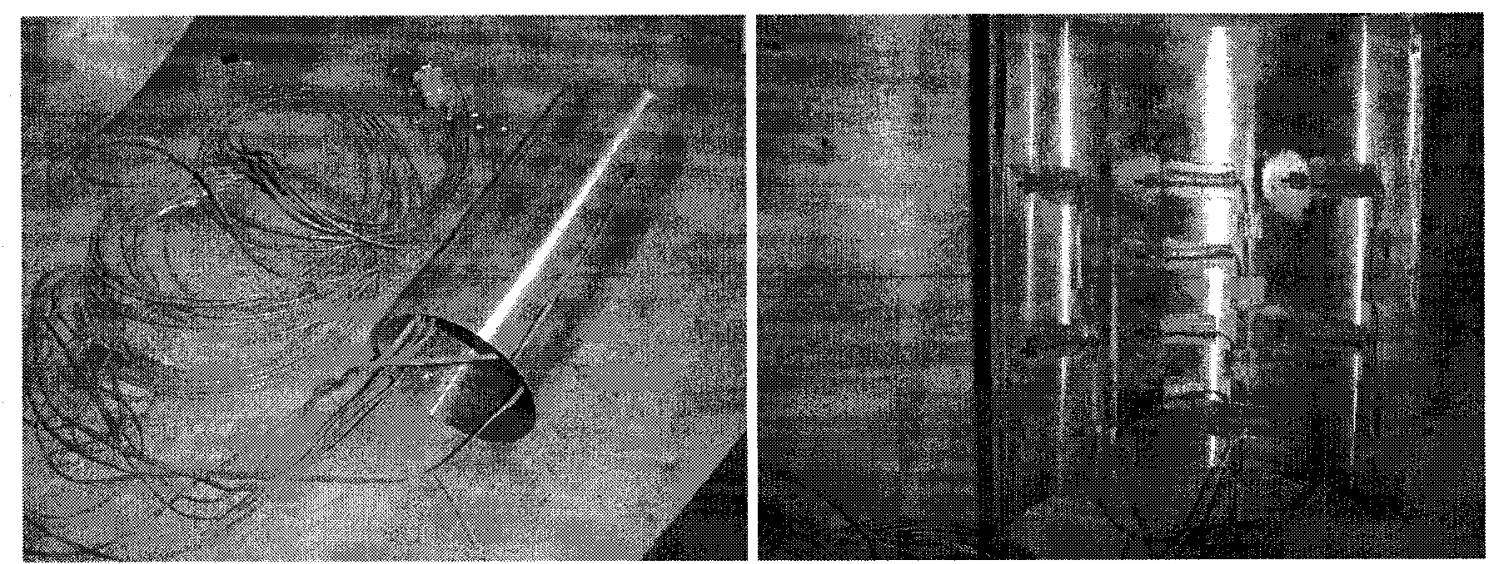

Figure 3.6 - Monitoring Pipe (Assembled and Open)

The final lining was 5 inch $(0.13 \mathrm{~m})$ in diameter and was instrumented with 8 strain gauges oriented perpendicular to the lining's centerline. The pipe diameter was selected to allow for a physical gap of about $0.025 \mathrm{~m}$ between the shield and the lining.

\subsubsection{Model piles}

Model piles were selected to simulate the case of deep piles extended in soft clay and supported in a strong soil or bedrock layer below the tunnel level. The model piles consisted of thirty 1-inch $(0.025 \mathrm{~m})$ diameter steel rebars distributed symmetrically in three rows of five piles on both sides of the tunnel (See Figure 3.7 Left and Appendix B). Although the model piles were not loaded as would be the case in an actual setting, they were nonetheless fixed in the $x-y$ direction at the top and bottom of the box using a metal 
grid and a perforated wooden plate, respectively. Fixing the pile groups at the top and bottom of the box was also necessary to prevent their movement during testing.

Pile compressibility and flexibility factors were calculated using the relationships of Poulos and Davis (1974) (see Equations 3.1). Respective values of 40 and 0.0016 correspond to incompressible pile of medium flexibility.

$$
\begin{aligned}
& C_{p}=\frac{E_{p}}{E_{s}} A_{p} \\
& F_{p}=\frac{E_{p} I_{p}}{E_{s} L^{4}}
\end{aligned}
$$

Where,

$E_{p}=$ Young's modulus of pile

$E_{s}=$ Young's modulus of soil

$\mathrm{L}_{\mathrm{p}}=$ length of pile

$A_{p}=$ cross-sectional area of pile

$I_{p}=$ second moment of area of pile
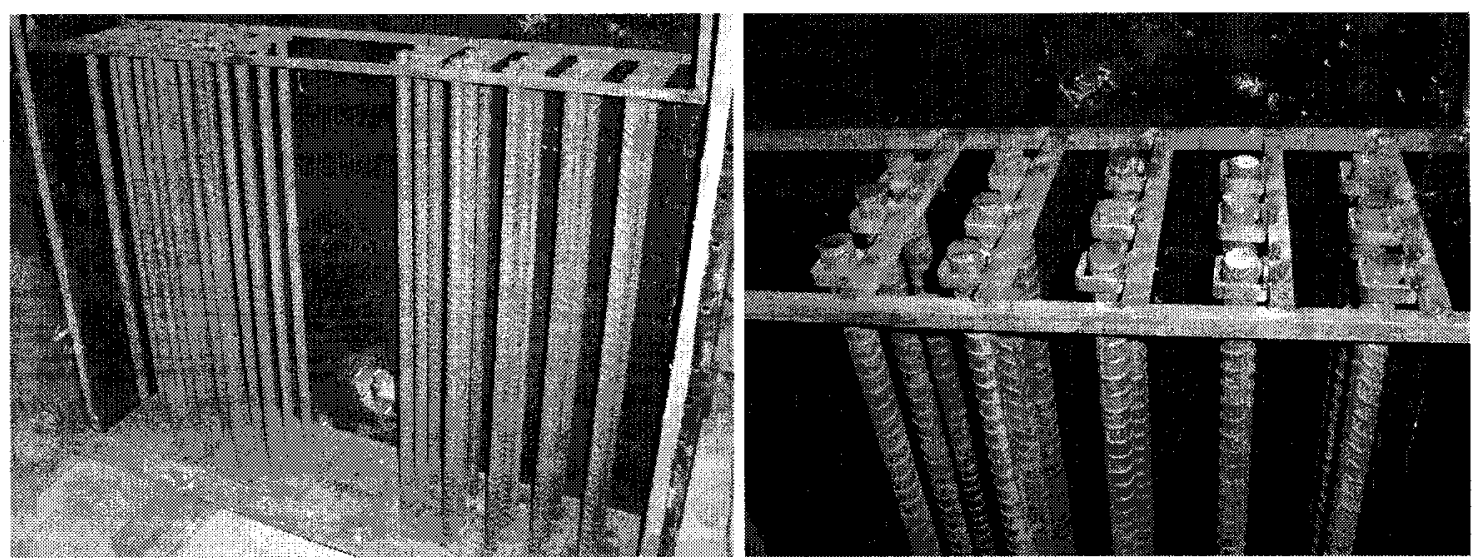

Figure 3.7 - Model Piles 
The wooden plate was cut to the inner dimensions of the box and thirty 1 -inch $(0.025 \mathrm{~m})$ diameter holes were drilled and spaced according to a grid pattern. The metal grid was constructed from $1 / 2$ inch $(0.013 \mathrm{~m})$ square section steel bars cut to the dimensions of the interior of the box and welded together. Similar bars were spread across the grid and welded to it. A square 2in-by-2in $(0.05 \mathrm{~m}$ by $0.05 \mathrm{~m})$ hollow steel section was used to create thirty $1 / 2$ inch $(0.013 \mathrm{~m})$ thick rebar holders to prevent pile movement at the top of the box (See Figure 3.7 Right). The piles were removable from their full grid setup to be re-arranged in a multitude of grid patterns (see Appendix B).

\subsection{Tunnel excavation}

Several trial techniques have been used to simulate the process of tunnel excavation and lining installation in soft clay. Temporary supporting the excavated opening during excavation with minimum induced disturbance was one of the challenging tasks. A summary of these trial methods is given below.

\subsubsection{Unsupported excavation system}

In this method, the soil excavation was performed with no temporary support, relying on the soil stiffness to support the excavated opening as the lining is installed.

This procedure was only possible for stiff clay material which requires a long-term consolidation process to reach the desired strength. The strength needed for a stable unsupported excavation as suggested by Peck (1969) is achieved if $\gamma z / c_{u} \leq 5$. For the given geometry (depth to cover (z) of approximately $1 \mathrm{~m}$ and soil unit weight $(\gamma)$ of 18 $\mathrm{kN} / \mathrm{m}^{3}$ ), the shear strength $\left(\mathrm{c}_{\mathrm{u}}\right)$ should be around $4 \mathrm{kPa}$. 
For such a large soil volume, reaching the desired shear strength required several weeks of consolidation time which was considered unpractical within the scope of this study.

\subsubsection{Thin rods shield system}

Thin steel rods ( $30 \mathrm{~cm}$ in length, $2 \mathrm{~mm}$ in diameter) were installed and supported at a small distance outside the tunnel perimeter (see Figure 3.8 below). Tunnelling simulation was achieved by augering inside the cylindrical shaped soil created within the area surrounded by the metal rods. The flexible metal lining was then installed inside the excavation. The rods were allowed to move towards the installed lining.

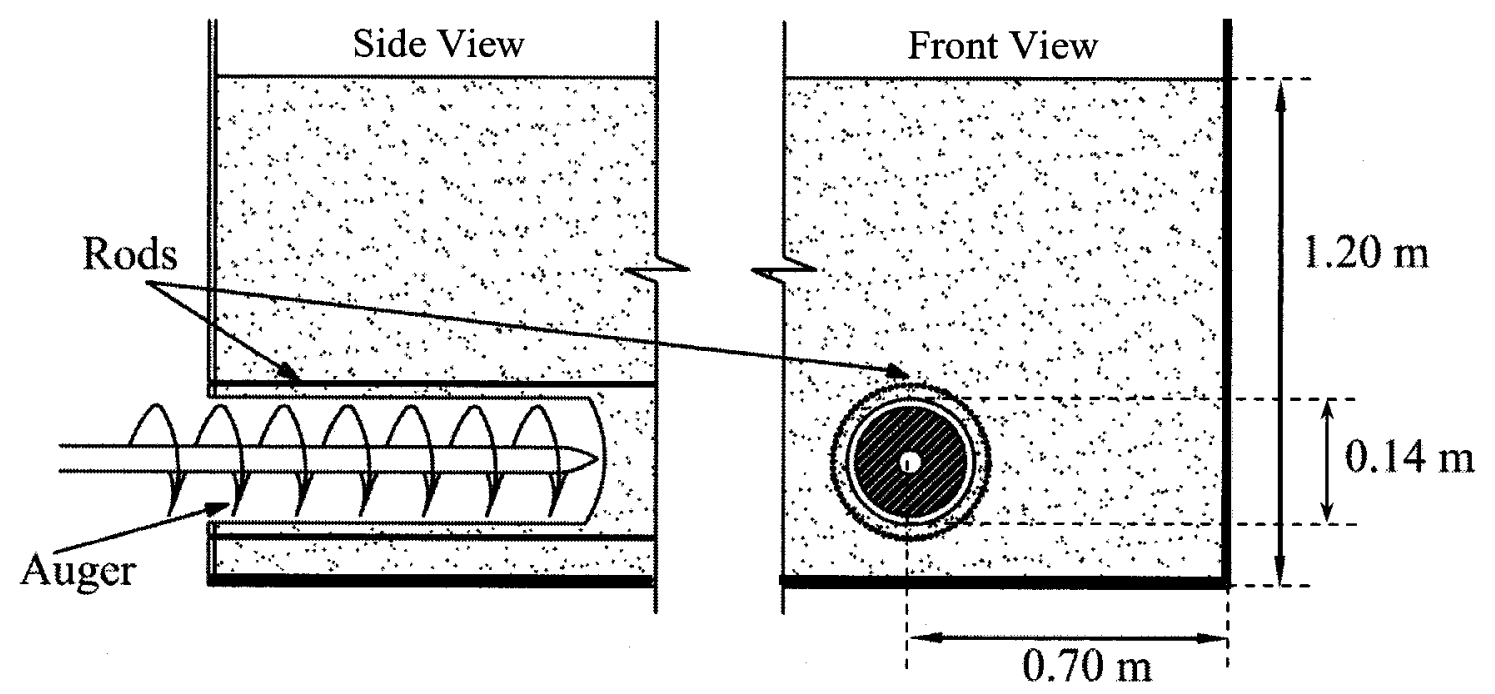

Figure 3.8 - Thin Rods Shield System

The advantage of using thin metal rods as a shield was that shearing of soils due to installation was minimal because the rods were left in place to collapse with the soil. A preliminary test was carried out to check the practicality of the method (see Figure 3.9). During installation, the rod alignment was found to be challenging. Several trials were performed by moving the rods back and forth inside the soil which lead to soil 
disturbance around the tunnel perimeter. This problem rendered the use of metal rods unpractical and hard to repeat under the same testing conditions.

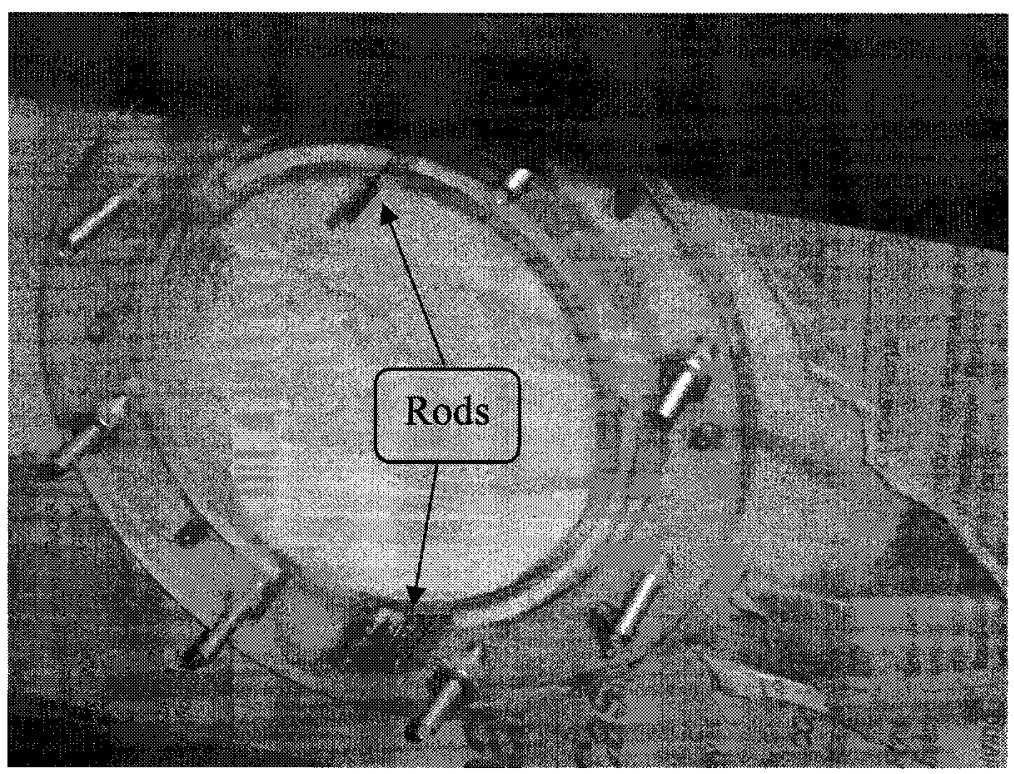

Figure 3.9 - Preliminary Sand Test with Metal Rods

\subsubsection{Fully shielded excavation}

This procedure consisted of pulling a shield (stiff steel cylinder) progressively through the soil. The soil inside the shield was then removed incrementally and a monitoring cylinder (lining) placed inside the newly created void just before the shield was removed completely from the steel box to allow the soil to move towards the centre of the tunnel (see Figure 3.10).

As mentioned earlier, the shield cylinder was connected to a hydraulic jack via a long threaded rod that was attached to the jack from one side and attached to the cylinder from the other side via 4 spokes welded with a nut. To improve the repeatability of the test the 
shield and the jack were placed on a steel track consists of a large I-beam section to guide the shield during testing and insure a consistent path for different tests.

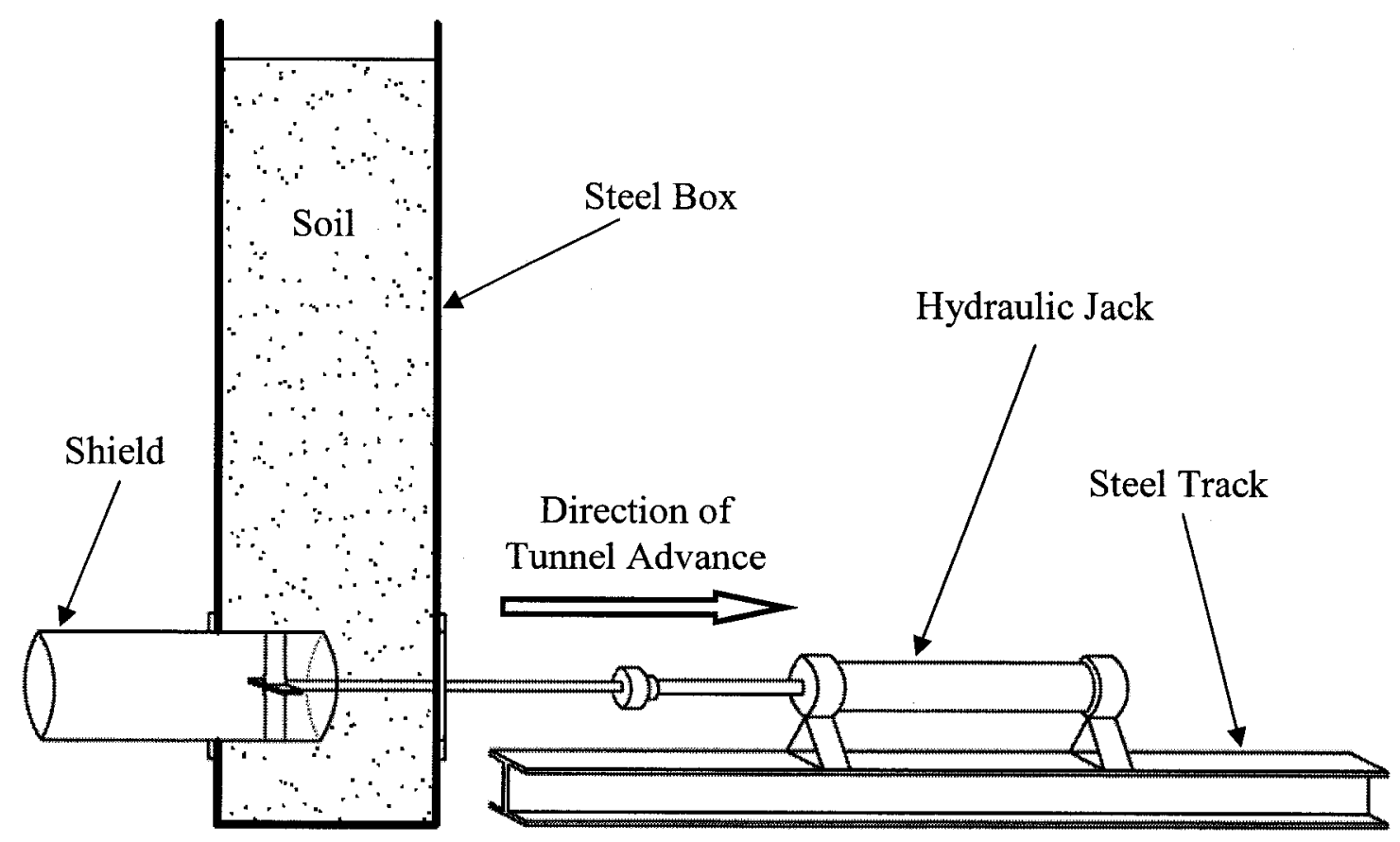

Figure 3.10 - Fully Shielded Excavation

A preliminary test on wet sand was carried out to validate the repeatability of the method. The shield installation worked consistently and the shield cylinder followed the predetermined track. The shield has shown to be rigid as compared to the supported soil and no deflection was observed as a result of the applied soil pressure.

The test was repeated with a clay mix to validate the procedure for cohesive soils. The test was also successful and the measured lining stresses based on the strain gauge readings were consistent with the theoretical results reported in the literature. Details of these results will be discussed in Chapter 5. 
To facilitate the comparison between the control test and the case where a deep foundation already exists in soil prior to tunnelling, two pile groups were installed symmetrically on each side of the tunnel location prior to soil placement as shown in Figure 3.11.

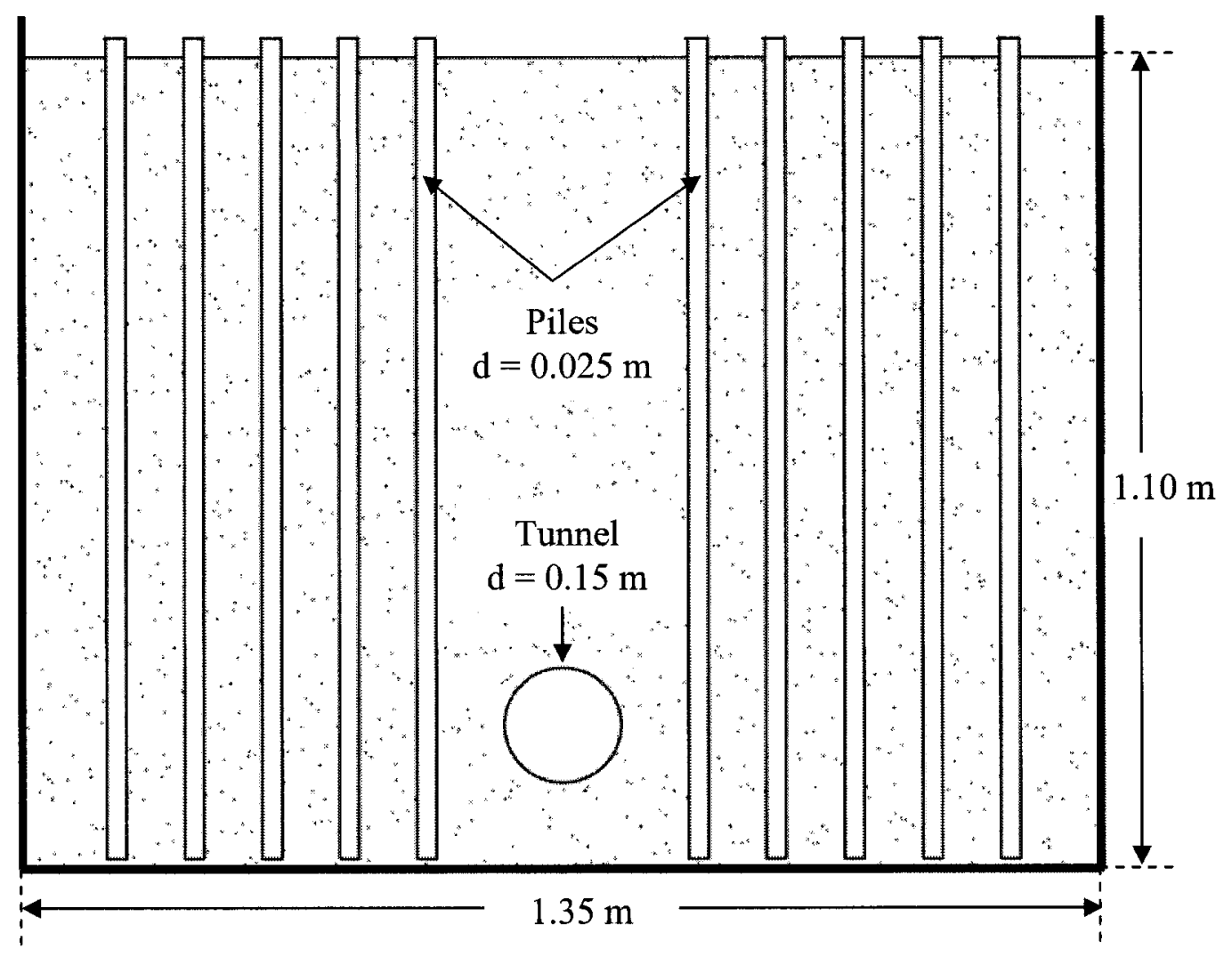

Figure 3.11 - Pile Groups Installed around the Tunnel 


\subsection{Soil preparation and characterization}

Consolidating a large clay volume from slurry is a time consuming process due to the fact that clays usually have low hydraulic conductivity and the drainage path is relatively long particularly near the sample centre. Previous researchers (Stimpson, 1970, Dykeman and Valsangkar, 1996) used cement-sand-clay mixes to simulate stiff clay and weak rock material. These methods allowed for control of the soil strength and minimized the need for consolidation. In this study, a clay powder (bentonite) was mixed with a percentage of sand and a small amount of cement to simulate the clay material.

Table 3.1 - Trial Mixes and Observations

\begin{tabular}{|c|c|c|c|c|c|c|}
\hline \# & $\begin{array}{c}\text { Water } \\
\%\end{array}$ & $\begin{array}{l}\text { Sand } \\
\%\end{array}$ & Clay\% & $\begin{array}{c}\text { Cement } \\
\%\end{array}$ & $\begin{array}{c}\text { Final } \\
\text { Observations }\end{array}$ & $\begin{array}{c}\text { Time between } \\
\text { Mixing and } \\
\text { Observation }\end{array}$ \\
\hline 1 & $20 \%$ & $70 \%$ & I $4 \%$ & $6 \%$ & Very Solid (Smooth Surface) & \\
\hline 2 & $16 \%$ & $74 \%$ & I $6 \%$ & $4 \%$ & Very Solid (More Brittle) & \\
\hline 3 & $17 \%$ & $73 \%$ & B $6 \%$ & $4 \%$ & Not Workable Hard \& Brittle & $3 h 00$ \\
\hline 4 & $40 \%$ & $36 \%$ & B $20 \%$ & $4 \%$ & Stiff \& Cohesive & $3 h 30$ \\
\hline 5 & $25 \%$ & $61 \%$ & B $10 \%$ & $4 \%$ & Stiff \& Granular & $3 h 30$ \\
\hline 6 & $36 \%$ & $50 \%$ & B $10 \%$ & $4 \%$ & Soft \& Cohesive & $2 \mathrm{~h} 00$ \\
\hline 7 & $36 \%$ & $50 \%$ & K $10 \%$ & $4 \%$ & Too Liquid (Discarded) & \\
\hline 8 & $40 \%$ & $36 \%$ & K $20 \%$ & $4 \%$ & Too Liquid (Discarded) & \\
\hline 9 & $16 \%$ & $74 \%$ & K $6 \%$ & $4 \%$ & Slushy Granular & $2 \mathrm{~h} 30$ \\
\hline 10 & $14 \%$ & $74 \%$ & $\mathrm{~K} 8 \%$ & $4 \%$ & Less Slushy Granular \& Dry & $2 \mathrm{~h} 30$ \\
\hline 11 & $37 \%$ & $51 \%$ & B $11 \%$ & $1 \%$ & Discarded & \\
\hline 6 & $36 \%$ & $50 \%$ & B $10 \%$ & $4 \%$ & Stiff \& Workable & $3 \mathrm{~h} 00$ \\
\hline $6^{*}$ & $37 \%$ & $49 \%$ & B $10 \%$ & $4 \%$ & Minor Difference & $3 \mathrm{~h} 00$ \\
\hline 12 & $42 \%$ & $44 \%$ & B $10 \%$ & $4 \%$ & $\begin{array}{l}\text { Used throughout the } \\
\text { Experiment }\end{array}$ & \\
\hline
\end{tabular}

* I (Illite), B (Bentonite), and K (Kaoline)

Several mixes with different cement/clay/sand content were tried to obtain sufficient strength and prevent soil from flowing into the excavated opening. A complete list of the 
mix proportions and observations made on soil consistency is summarized in Table 3.1. The selected mix was based on trial mix 12 (4\% type- 10 cement, $10 \%$ bentonite clay, $44 \%$ fine sand, and $42 \%$ water) because it provided enough workability to allow soil placement and reasonable shear strength few hours after placement.

\subsubsection{Clay mix properties}

Laboratory testing was conducted to determine the properties of the soil components (clay powder and sand) as well as the properties of the clay mix. Table 3.2 lists the various measured soil properties.

Table 3.2 - Soil Properties

\begin{tabular}{lc}
\hline SOIL PROPERTIES & \\
\hline $\mathrm{G}_{\mathrm{s}}$ (Specific Gravity of Sand Mineral) & 2.66 \\
$\mathrm{D}_{10}$ (Effective Size of Sand Particle) & 0.28 \\
$\mathrm{C}_{\mathrm{u}}$ (Uniformity Coefficient of Sand) & 1.25 \\
LL (Bentonite Clay Liquid Limit) & $84 \%$ \\
PL (Bentonite Clay Plastic Limit) & $60 \%$ \\
$\mathrm{w}_{\mathrm{c}}$ (Water Content of Clay Mix) & $40 \%$ \\
$\mathrm{c}_{\mathrm{u}}$ (Undrained Shear Strength) & $3-4 \mathrm{kPa}$ \\
$\gamma_{\mathrm{sat}}$ (Saturated Unit Weight) & $18 \mathrm{kN} / \mathrm{m}^{3}$ \\
\hline
\end{tabular}

Shear vane tests were conducted to measure the undrained shear strength of the soil right after the tunnel excavation. A hand-held shear vane with a blade diameter of $19 \mathrm{~mm}$ was used. Figure 3.12 shows a diagram of the various vane test locations. Figure 3.13 shows the grain size distribution curve for the sand used in the soil mix. It was found that the sand is uniformly graded (Uniformity coefficient $C_{u}=1.4$ ) with an effective size $\left(D_{10}\right)$ of $0.25 \mathrm{~mm}$. 


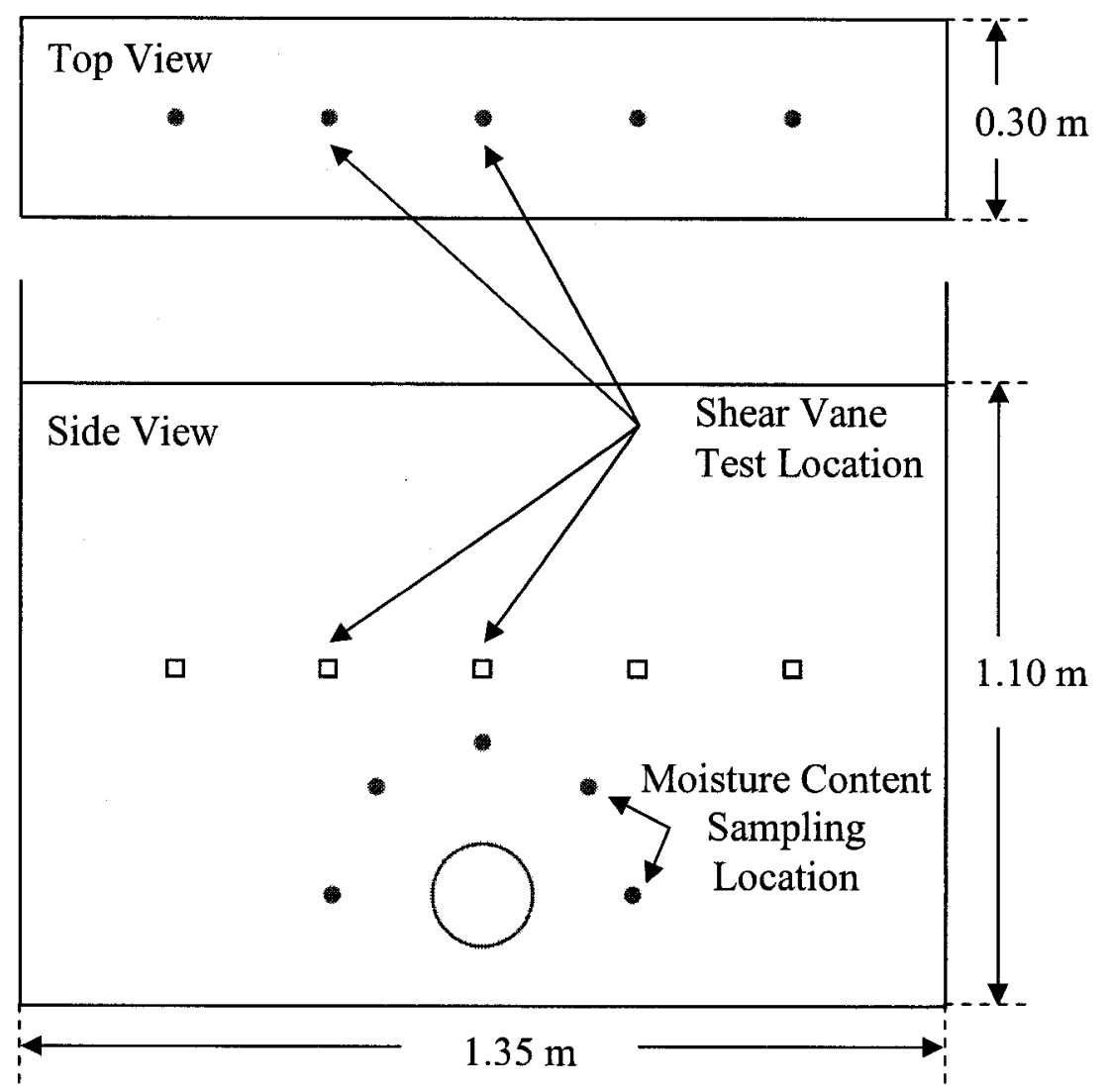

Figure 3.12 - Location of Shear Vane Tests

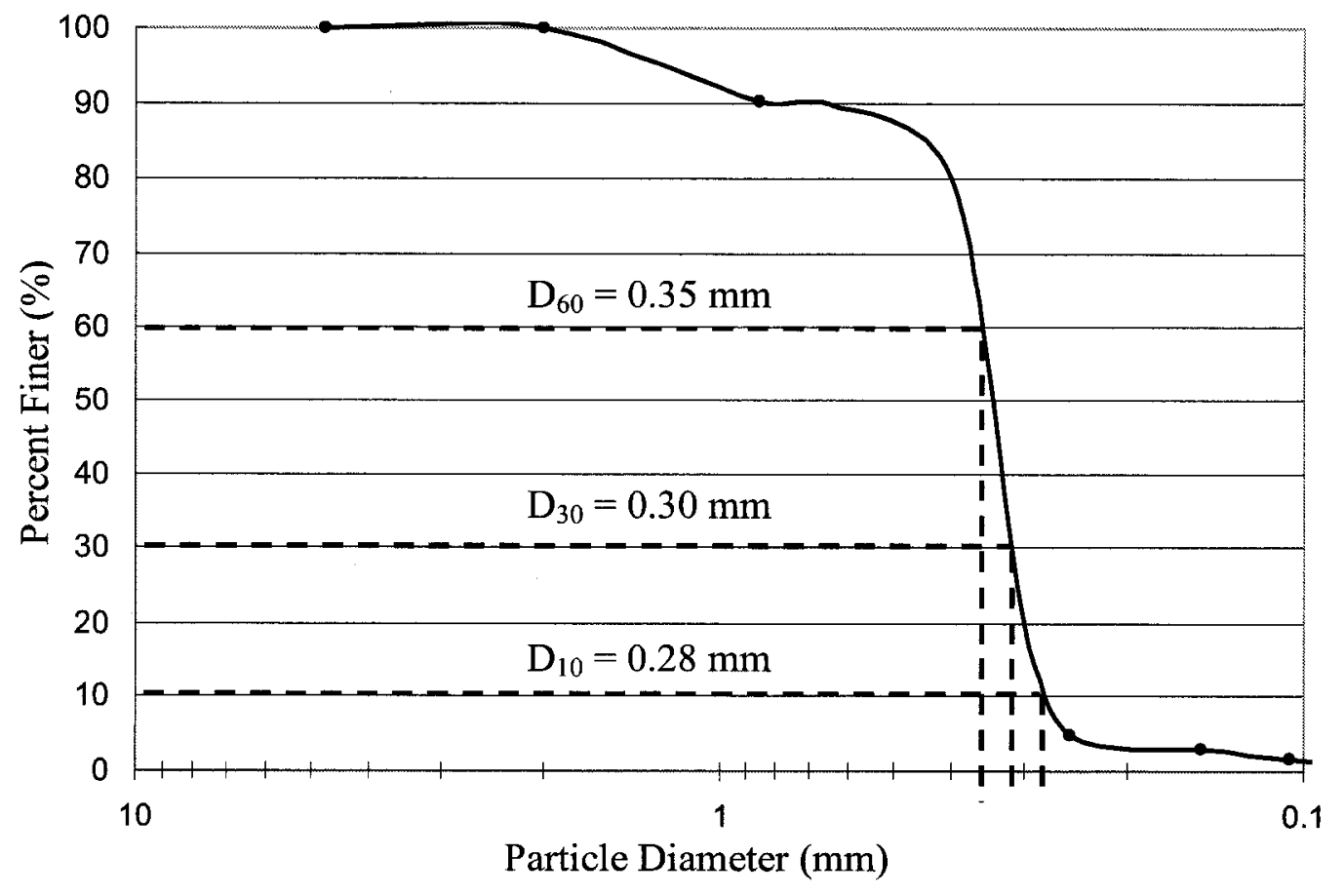

Figure 3.13 - Grain Size Distribution of the Sand 


\section{TESTING PROCEDURE AND DATA ACQUISITION}

The present chapter describes the testing procedure used to conduct the experimental work throughout this study. It is divided into two sections: first, soil preparation, tunnelling and lining installation; and second, the monitoring phase and data acquisition.

\subsection{Testing procedure}

To minimize boundary friction between the soil and the steel sides as well as the Plexiglas face, the inner faces of testing box were painted with silicon grease. The different constituents of the mix (cement, clay, sand, and water) were divided into five equal parts to be mixed in the concrete mixer one batch at a time for an average mixing time of about 15 minutes (See Figure 4.1 Left).
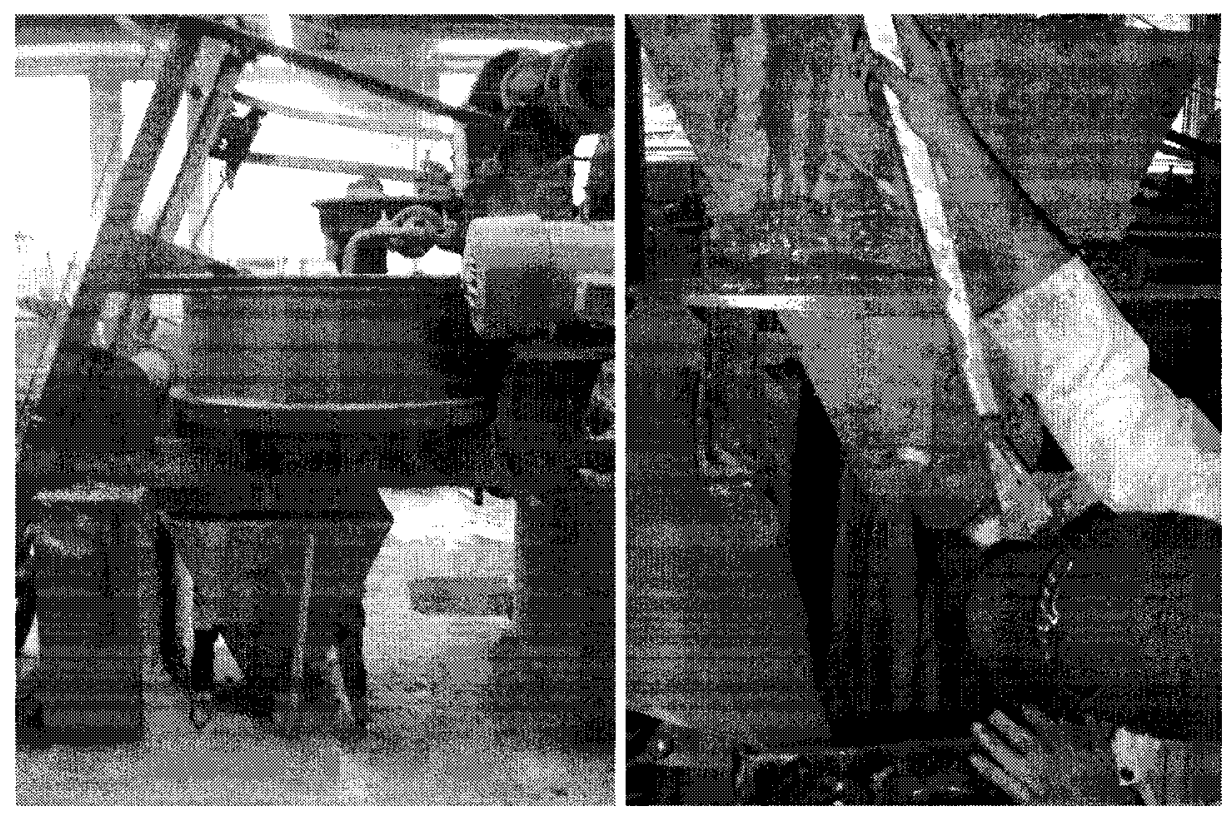

Figure 4.1 - Left: Single Batch Mixing - Right: Unloading Clay with Hopper 
The clay mix was first poured into the feed hopper situated beneath the mixer. The hopper was then lifted and moved above the box with the help of a forklift. Finally, the door at the bottom of the hopper was released to pour the mix in the box. The procedure was repeated for each batch of the test until the target volume was achieved.

For the tests where tunnel-soil-pile interaction was examined, upper and lower fixities were installed first. The fixities consisted of a metal grid at the top resting on both side faces of the test box and a slotted wooden plate at the bottom of the box. The steel model piles were then installed in the corresponding slots. The setup is shown in Figure 4.2 below. Other pile grid setups are provided in Appendix B.

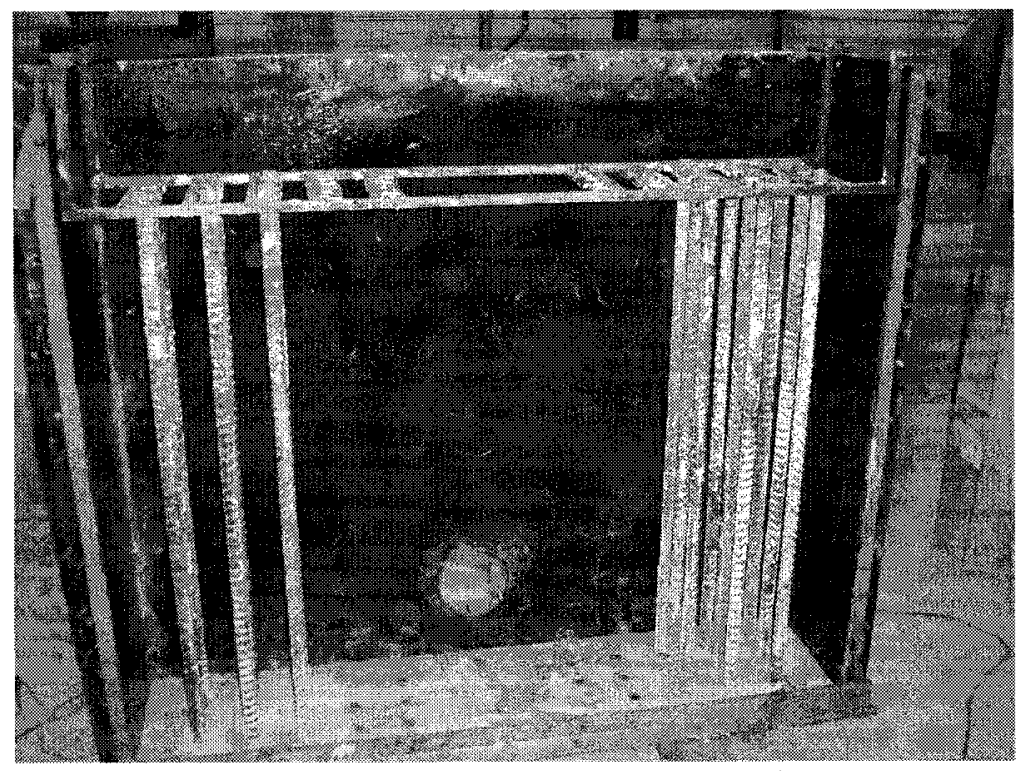

Figure 4.2 - Pile Installation

After the clay-cement mix had been left for an hour approximately to reach the desired strength, the shield was connected to a hydraulic jack located behind the back face of the box using a threaded rod. The excavation process started with the removal of the front Plexiglas flange to allow for the jacking of the shield (See Figure 4.3). The process of 
pushing the shield towards the soil was done in five increments to allow for the removal of the clay from inside the shield. Just before the cylinder was completely inserted in the soil, the second flange was loosened and removed as the tip of the cylinder took its place.
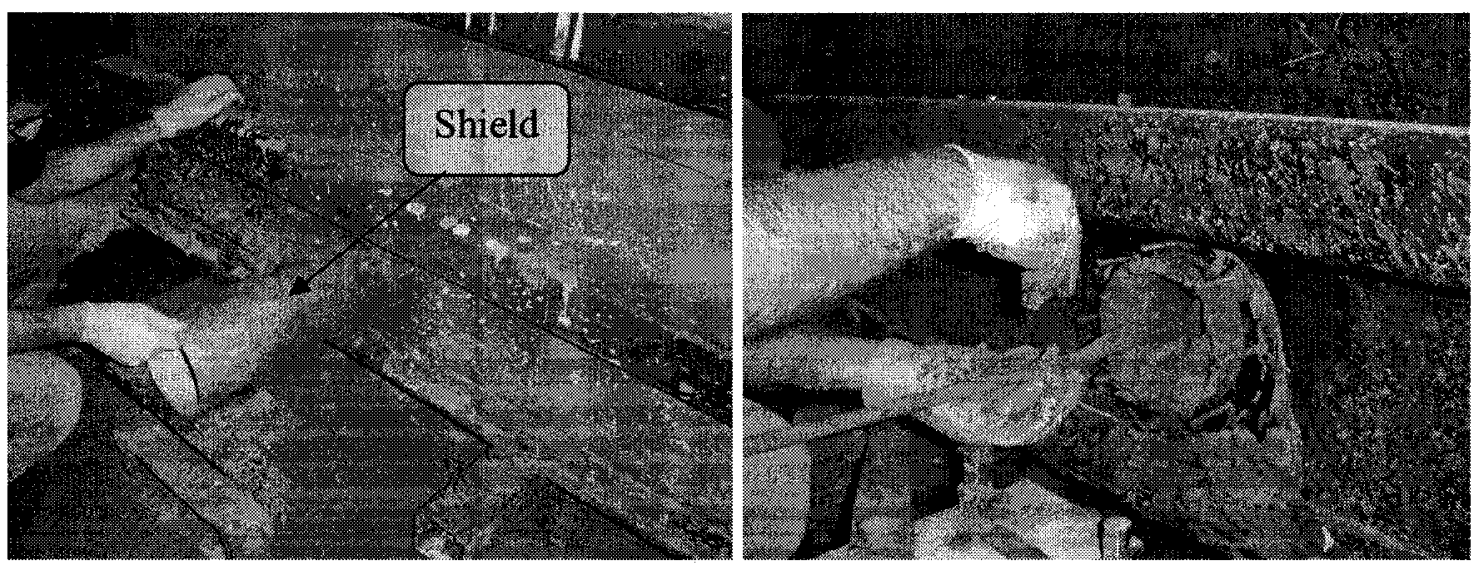

Figure 4.3 - Insertion and Extraction of Shield

After the inside of the shield had been completely cleaned of soil, the lining was placed into the shield and connected to the data acquisition system to acquire lining strains. This phase was completed with the pulling of the shield completely out of the box allowing the soil to move radially into the gap between the excavated soil and the lining (see Figure 4.4).
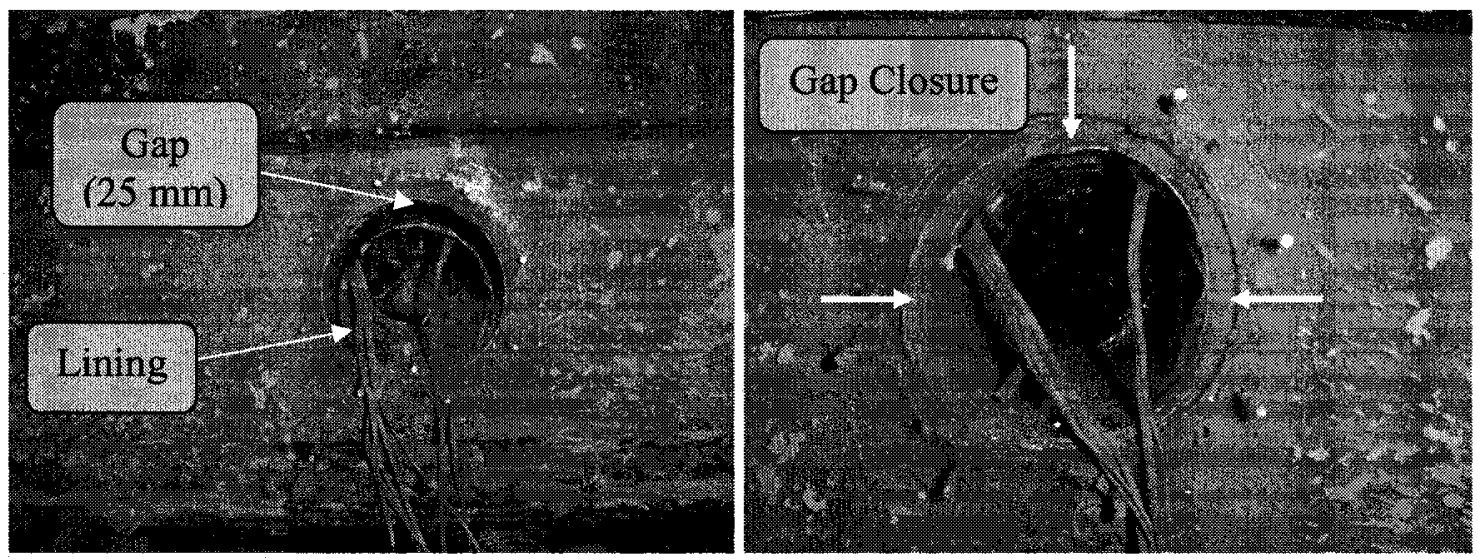

Figure 4.4 - Pre- and Post-Extraction of the Shield 


\subsection{Data acquisition}

The lining was instrumented using 8 strain gauges installed inside the pipe. Four strain gauges were installed at the springlines, and four were installed at the crown. The strain gauges were connected to the data acquisition system (StrainBook 616, IOtech Inc., 2005) via 9 pin D-shell connectors. The data acquisition system was connected to a computer via USB connection and made use of WaveBook acquisition software (IOtech Inc., 2005). The data acquisition channels were configured to a $1 / 4$ bridge circuit. A complete setup is shown in Figure 4.5.

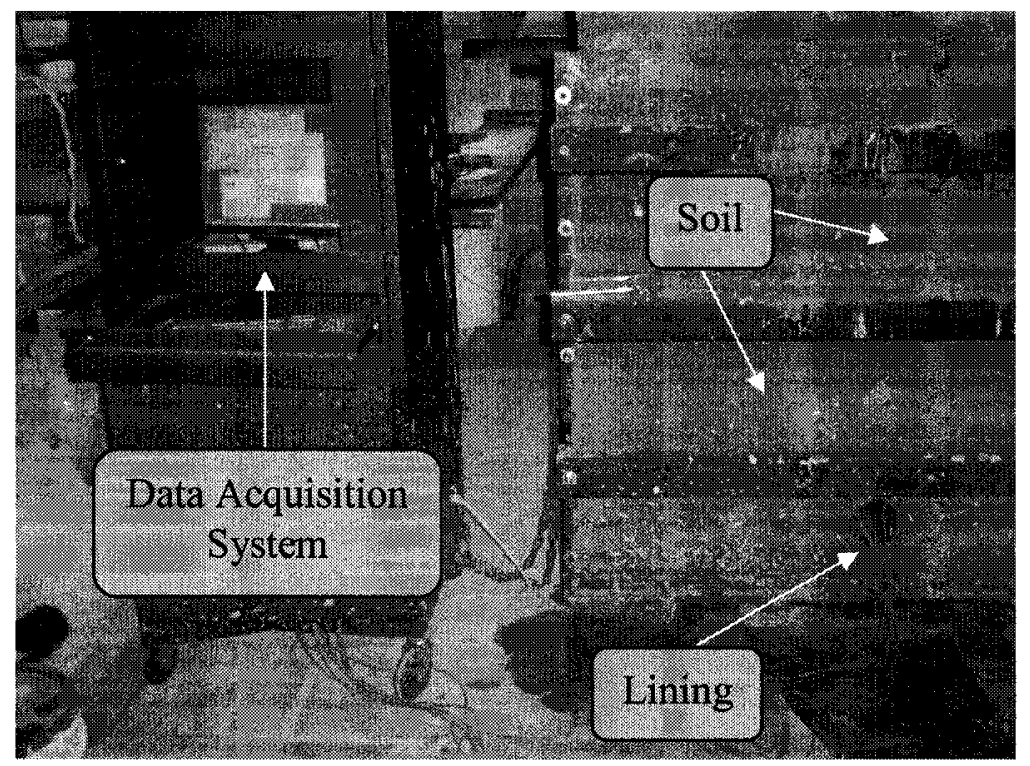

Figure 4.5 - Complete Data Acquisition Setup 


\section{EXPERIMENTAL AND NUMERICAL RESULTS}

This chapter presents the experimental results obtained using the testing procedures described in Chapter 4. In addition, the results of the finite element analyses conducted to calculate the lining response are also discussed.

\subsection{Experimental results}

Figure 5.1 shows the typical deformed shape of the lining along with the location of the strain gauges. The solid line represents the initial geometry of the lining; the deformed shape is represented by the dotted line. Figure 5.2 shows a typical reading of two strain gauges: one is located at the tunnel crown, and the second at the springlines.

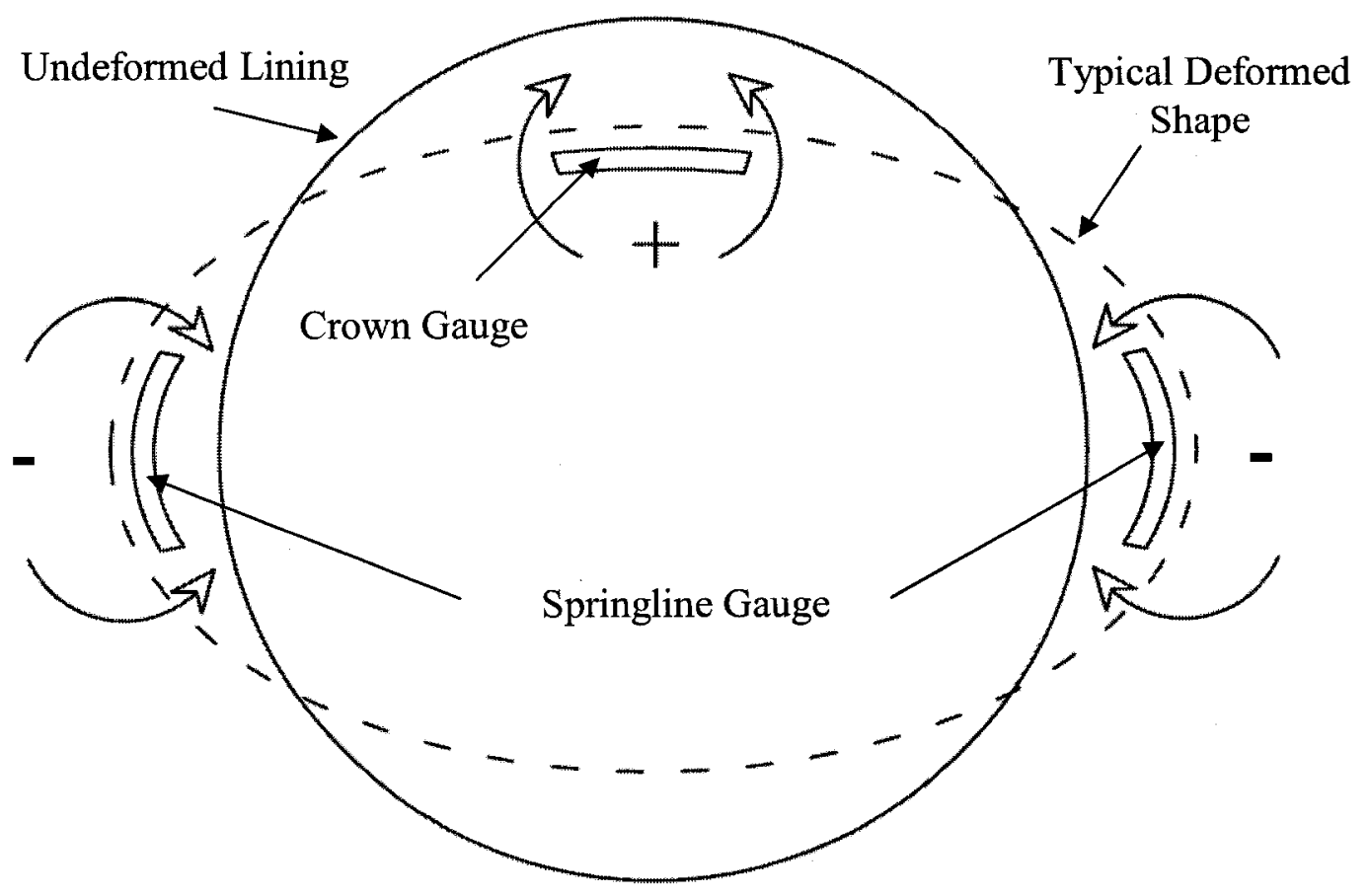

Figure 5.1 - Typical Lining and Strain Gauges Locations 
As the lining deforms, strain gauges installed at the crown (on the inner side) elongates. On the other hand, springline strain gauges (on the inner side) contracts. These actions are identified by the positive values of strain at the crown and negative values at the springline.

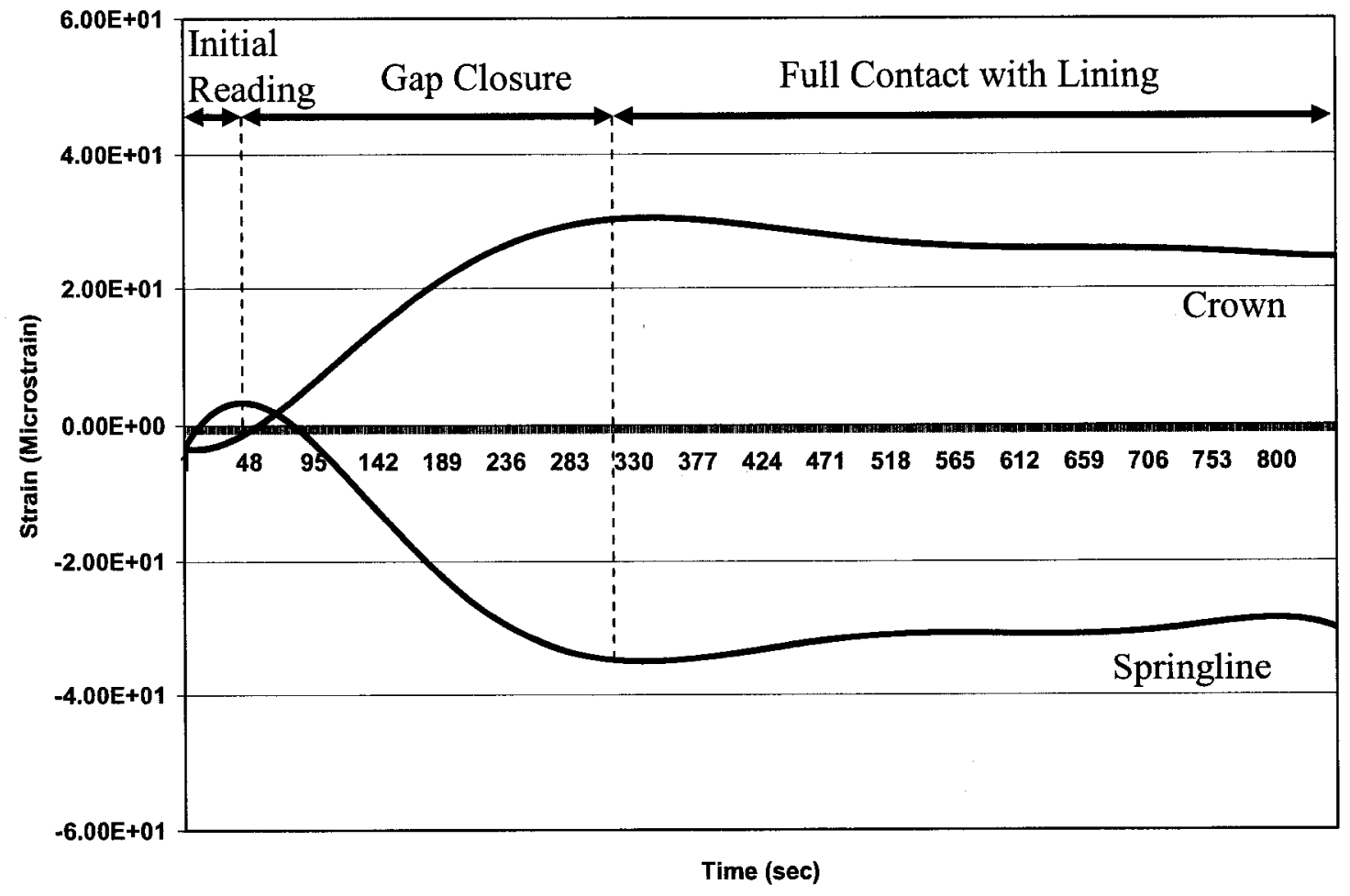

Figure 5.2 - Typical Strain Gauge Readings

Figure 5.3 illustrates the locations of the strain gauges installed inside the lining. When the lining is advanced in the excavated tunnel opening, the first section instrumented by gauges $\mathrm{C} 1, \mathrm{~S} 1$, and S3 goes in first. As the shield is extracted, the soil closes on the last section instrumented by gauge $\mathrm{C} 22$ triggering the first strain gauge reading. After a test is completed and strain gauge readings are recorded as shown in Figure 5.4, the results are analyzed considering the following: 
1) The initial readings ( 0 to $30 \mathrm{sec}$ approximately) correspond to the recorded strains before the shield is completely removed. These consist mostly of noise.

2) Gauges started to record strains at four different times (corresponding to the four sections/lines of gauges) as the gap is progressively closing in the direction of the tunnel advance (see Figure 5.3). In most instances, the initial value of the gauges at the moment of gap closure is different than zero because of the prior manual handling of the lining.

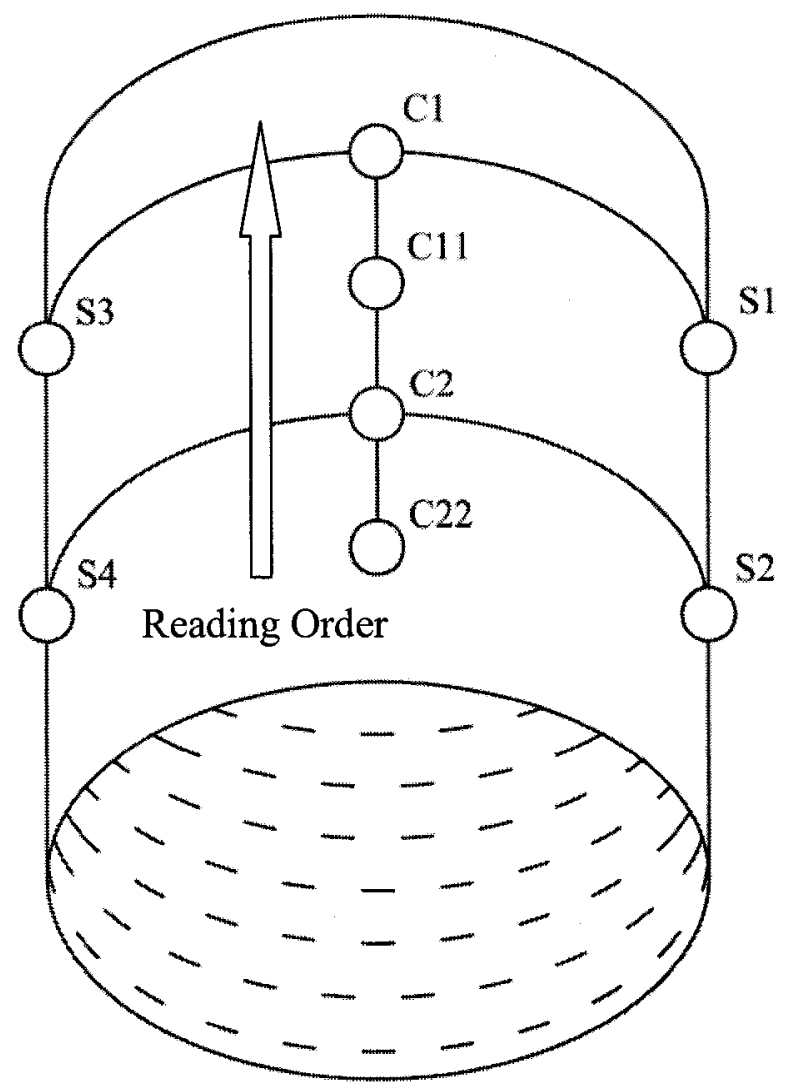

Figure 5.3 - Layout of Strain Gauge Locations on Lining

Adjusting the readings was conducted by identifying the time stamps that correspond to the start of the strain increase due to gap closure and offsetting these points to zero along the y-axis. A sample of the adjusted plots is shown in Figure 5.5. 


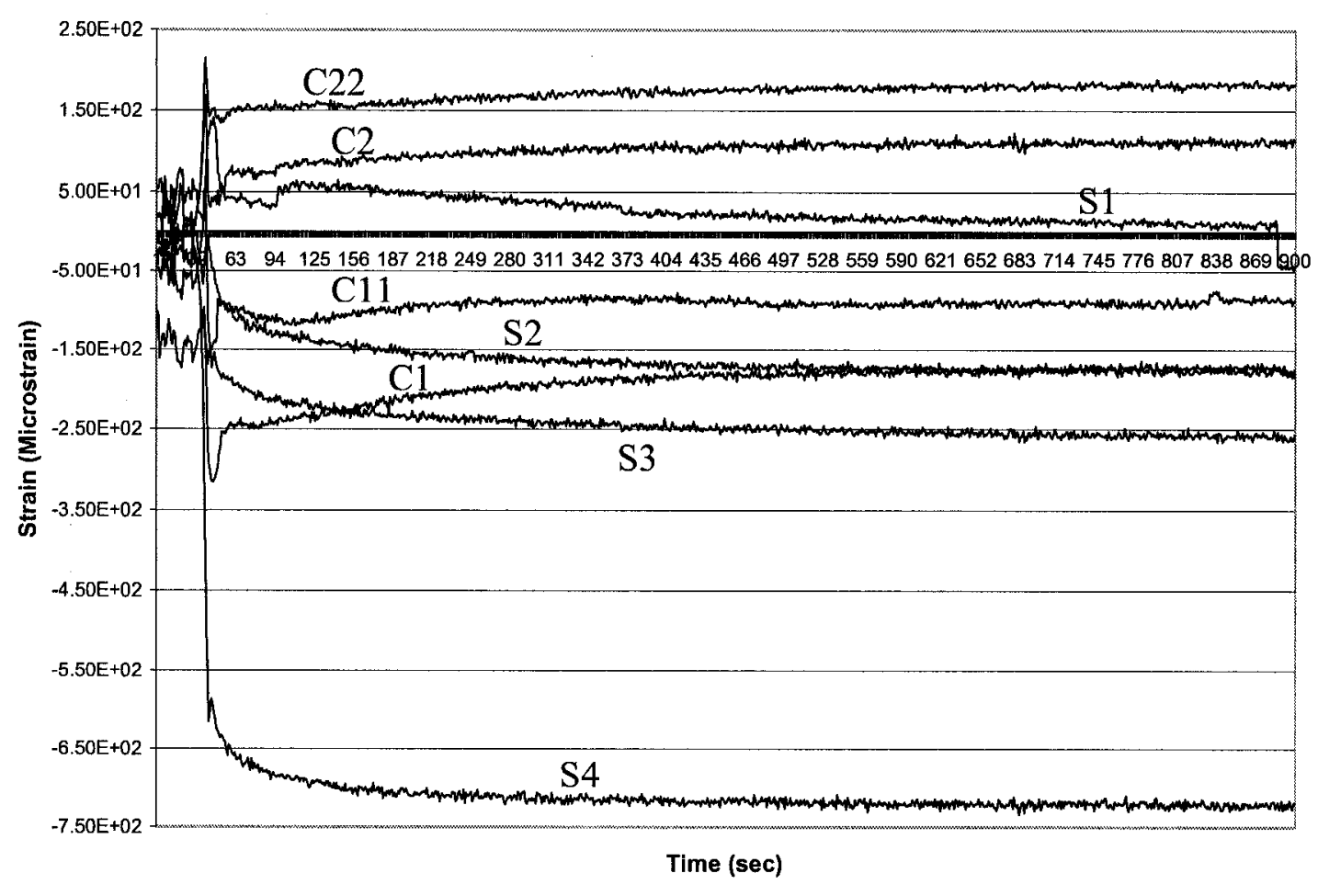

Figure 5.4 - Strain Gauge Readings before Correction

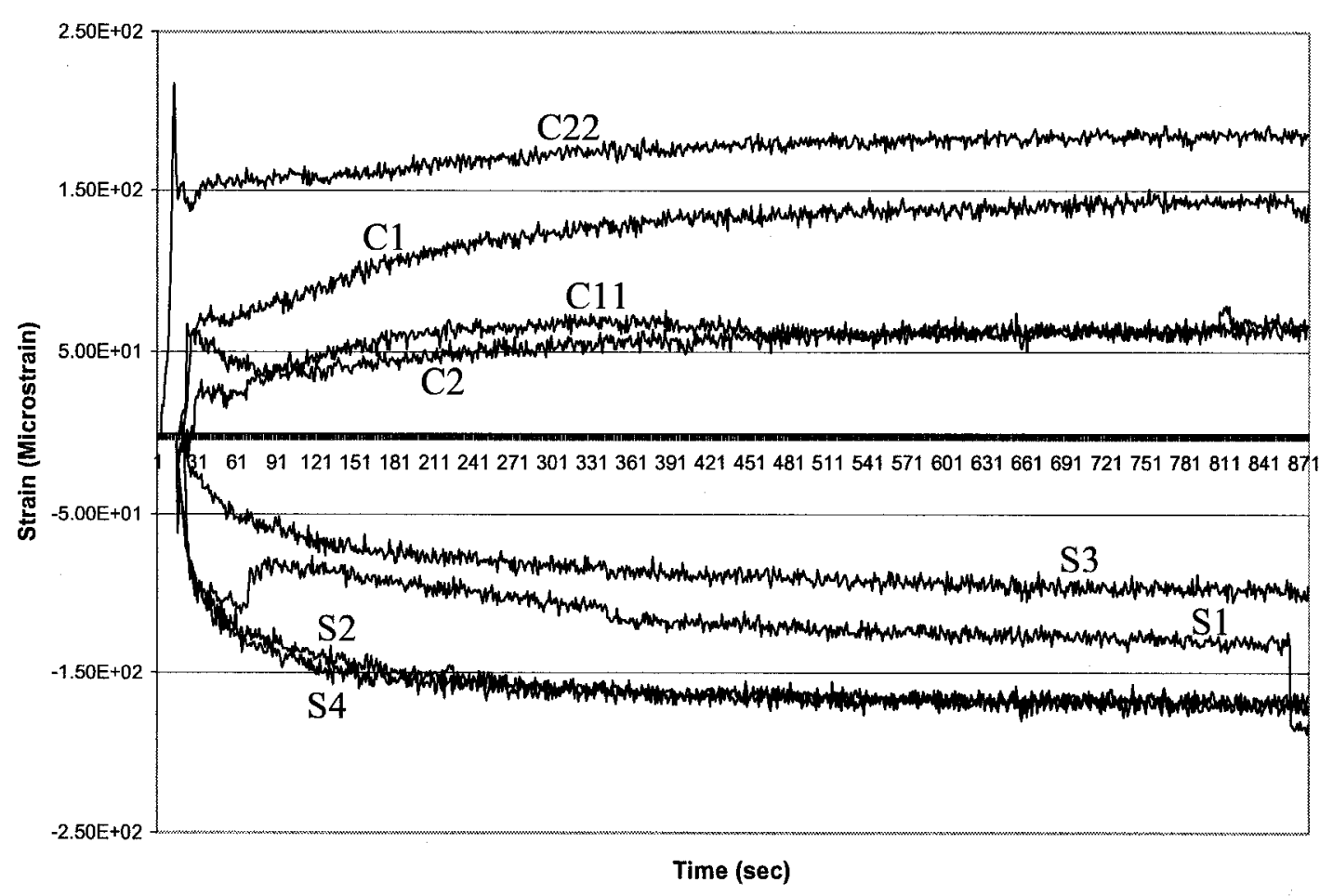

Figure 5.5 - Corrected Strain Gauge Readings 
A total of five experiments were carried out including control tests and tests involving pile foundations. Results of four tests were successful and are reported in this section.

\subsubsection{Control test}

Figure 5.6 presents the results obtained for the control test (i.e. no piles). In this case, the crown readings ranged between 57 and 181 microstrains for an average value of 109 microstrains. On the other hand, the springline readings ranged between -87 and -171 microstrains for an average value of -133 microstrains.

\subsubsection{Piles located at 3D away from the tunnel centerline}

Figure 5.7 presents the next case where piles exist in the close vicinity of the tunnel. A pile group ( 2 by 3 ) pre-installed on each side of the tunnel at a distance of approximately 3 tunnel diameters away from the tunnel centerline (actual distance $=3.16 \mathrm{D})$. Recorded crown readings ranged between 37 and 76 microstrains for an average value of 52 microstrains. Strain values at the springline ranged between -124 and -247 microstrains with an average of -171 microstrains.

In this case, strains at the crown decreased considerably (by about $50 \%$ as compared to the control test) while strains at the springlines attained a higher value than the control test. This is thought to be attributed to the fact that, during testing, uneven lateral movement of soil occurred, which led to higher strain gauge readings on one side compared to the other. 


\subsubsection{Piles located at 2.5D away from the tunnel centerline}

Figure 5.8 presents the case where the pile groups ( 3 by 3 ) were located at a distance of 2.5D away from the tunnel centerline on both sides of the lining. Crown readings fell between 18 and 38 microstrains for an average of 29 microstrains and springline values between -22 and -52 microstrains for an average of -33 microstrains. In this case, strains at the crown essentially decreased (by about $50 \%$ as well) as compared to the previous case. Strains at the springline were significantly lower than both the previous case and the control test (by about $75 \%$ as compared to the control test).

\subsubsection{Piles located at $1 D$ away from the tunnel centerline}

Finally, Figure 5.9 presents the case where the piles are installed the closest to the tunnel: A larger pile group ( 5 by 3 ) was located at a distance of approximately $1 \mathrm{D}$ away from the tunnel centerline (actual distance $=1.16 \mathrm{D}$ ) on both sides of the lining. No significant strain values were recorded for this case as minimum soil movements around the lining were observed during the test.

In summary, experimental results indicated a decreasing trend in circumferential strains/stresses around the lining. This trend is clearly visible for crown readings where values of strains decreased by $50 \%$ from the control test to the case involving piles at $3 \mathrm{D}$ separation distance (3D Case) and by a further $50 \%$ from the $3 \mathrm{D}$ case to the $2.5 \mathrm{D}$ case. No significant strain results were measured for the $1 \mathrm{D}$ case which confirms the decreasing trend. 
Springline readings also confirm this trend in spite of values collected for the 3D case.

When comparing the $2.5 \mathrm{D}$ case with the control test, we notice a decrease of $75 \%$ which is consistent with the trend observed at the crown. Similarly, no significant results were measured for the 1D case and also agree with the decreasing strain trend. 


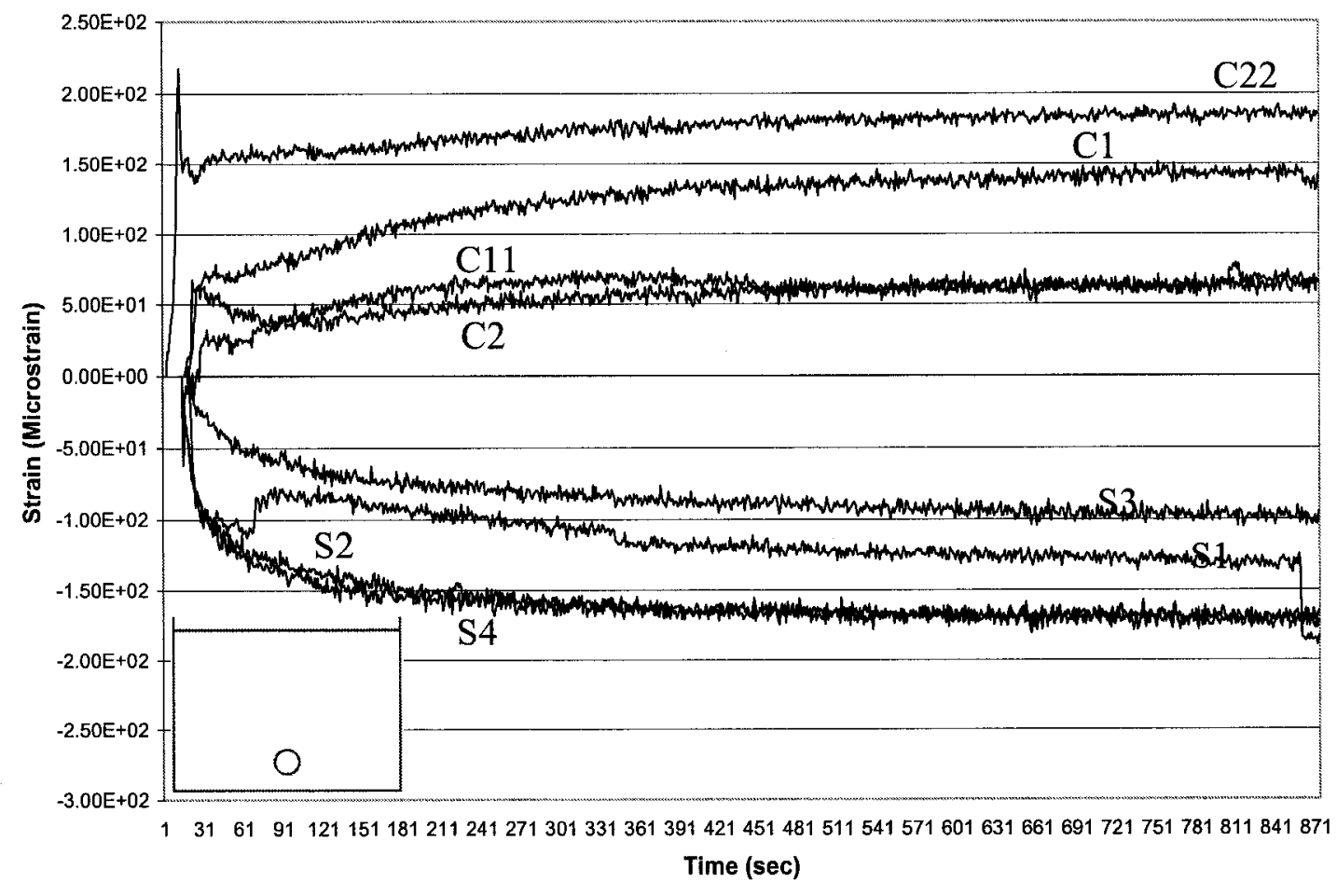

Figure 5.6 - Strain Gauge Readings for the Control Test

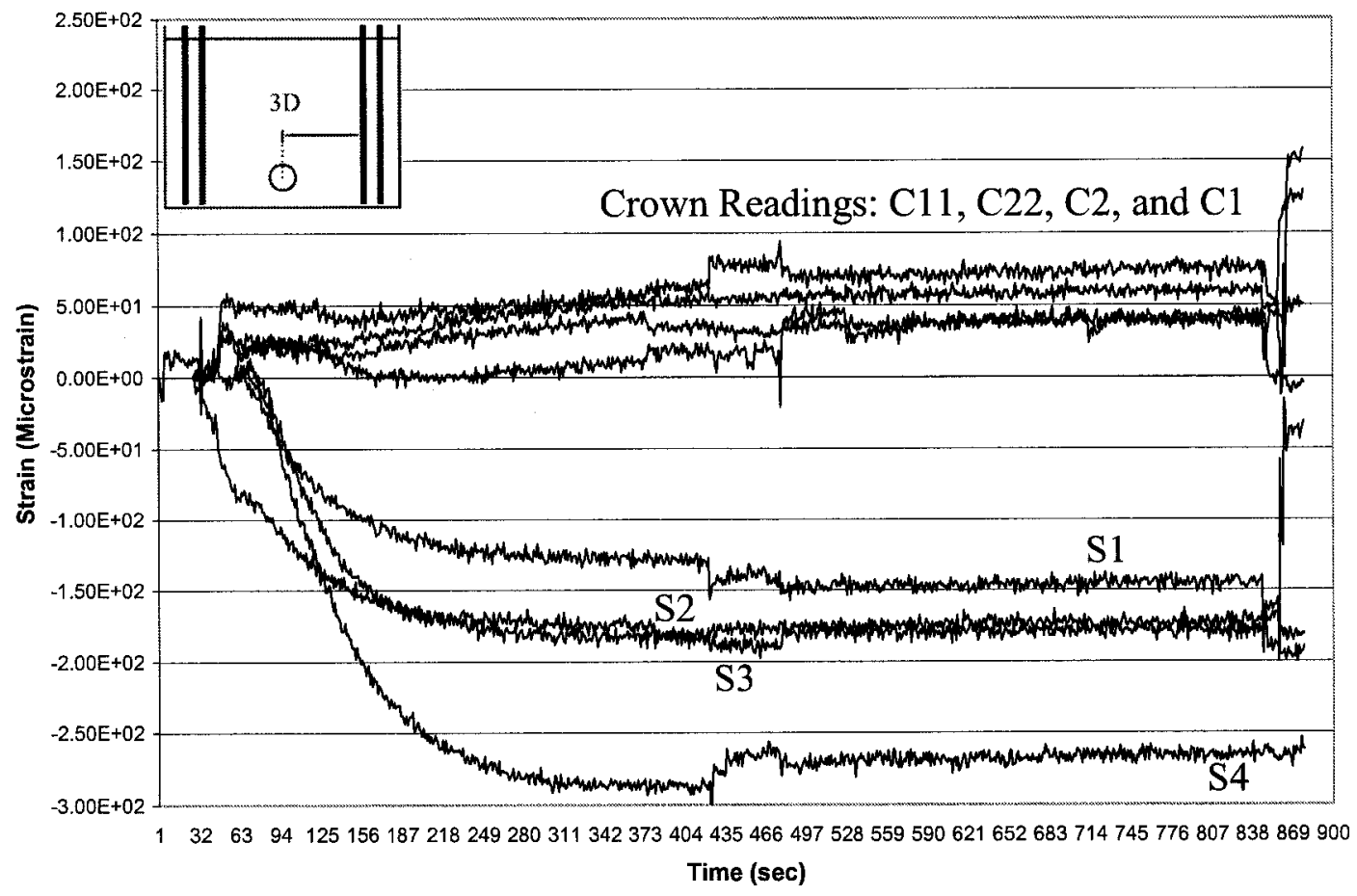

Figure 5.7 - Strain Gauge Readings for the 3D Case 


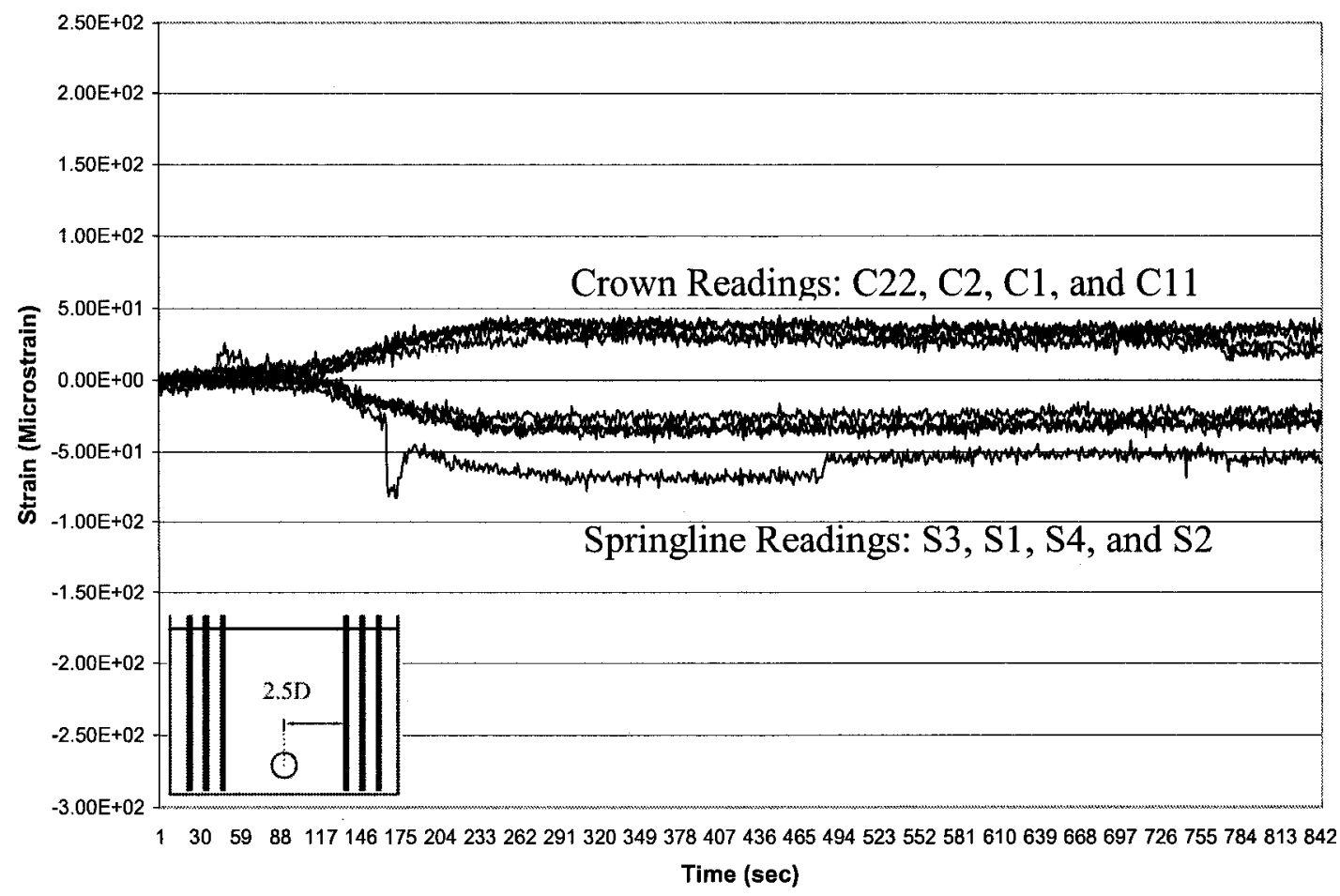

Figure 5.8 - Strain Gauge Readings for the 2.5D Case

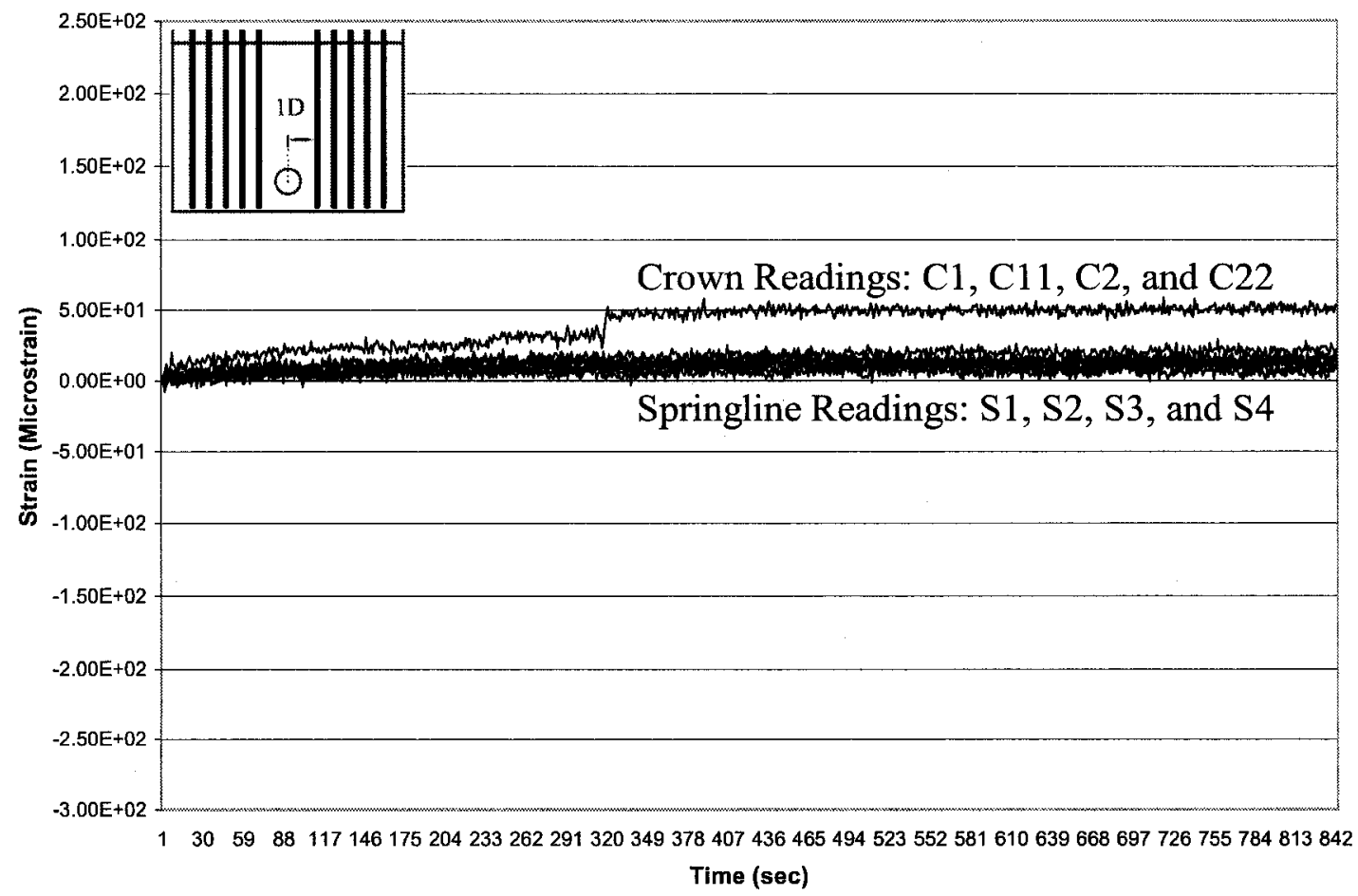

Figure 5.9 - Strain Gauge Readings for the 1D Case 


\subsection{Numerical results}

2D Finite Element analysis was conducted using Plaxis software package (Plaxis B.V., 2004) to calculate the lining deformation and circumferential stresses resulting from the tunnel excavation. Plaxis is a Finite Element program used mostly for geotechnical applications.

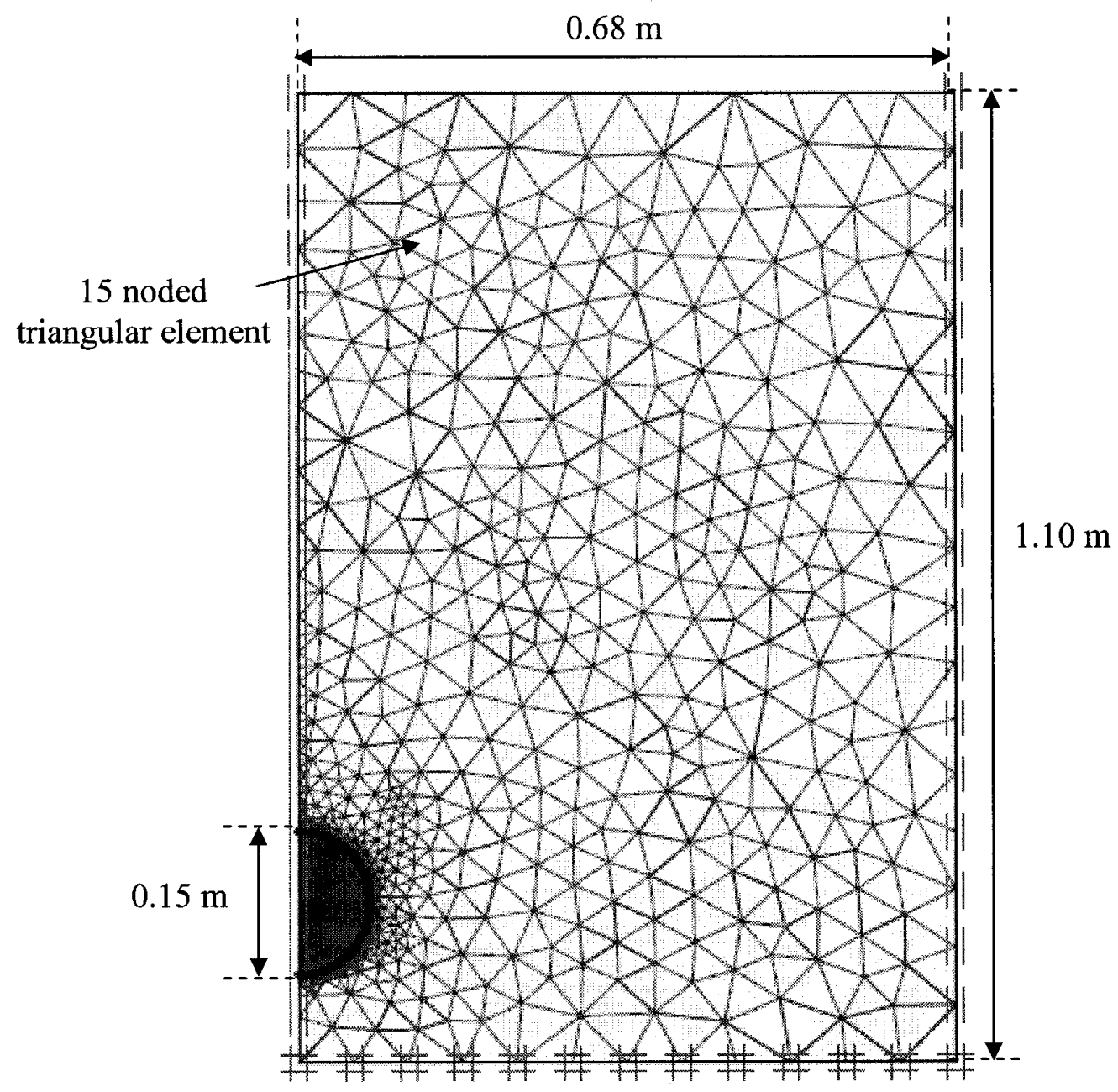

Figure 5.10 - Finite Element Mesh: Control Test

Three cases were considered in the numerical analyses. The first case was the Greenfield condition named Control Test. The others are two cases with pre-installed piles located at 
different distances from the tunnel centerline. A problem geometry and soil conditions identical to the actual experiment was used for all cases.

\subsubsection{Numerical details}

A plain strain finite element model was used to represent the soil and the tunnel lining. The lining was modeled using beam elements, whereas the soil was modeled using 15 noded triangular elements with a total of 2956 elements. A typical finite element mesh is shown in Figure 5.10. The model was restrained in the horizontal direction at the symmetry axis (smooth rigid) and was restrained in both the vertical and horizontal directions at the lower boundary (rough rigid). Fully drained condition was assumed in order to replicate the condition of the experiment where a geotextile grid was used under the soil to allow drainage through pre-drilled holes. The interaction between the lining and the soil was modeled using 5-noded interface elements. A strength factor $R_{\text {int }}$ is used by Plaxis to define the strength parameters of the interface relative to those of the original material. Throughout this investigation, a standard value for interaction with clay of 0.67 was assigned to the strength factor $R_{\text {int }}$.

\subsubsection{Constitutive model}

For the saturated clay material, the Hardening-Soil model (Schanz, 1998, Schanz et al., 1999) as implemented in the Finite-Element code Plaxis (Brinkgreve and Vermeer, 1998) iss used. A detailed description of this model is given in the program manual. Emphasis will be placed here on the meaning of the input parameters rather than describing the mathematical formulation of the model. 
Figure 5.11 shows a typical curve of a drained triaxial test with constant lateral pressure, $\sigma^{\prime}{ }_{3}$. Under primary loading the behaviour is distinctly nonlinear and is assumed to be hyperbolic up to a failure stress. Here compressive stresses and strains are considered positive. While the maximum stress is determined by the Mohr-Coulomb failure criterion, the hyperbolic part of the curve is defined by using a single secant modulus as additional input parameter, $\mathrm{E}_{50}$, as shown in Figure 5.11. It determines the magnitude of both the elastic and the plastic strains.

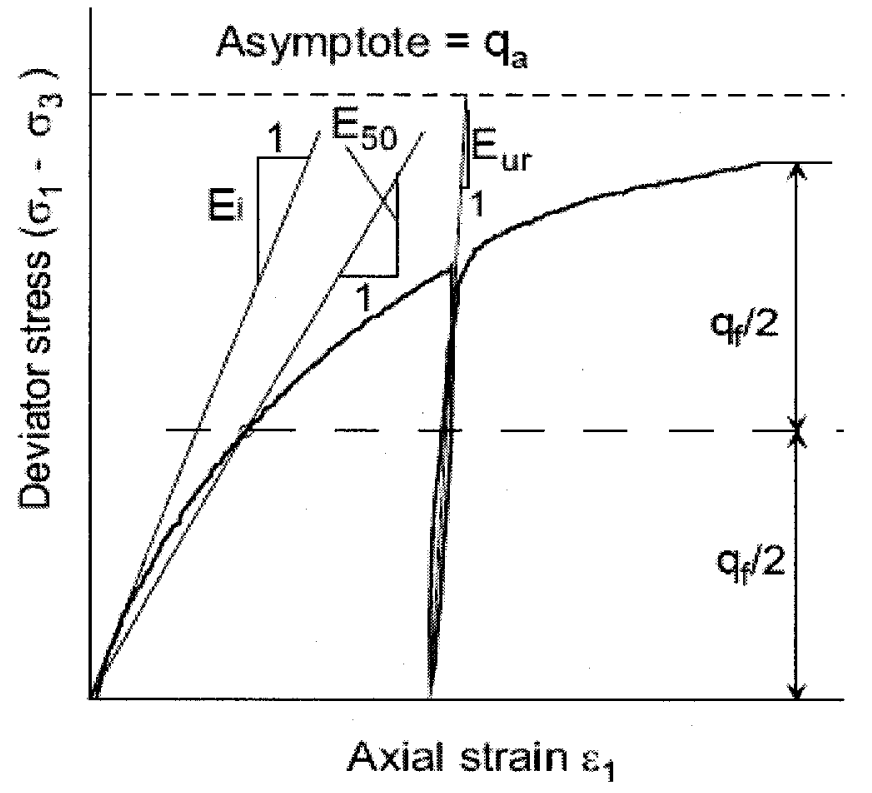

\section{Figure 5.11 - Hyperbolic Stress-Strain Relationship in Primary Loading for a Standard Drained Triaxial Test (Adapted from Plaxis User Manual, 2004)}

In contrast, $\mathrm{E}_{\mathrm{ur}}$ is an elasticity modulus. In conjunction with a Poisson's ratio $\mathrm{v}_{\mathrm{ur}}$, the elasticity modulus $\mathrm{E}_{\mathrm{ur}}$ determines the soil behaviour under unloading and reloading; the indice "ur" stands for "unloading/reloading". Both the secant virgin loading modulus $\mathrm{E}_{50}$ and the unloading modulus $\mathrm{E}_{\mathrm{ur}}$ are stress-level dependent defined by: 
$E_{50}=E_{50}^{r e f}\left(\frac{c \cot \varphi-\sigma_{3}^{\prime}}{c \cot \varphi+p^{r e f}}\right)^{m}$

$E_{u r}=E_{u r}^{r e f}\left(\frac{c \cot \varphi-\sigma_{3}^{\prime}}{c \cot \varphi+p^{r e f}}\right)^{m}$

$\mathrm{E}_{50}{ }^{\text {ref }}$ and $\mathrm{E}_{\mathrm{ur}}{ }^{\text {ref }}$ are input parameters for a particular reference pressure $\mathrm{p}^{\text {ref }}$. The exponent $\mathrm{m}$ can be measured both in oedometer tests and in triaxial tests and ranges between 0.4 and 1.0. A value of 0.5 is typical for sands whereas clays tend to have an m value of 1.0.

The virgin oedometer stiffness, $\mathrm{E}_{\mathrm{oed}}$, for one-dimensional compression obeys a stress dependency according to Equation 5.3 where $\mathrm{E}_{\text {oed }}{ }^{\text {ref }}$ is a tangent stiffness at a vertical stress of $-\sigma^{\prime}{ }_{1}=\mathrm{p}^{\text {ref }}$.

$$
E_{o e d}=E_{o e d}^{r e f}\left(\frac{c \cot \varphi-\sigma_{1}^{\prime}}{c \cot \varphi+p^{r e f}}\right)^{m}
$$

In the special case of $\mathrm{m}=1.0$ one obtains a linear stress dependency as usual for a clay. In addition to $\mathrm{E}_{50}{ }^{\text {ref }}$ and $\mathrm{E}_{\mathrm{ur}}$ ref , the oedometer modulus $\mathrm{E}_{\mathrm{oed}}{ }^{\text {ref }}$ is also an input parameter. Together with the parameters $\mathrm{m}, v_{\mathrm{ur}}, \mathrm{c}^{\prime}, \varphi^{\prime}$ and the dilatancy angle, $\psi$, there is a total of eight material parameters. Often, no triaxial test results are available for determining $v_{\mathrm{ur}}$, $\mathrm{E}_{50}{ }^{\text {ref }}$ and $\mathrm{E}_{\mathrm{ur}}^{\text {ref }}$, in which case one has to rely on oedometer results and general empirical data, such as $v_{u r},=0.1$ to 0.2 . For sands and stiff clays, one can mostly use $E_{50}{ }^{\text {ref }}=E_{u r}{ }^{\text {ref }}$. The elasticity modulus $\mathrm{E}_{\mathrm{ur}}^{\mathrm{ref}}$ can be determined directly from a triaxial test or indirectly with the help of oedometer results. If the unloading modulus from the oedometer test is 
termed $E_{\text {oed }}{ }^{\text {ur }}$, according to isotropic linear elasticity the following relationship holds (Vermeer et al., 2002):

$E_{u r}=\left(1-2 v_{u r}\right) \frac{1+v_{u r}}{1-v_{u r}} E_{o e d}^{u r}$

Hence the proper estimates of $E_{u r}$ can be calculated from $\mathrm{E}_{\text {oed }}{ }^{\mathrm{ur}}$.

The stiffness properties of the saturated clay in this study are assumed based on the range of values proposed by Kempfert and Gebreselassie (2006) for $\sigma_{3}^{\prime} / \mathrm{p}^{\text {ref }}$ of about 0.10 as shown in Figure 5.12. This value simulates the low overburden pressure expected in the small scale tests conducted in this study. The assigned soil properties are listed in Table 5.1.

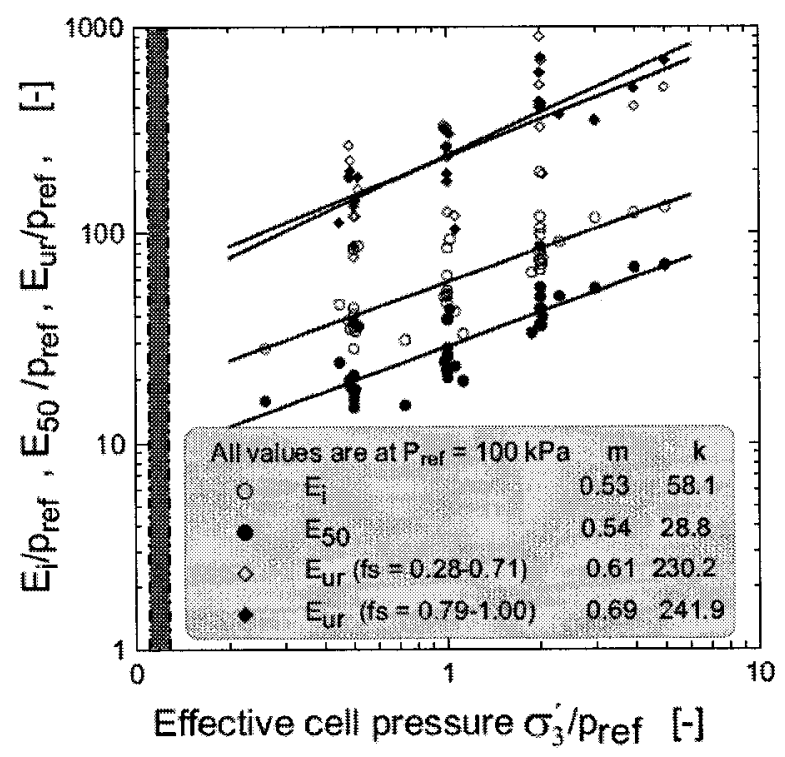

Figure 5.12 - The Variation of the Modulus of Elasticity with Confining Pressure under CID Test Condition (Kempfert and Gebreselassie, 2006) 
Table 5.1 - Soil Properties in the Numerical Model

\begin{tabular}{lc}
\hline SOIL PROPERTIES & \\
\hline $\mathrm{E}_{50}{ }^{\text {ref }}$ & $800 \mathrm{kN} / \mathrm{m}^{2}$ \\
$\mathrm{E}_{\text {oed }}{ }^{\text {ref }}$ & $800 \mathrm{kN} / \mathrm{m}^{2}$ \\
$\mathrm{E}_{\mathrm{ur}}{ }^{\text {ref }}$ & $2400 \mathrm{kN} / \mathrm{m}^{2}$ \\
$v_{\mathrm{ur}}$ & 0.20 \\
$\mathrm{p}^{\text {ref }}$ & $100 \mathrm{kN} / \mathrm{m}^{2}$ \\
$\varphi$ & $20^{\circ}$ \\
$\mathrm{m}$ & 1.0 \\
$\gamma_{\mathrm{d}}$ & $16 \mathrm{kN} / \mathrm{m}^{3}$ \\
$\gamma_{\mathrm{sat}}$ & $18 \mathrm{kN} / \mathrm{m}^{3}$ \\
$K_{o}$ & 0.658 \\
$\mathrm{c}^{\text {ref }}$ & $0.05 \mathrm{kN} / \mathrm{m}^{2}$ \\
\hline
\end{tabular}

The lining was modeled using beam elements with section properties (EA, EI) comparable to the actual lining. The lining properties are listed in Table 5.2.

Table 5.2 - Tunnel/Lining Properties

\begin{tabular}{lc}
\hline TUNNEL AND LINING PROPERTIES & \\
\hline $\mathrm{H}$ (Depth of Cover) & $0.89 \mathrm{~m}$ \\
$\mathrm{R}_{\mathrm{o}}$ (Radius of Lining) & $0.064 \mathrm{~m}$ \\
$\mathrm{E}_{\mathrm{s}}$ (Young's Modulus of Lining) & $65 \mathrm{GPa}$ \\
$\mathrm{v}_{\mathrm{s}}$ (Poisson's Ratio of Lining) & 0.3 \\
$\mathrm{t}$ (Thickness of Lining) & $2.5 \mathrm{E}-04 \mathrm{~m}$ \\
$\mathrm{~A}_{\mathrm{s}}$ (Cross Sectional Area of Lining) & $2.5 \mathrm{E}-04 \mathrm{~m}^{2}$ \\
$\mathrm{I}_{\mathrm{s}}$ (Second Moment of Area) & $1.3 \mathrm{E}-12 \mathrm{~m}^{4} / \mathrm{m}$ \\
$\mathrm{E}_{\mathrm{s}} \mathrm{A}_{\mathrm{s}}$ & $1.63 \mathrm{E}+04 \mathrm{kN}$ \\
$\mathrm{E}_{\mathrm{s}} \mathrm{I}_{\mathrm{s}}$ & $8.45 \mathrm{E}-05 \mathrm{kN} \cdot \mathrm{m}^{2} / \mathrm{m}$ \\
\hline
\end{tabular}




\subsubsection{Two-dimensional approximation of the pile group}

Soil-pile interaction is a truly three-dimensional problem. However a simplified twodimensional approach was used in this study, it assumes full bonding between soil and piles. Each 3 piles were replaced by an equivalent pile-soil section of similar stiffness (see Figure 5.13). The properties of the section were obtained by adding the stiffness value of the soil (EI) to the stiffness value of the piles $\left(\mathrm{E}_{\mathrm{p}} \mathrm{I}_{\mathrm{p}}\right)$ (See Equation 5.5). Therefore, an equivalent value of Young's Modulus $\left(\mathrm{E}_{\mathrm{eq}}\right)$ and Second Moment of Area $\left(\mathrm{I}_{\mathrm{eq}}\right)$ are obtained and incorporated in the numerical model definition.

$E_{e q} I_{e q}=3 E_{p} I_{p}+E I$

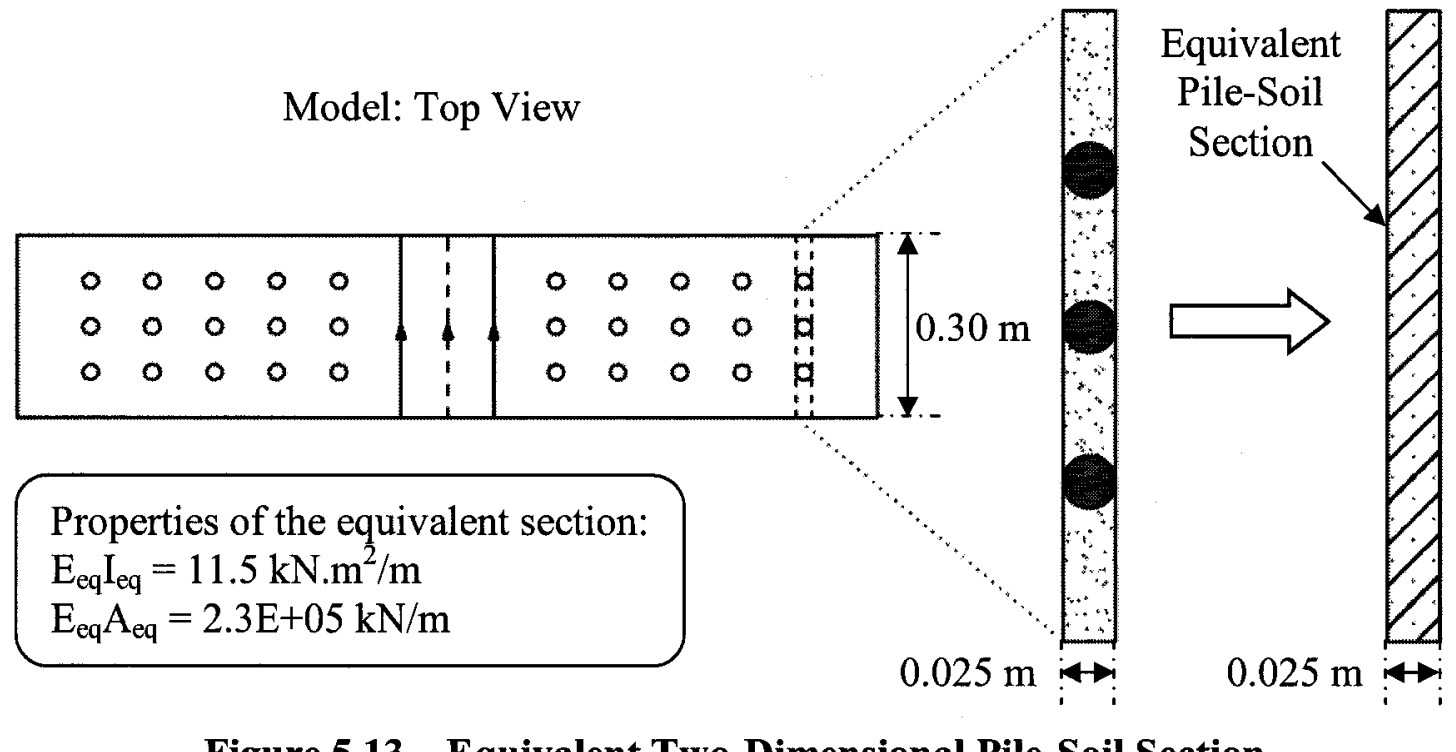

Figure 5.13 - Equivalent Two-Dimensional Pile-Soil Section

The pile and pile-soil section properties are listed in Tables 5.3: 
Table 5.3 - Pile Properties

\begin{tabular}{lc}
\hline PILE PROPERTIES & \\
\hline $\mathrm{L}_{\mathrm{p}}$ (Length of Pile) & $1 \mathrm{~m}$ \\
$\mathrm{D}_{\mathrm{p}}$ (Diameter of Pile) & $0.025 \mathrm{~m}$ \\
$\mathrm{E}_{\mathrm{p}}$ (Young's Modulus of Pile) & $200 \mathrm{GPa}$ \\
$\mathrm{A}_{\mathrm{p}}$ (Cross Sectional Area of Pile) & $5.3 \mathrm{E}-04 \mathrm{~m}^{2}$ \\
$\mathrm{I}_{\mathrm{p}}$ (Second Moment of Area) & $1.92 \mathrm{E}-08 \mathrm{~m}^{4}$ \\
$\mathrm{E}_{\mathrm{p}} \mathrm{A}_{\mathrm{p}}$ & $10.6 \mathrm{E}+04 \mathrm{kN}$ \\
$\mathrm{E}_{\mathrm{p}} \mathrm{I}_{\mathrm{p}}$ & $3.84 \mathrm{kN} \cdot \mathrm{m}^{2} / \mathrm{m}$ \\
$\mathrm{W}_{\mathrm{eq}}$ (Width of Pile-Soil Section) & $0.30 \mathrm{~m}$ \\
$\mathrm{~T}_{\mathrm{eq}}$ (Thickness of Pile-Soil Section) & $0.025 \mathrm{~m}$ \\
\hline
\end{tabular}

\subsubsection{Numerical analyses}

The numerical simulation was initiated by subjecting the soil to initial stresses using the $\mathrm{K}_{0}$-procedure which involves the specification of the at rest earth pressure coefficient $\mathrm{K}_{0}$ (equal to $1-\sin \varphi$ ). Figure 5.14 shows the finite element mesh used in the case where piles were located at $2.5 \mathrm{D}$ from the tunnel centerline. It is worth mentioning that no significant strains were measured in the case where the piles are located 1D away from the tunnel centerline and therefore was excluded from the numerical analysis.

This was followed by the tunnel excavation and lining installation which are simulated using the staged construction procedure. This involves the activation of the lining elements and deactivating the soil cluster inside the tunnel as well as setting it to dry condition to remove water pressures. 
Finally, a contraction is applied to the lining to complete the process. A contraction corresponding to a volume loss of about $27 \%$ was specified to simulate the actual gap induced between the shield and the lining.

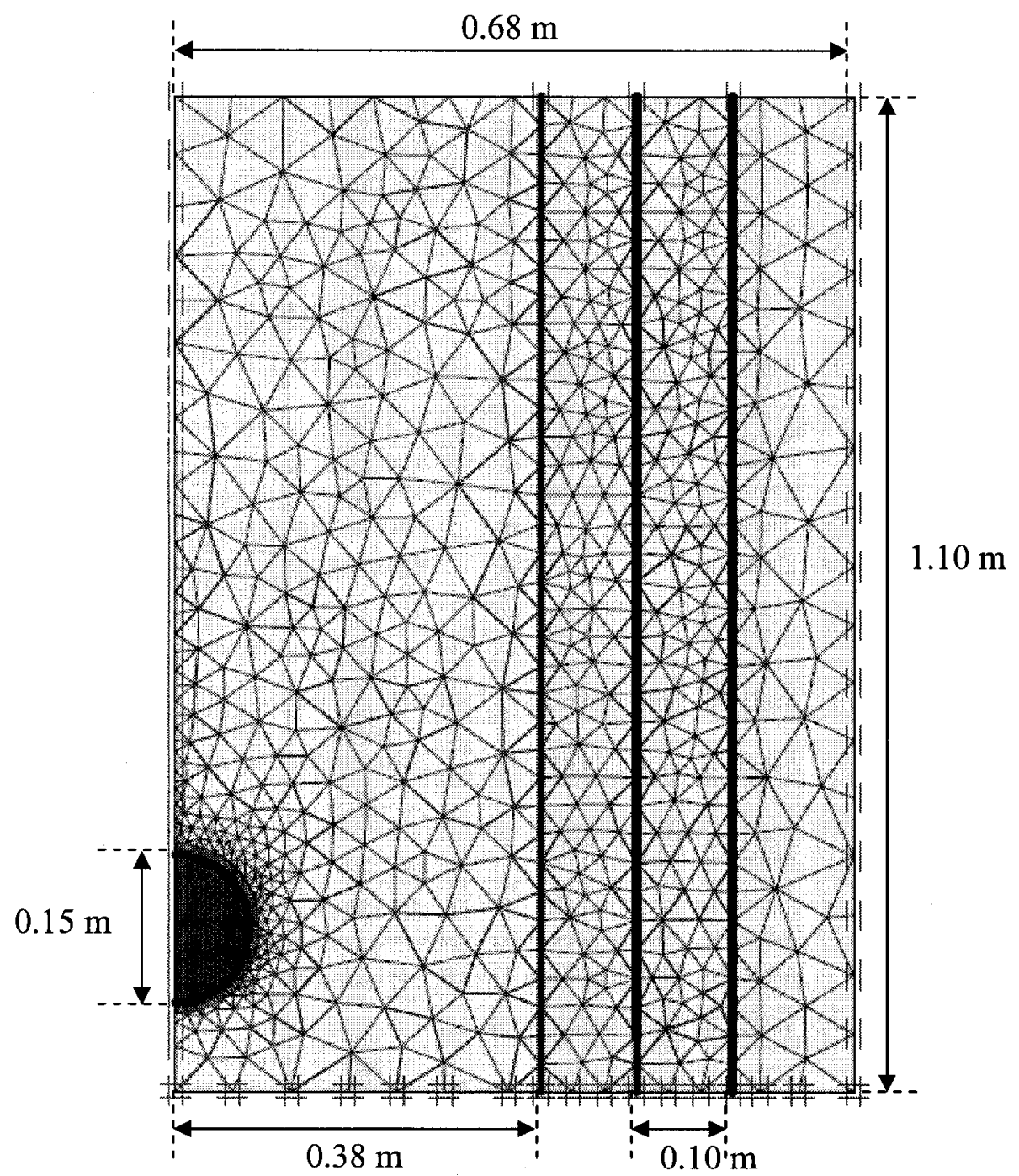

Figure 5.14 - Finite Element Mesh: Piles Located 2.5D Away from Tunnel Centerline

. The deformed shape of the lining for the control test, calculated using the finite element analysis, is shown in Figure 5.15. The maximum realized displacement at the crown was found to be $0.018 \mathrm{~m}$. 


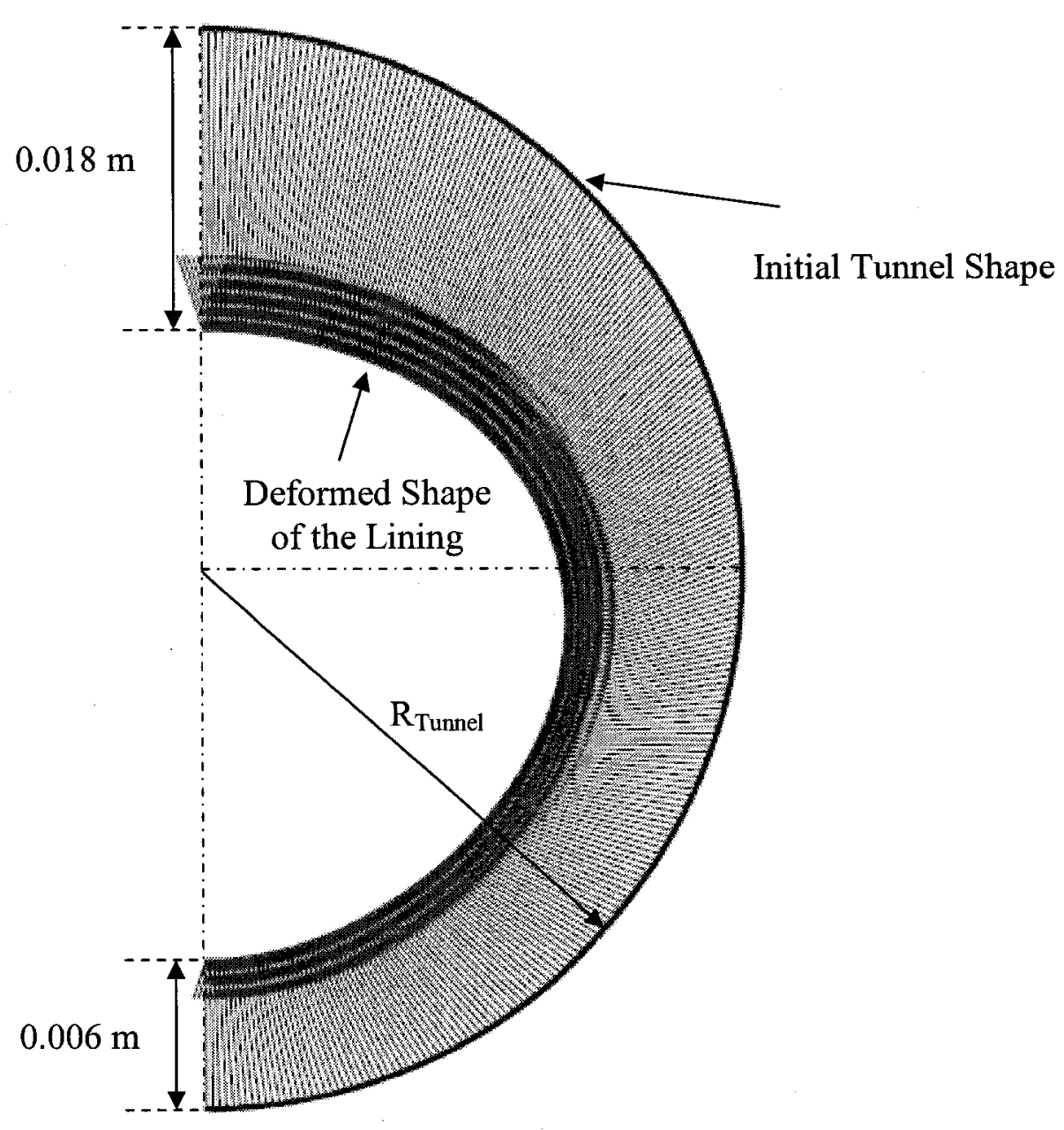

Figure 5.15 - Deformed Shape of the Lining: Control Test

Figure 5.16 shows the distribution of bending moment ratio $\left(\mathrm{M} / \gamma_{\mathrm{sat}} \mathrm{HR}_{\mathrm{o}}{ }^{2}\right)$ in the lining for the control test as well. The calculated moment is normalized with respect to the soil unit weight $\gamma_{\mathrm{sat}}$ (in $\mathrm{kN} / \mathrm{m}^{3}$ ), the depth of cover to the centerline of the tunnel $\mathrm{H}(\mathrm{m})$, and the squared radius of lining $\mathrm{R}_{\mathrm{o}}{ }^{2}\left(\mathrm{~m}^{2}\right)$.

The maximum bending moment ratio (-17.4E-04) was found to occur at an angle of about $20^{\circ}$ from the springline. 


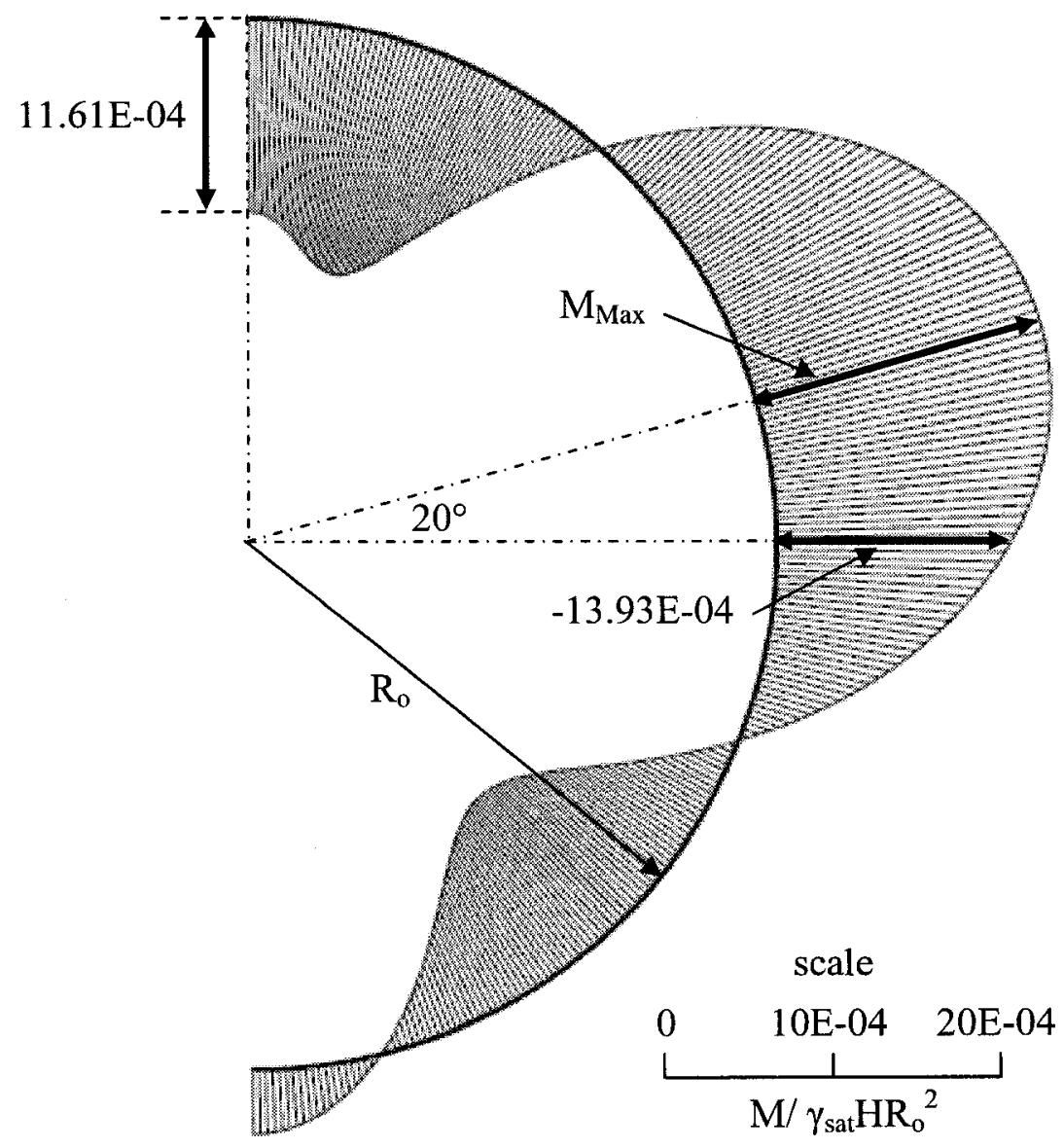

Figure 5.16 - Normalized Bending Moments Distribution: Control Test

The distribution of axial force ratio $\left(\mathrm{N} / \gamma_{\mathrm{sat}} \mathrm{HR}_{\mathrm{o}}\right)$ in the lining for the control test is presented in Figure 5.17 normalized with respect to the unit weight of soil $\left(\mathrm{kN} / \mathrm{m}^{3}\right)$, the depth of cover to the centerline of the tunnel (m), and the radius of the lining (m). The maximum axial force was calculated at the invert with a relatively uniform distribution along the lining and ranges between 0.786 and 0.930 . 


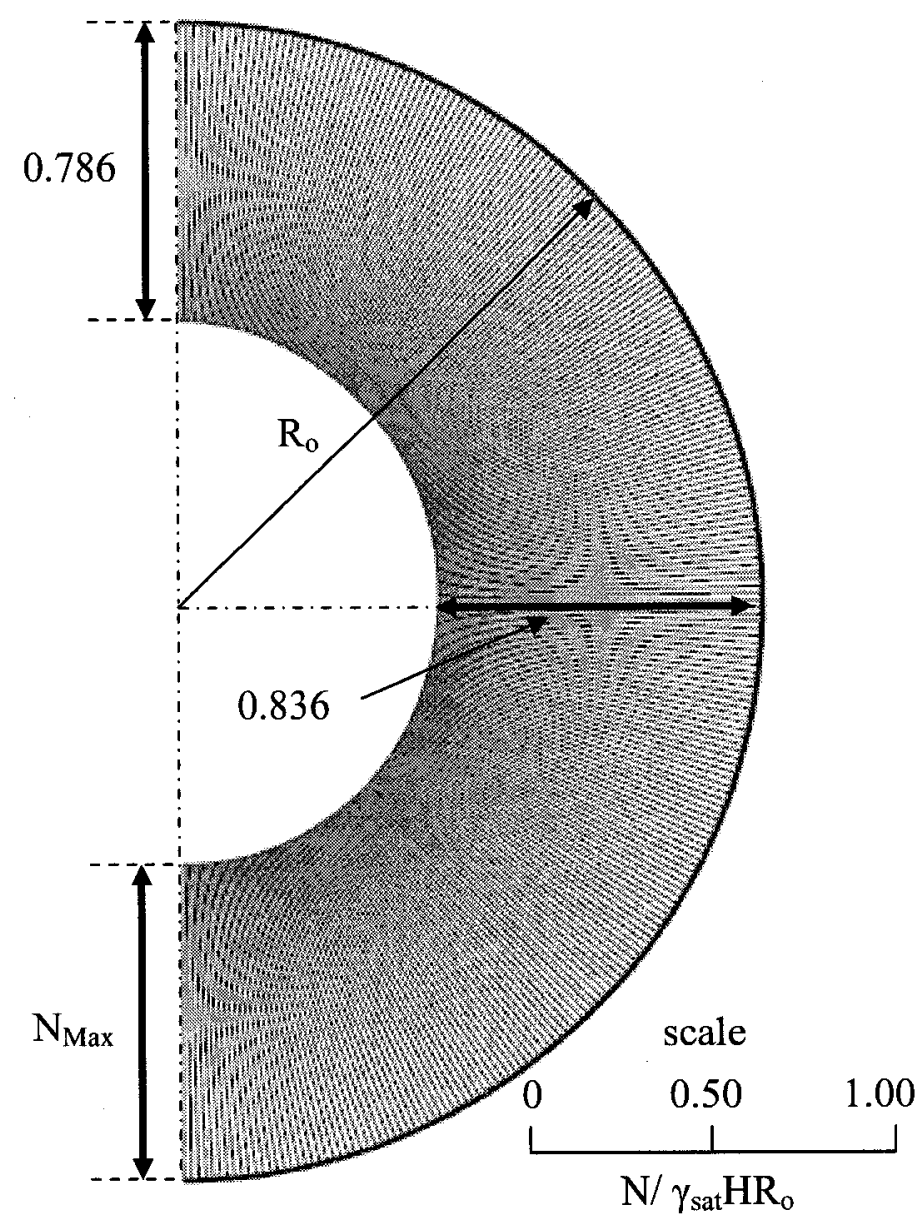

Figure 5.17 - Normalized Axial Force Distribution: Control Test

For the case where the pile-soil section was 3D ( 3 tunnel diameters) away from the tunnel centerline, bending moment values dropped for both the crown $(9,29 \mathrm{E}-04)$ and the springline $(-12.07 \mathrm{E}-04)$. For the case where the section was $2.5 \mathrm{D}$ away from the tunnel centerline, bending moment values dropped further at both the crown (7.74E-04) and the springline (-10.84E-04). The decrease in bending moments was found to be about $17 \%$ from the control test to the $3 \mathrm{D}$ case and an additional $15 \%$ from the $3 \mathrm{D}$ case to the $2.5 \mathrm{D}$ case. Axial forces followed a decreasing trend as well when comparing the cases with pre-installed piles to the control test. 


\section{DATA ANALYSIS AND DISCUSSION}

The measured strains were used to calculate the maximum stress values at the same locations along the lining. This was achieved by assuming an elastic response for the lining $(\sigma=$ E.ع). The stresses were simply calculated by multiplying the measured maximum strains by the elastic modulus of the lining ( $65 \mathrm{GPa})$. The results as well as the average and standard deviation values for both strains and stresses are presented in Table 6.1.

Table 6.1 - Experimental Strain and Stress Values at Crown and Springline

\begin{tabular}{cccccc}
\hline $\begin{array}{c}\text { Distance From } \\
\text { Tunnel Centerline } \\
\text { (meters) }\end{array}$ & \multicolumn{3}{c}{$\begin{array}{c}\text { Measured Strains } \\
\text { Average }\end{array}$} & $\begin{array}{c}\text { S Calculated Stresses } \\
\text { (microstrain) } \\
\text { Crown }\end{array}$ & $\begin{array}{c}\text { Maximum } \\
\text { (kPa per metre lining) }\end{array}$ \\
\hline Control Test & 181 & 109 & \pm 58 & 11733 & 7101 \\
3D & 76 & 52 & \pm 18 & 4940 & 3396 \\
2.5D & 38 & 29 & \pm 8 & 2470 & 1853 \\
1D & 0 & 0 & 0 & 0 & 0 \\
& \multicolumn{7}{c}{ Springline } & & \\
\hline Control Test & -171 & -133 & \pm 38 & -11115 & -8645 \\
3D & -247 & -171 & \pm 53 & -16055 & -11115 \\
2.5D & -52 & -33 & \pm 13 & -3396 & -2161 \\
1D & 0 & 0 & 0 & 0 & 0 \\
\hline
\end{tabular}

Bending moment values can be calculated from the obtained stress values using Equation 6.1 below. These values are in turn normalized using $M / \gamma_{\mathrm{sat}} \mathrm{HR}_{\mathrm{o}}{ }^{2}$.

$$
M=\frac{\sigma . I}{0.5 \cdot t}
$$


Where $\mathrm{M}=$ moment in $\mathrm{kN} \cdot \mathrm{m}$

$\sigma=$ stress in $\mathrm{kN} / \mathrm{m}^{2}$

$\mathrm{I}=$ second moment of area of lining in $\mathrm{m}^{4}$

$\mathrm{t}=$ lining thickness in $\mathrm{m}$

A comparison between the measured and calculated bending moment ratios for the control test is presented in Figure 6.1.

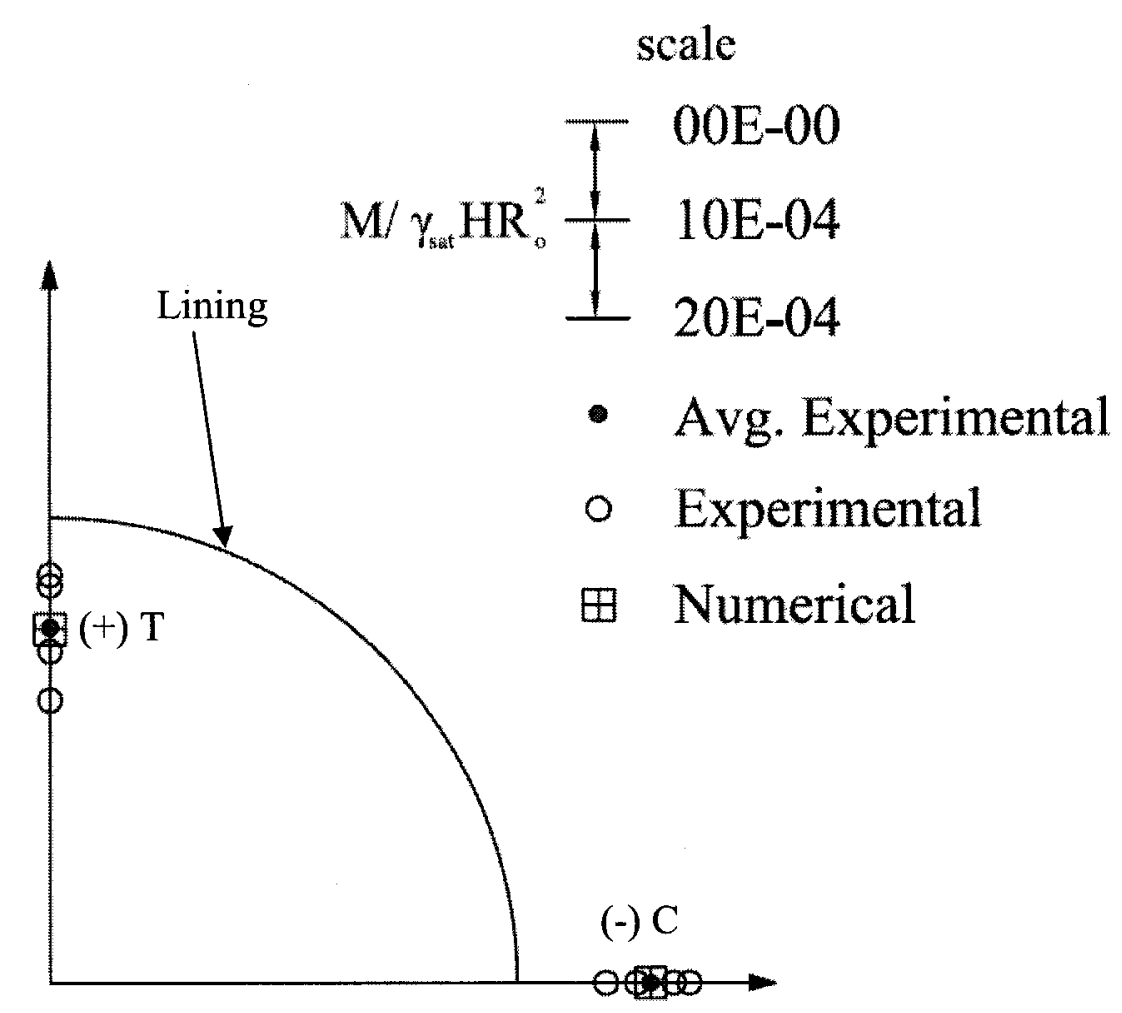

Figure 6.1 -Bending Moment Ratios at the Crown and the Springline (Control Test)

Reasonable agreement was found between the experimental and numerical results for the control test.

The complete normalized values of bending moments are summarized in Table 6.2. These include the maximum bending moments at the crown and springline as well as the 
average values for the four experiments. The third and fifth sets contain the calculated numerical bending moment and axial force values for the control test and the cases involving piles. The fourth set contains the calculated analytical bending moments values for the control test using Bobet (2001).

Table 6.2 - Experimental and Numerical Bending Moment Ratios at the Crown and Springline

\begin{tabular}{|c|c|c|c|c|c|}
\hline \multirow{4}{*}{$\begin{array}{c}\begin{array}{c}\text { Distance } \\
\text { from }\end{array} \\
\text { Tunnel Axis } \\
\text { (meters) }\end{array}$} & \multicolumn{4}{|c|}{$\begin{array}{c}\text { Bending Moment } \\
\text { Ratio }\end{array}$} & \multirow{4}{*}{$\begin{array}{c}\text { Axial Force } \\
\text { Ratio } \\
\text { Numerical }\end{array}$} \\
\hline & \multicolumn{2}{|c|}{ Experimental } & \multirow[t]{2}{*}{ Numerical } & \multirow{3}{*}{$\begin{array}{c}\text { Analytical } \\
\text { Bobet }(2001)\end{array}$} & \\
\hline & Maximum & Average & & & \\
\hline & \multicolumn{3}{|c|}{ Crown } & & \\
\hline Control Test & $18.84 \mathrm{E}-04$ & $11.43 \mathrm{E}-04$ & $11.61 \mathrm{E}-04$ & $1.70 \mathrm{E}-04$ & 0.786 \\
\hline $3 \mathrm{D}$ & $7.96 \mathrm{E}-04$ & $5.46 \mathrm{E}-04$ & $9.29 \mathrm{E}-04$ & - & 0.747 \\
\hline $2.5 \mathrm{D}$ & $3.97 \mathrm{E}-04$ & $2.98 \mathrm{E}-04$ & 7.74E-04 & - & 0.177 \\
\hline \multirow[t]{2}{*}{$1 \mathrm{D}$} & $0.00 \mathrm{E}+00$ & $0.00 \mathrm{E}+00$ & - & - & - \\
\hline & \multicolumn{4}{|c|}{ Springline } & \\
\hline Control Test & $-17.89 \mathrm{E}-04$ & $-13.92 \mathrm{E}-04$ & $-13.93 E-04$ & $-1.86 \mathrm{E}-04$ & 0.836 \\
\hline $3 \mathrm{D}$ & $-25.85 \mathrm{E}-04$ & $-17.90 \mathrm{E}-04$ & $-12.07 \mathrm{E}-04$ & - & 0.786 \\
\hline $2.5 \mathrm{D}$ & $-5.46 \mathrm{E}-04$ & $-3.48 \mathrm{E}-04$ & $-10.84 \mathrm{E}-04$ & - & 0.216 \\
\hline $1 \mathrm{D}$ & $0.00 \mathrm{E}+00$ & $0.00 \mathrm{E}+00$ & - & - & - \\
\hline
\end{tabular}

Similar results are presented in Figure 6.2 for the different cases. The measured bending moment diagrams at the crown and the springline are plotted along with the predicted values using finite element analysis. The following observations can be made based on the above experimental and numerical results: Despite the relatively high measured strains at the springline for the case where the piles are located $3 \mathrm{D}$ away from the tunnel, the overall measured strains significantly dropped by about $50 \%$ as piles are introduced in the close vicinity of the tunnel (3D). As the separating distance gets smaller (2.5D), the strains further drop by an additional $50 \%$ ( $75 \%$ as compared to the control test). The 
experimental and numerical are also grouped in Figure 6.3 and Figure 6.4 for the crown and the springline respectively.
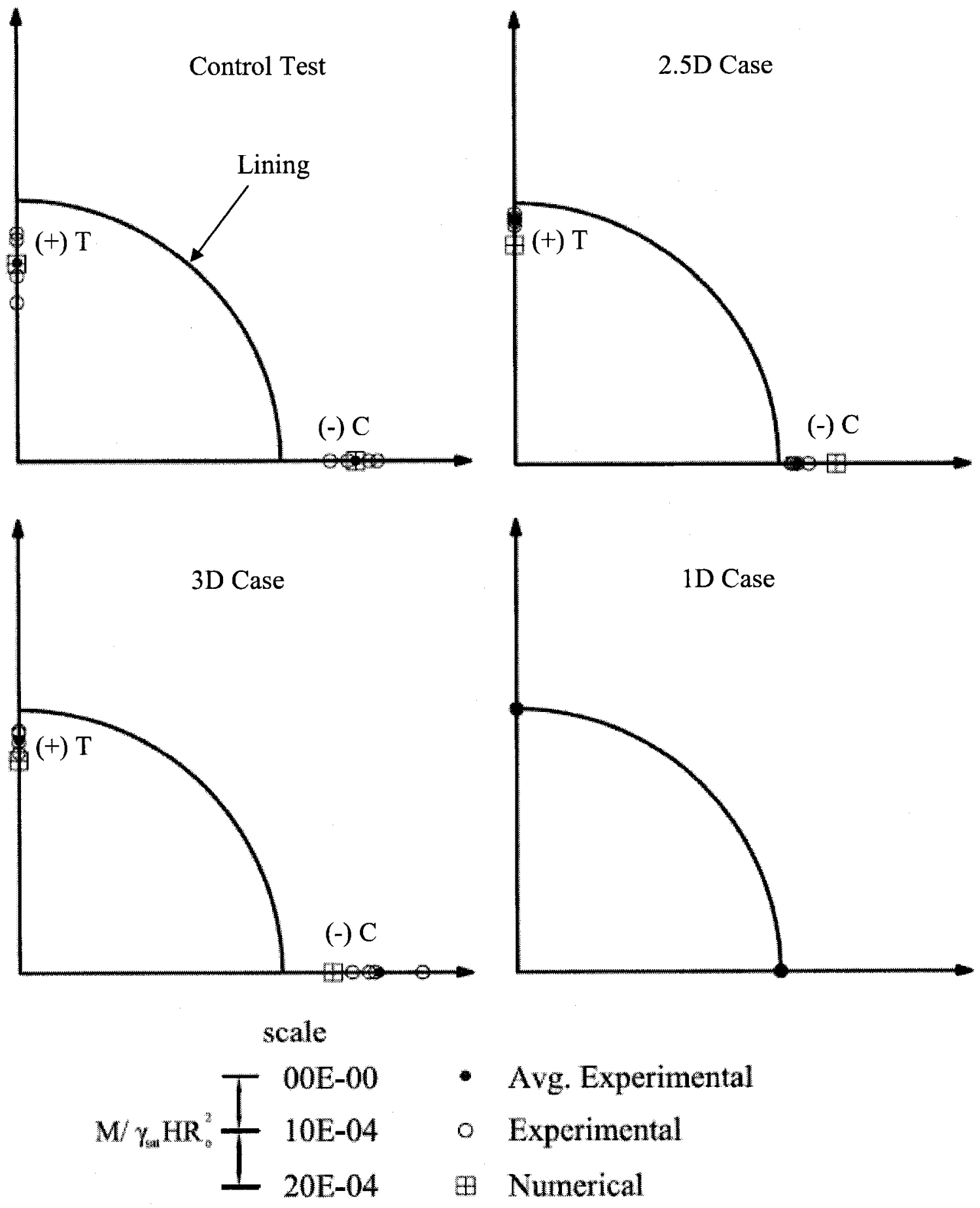

Figure 6.2 - Bending Moment Ratios at the Crown and the Springline 


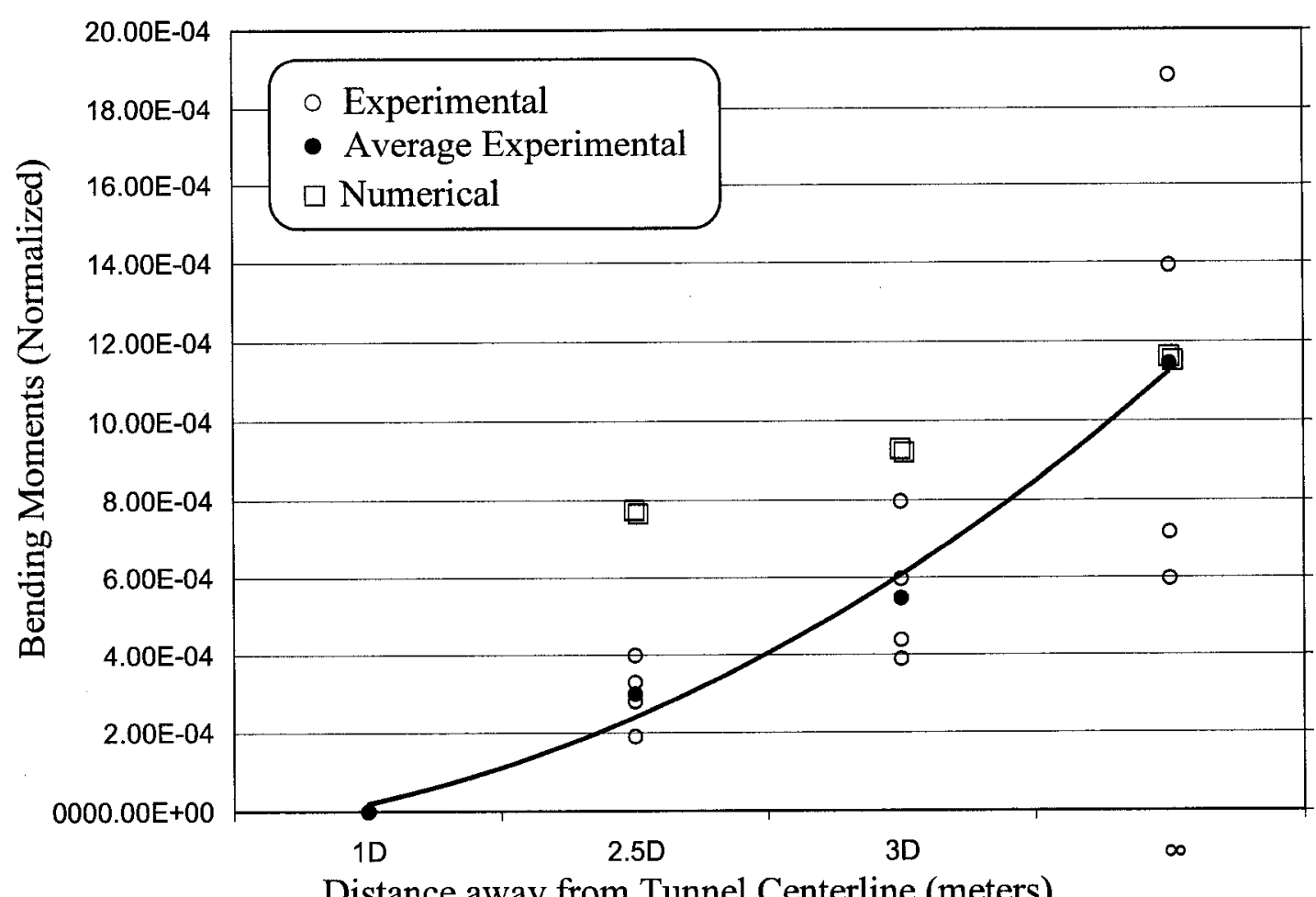

Figure 6.3 - Bending Moments Ratios and Trend at the Crown

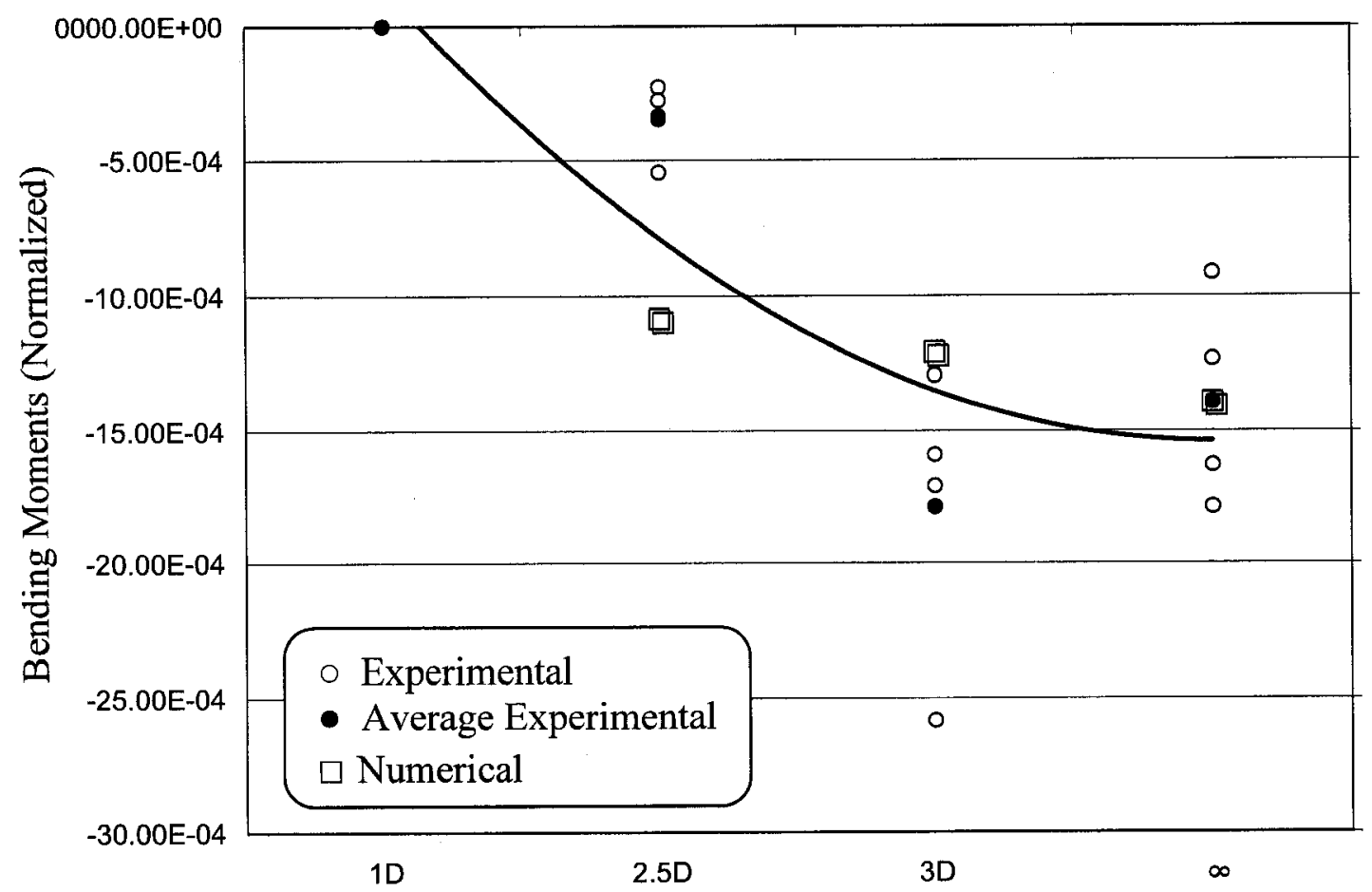

Distance away from Tunnel Centerline (meters)

Figure 6.4 - Bending Moments Ratios and Trend at the Springline 
Trendlines are added to demonstrate the decreasing levels of lining stresses as the piles are located closer to the tunnel centerline. The discrepancies between the measured and calculated strains for the cases where piles exist near the tunnel can be explained by the simplifications made to facilitate the 2-dimensional simulation of the piles. The decreasing trends could be explained by the restraining actions imposed by the piles on the soil movement during the gap closure process.

Another way of examining the interaction between the tunnel and the existing piles is by qualitatively comparing the change in bending moments ratios in the lining obtained in this study and the change in bending moments in piles located at different distance from the tunnel centerline which were observed in previous studies (Chen et al., 1999 and Kitiyodom et al., 2005). An increasing trend in bending moments in the piles was reported when they were located closer to the tunnel centerline (see Figure 6.5). It can be seen that decreasing moments in the lining is associated with an increase in moments in the surrounding piles. This is attributed to the redistribution of stresses/strains from the tunnel lining to the piles as the piles are located closer to the tunnel centerline. 

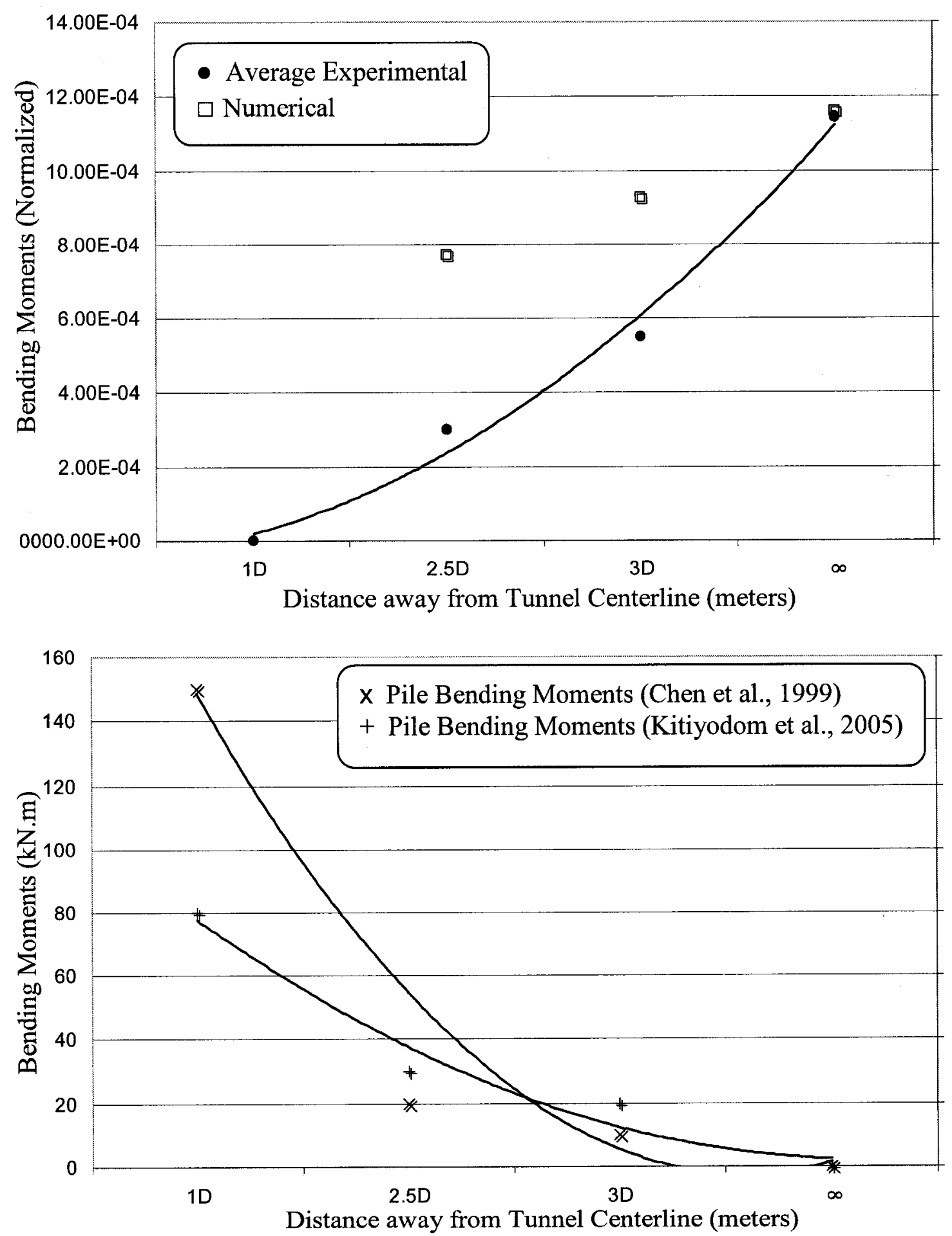

Figure 6.5 - Trend Comparison: Bending Moments in Lining (Top Chart) vs. Piles (Bottom Chart) 


\section{SUMMARY AND CONCLUSIONS}

\subsection{Summary}

A testing facility has been designed and built to investigate the effect of existing pile foundation on the stresses developing in a flexible lining due to tunnel construction in soft cohesive soils. The soil consisted of a mix of Bentonite clay powder, cement, sand and water. Pile groups were symmetrically installed around the tunnel at separation distances of 3D, 2.5D and 1D (diameters away from tunnel centerline). A total number of four tests were conducted (including a control test without piles). Strains were measured at the crown and springlines of the lining and were found to decrease by $50 \%$ to $75 \%$ when piles were located at distances of 3 then 2.5 diameters as compared to the control test. A series of 2-dimensional finite element analyses were also conducted to confirm the experimental results. The experimental results obtained from the control test were used to validate the numerical mode and results are generally in good agreement. A decrease in lining strains was also observed in the numerical analyses when piles are introduced in the close vicinity of the tunnel ( $14 \%$ to $20 \%$ for the $3 \mathrm{D}$ case and $23 \%$ to $34 \%$ for the $2.5 \mathrm{D}$ case).

\subsection{Conclusions}

For the investigated range of separating distance between the model piles and tunnel centerline, interaction increased as the tunnel is excavated at a smaller distance from the existing piles. Although the lining response was the prime interest in this study, the piles 
in the close vicinity of the tunnel usually experience an increased stress level due to the stress redistribution around the excavated tunnel.

Despite the limitations associated with $1 \mathrm{~g}$ experimental models, they have been proven to be a useful tool in validating numerical models.

\subsection{Recommendations for future research}

Based on the experience developed throughout this investigation, the following recommendations should be considered for future research:

- To conduct centrifuge testing to allow larger tunnels to be investigated.

- To conduct experimental investigations to study the effect of existing pile foundation on the lining stresses in the longitudinal direction.

- To conduct a full three-dimensional finite element analyses to better simulate the 3D nature of the pile behaviour. 


\section{REFERENCES}

Adachi, T., Kimura, M., and Kishida, K. (2003). 'Experimental Study on the Distribution of Earth Pressure and Surface Settlement through Three-Dimensional Trapdoor Tests'". Tunnelling and Underground Space Technology, Vol.: 18, pp 171183.

Adachi, T., Kimura, M., Nishimura, T., Koya, N., and Kosaka, K. (1997). "Trap Door Experiment under Centrifugal Conditions". Deformation and Progressive Failure in Geomechanics. Pergamon, pp. 725-730.

Adachi, T., Tamura, T., Kimura, K., and Nishimura, T. (1995). "Axial Symmetric Trap Door Tests on Sand and Cohesion Soil" [in Japanese]. Proc. of the $30^{\text {th }}$ Japanese National Conference on Geotechnical Engineering, pp. 1973-1976.

Atkinson, J.H., and Potts, D.M. (1977). "Stability of a Shallow Circular Tunnel in Cohesionless Soil". Geotechnique, Vol.: 27, No.: 2, pp 203-215. Cambridge, England and Rijswijk, Netherlands.

Atkinson, J.H., Potts, D.M., and Schofield (1977). "Centrifugal Model Tests on Shallow Tunnels in Sand". Tunnels and Tunnelling. Cambridge, U.K.

Attewell, P.B., Yeates, J., and Selby, A.R. (1986). "Soil Movements Induced by Tunnelling and Their Effects on Pipelines and Structures". Blackie and Son, London.

Bobet, A. (2001). "Analytical Solutions for Shallow Tunnels in Saturated Ground." Journal of Engineering Mechanics, Vol: 127, No: 12, pp 1258-1266.

Boscardin, M.D., and Cording, E.J. (1989). "Building Response to Excavation Induced Settlement". Journal of Geotechnical Engineering, ASCE, Vol: 115, No:1, pp 1-21.

Breth, H., and Chambosse, G. (1974). "Settlement Behaviour of Buildings above Subway Tunnels in Frankfurt Clay". Settlement of Structures, BGS Conference, Cambridge, pp 329-336.

Burland, J.B. (1995). "Assessment of Risk of Damage to Buildings due to Tunnelling and Excavation". Proceedings of the $1^{\text {st }}$ International Conference of Earthquake Geotechnical Engineering, Tokyo.

Chambon, P., and Corte, J.F. (1994). "Shallow Tunnels in Cohesionless Soil: Stability of Tunnel Face". Journal of Geotechnical Engineering, Vol.: 120, No.: 7. Nantes, France.

Chen, L.T., Poulos, H.G., and Loganathan, N. (1999). "Pile Response Caused by Tunnelling”. Journal of Geotechnical and Geoenvironmental Engineering. Vol: 125, No:3, pp 207-215.

Cheng, C.Y., Dasari, G.R., Chow, Y.K., and Leung, C.F. (2006). "Finite Element Analysis of Tunnel-Soil-Pile Interaction Using Displacement Controlled Model.

Chou, W.I., and Bobet, A. (2002). "Predictions of Ground Deformations in Shallow Tunnels in Clay". Tunnelling and Underground Space Technology, Vol: 17, pp 3-19. 
Coutts, D.R., and Wang, J. (2000). "Monitoring of Reinforced Concrete Piles under Horizontal and Vertical Loads due to Tunnelling". Tunnels and Underground Structures, London.

Curtis, D.J., Mott, H., and Anderson, C. (1976). "Correspondance on Muir Wood, A.M.: The Circular Tunnel in Elastic Ground”. Geotechnique, Vol: 26.

Dykeman, P., and Valsangkar, A.J. (1996). "Model Studies of Socketed Caissons in Soft Rock”. Canadian Geotechnical Journal, Vol: 33, pp 747-759.

Fraser, R.A., and Wardle, L.J. (1976). "Numerical Analysis of Rectangular Rafts on Layered Foundations". Geotechnique, Vol: 26, No: 4, pp 613-630.

Kempfert, G., and Gebreselassie, B. (2006). "Excavations and Foundations in Soft Soils". Springer Berlin Heidelberg, New York, pp. 57-116.

Kitiyodom, P., Matsumoto, T., and Kawaguchi, K. (2005). “ A Simplified Analysis Method for Piled Raft Foundations Subjected to Ground Movements Induced by Tunnelling". International Journal for Numerical and Analytical Methods in Geomechanics, Vol: 29, pp 1485-1507.

Lee, G.T.K., and Ng, C.W.W. (2005). "Effects of Advancing Open Face Tunnelling on an Existing Loaded Pile". Journal of Geotechnical and Geoenvironmental Engineering, Vol: 131, No: 2, pp 193-201.

Lee, Y, and Yoo, C. (2006). "Behavior of a bored tunnel adjacent to a line of load piles". Tunnelling and Underground Space Technology, Vol: 21, No: 3.

Loganathan, N., and Poulos, H.G. (1998). “Analytical Prediction for Tunnelling-Induced Ground Movements in Clays". Journal of Geotechnical and Geoenvironmental Engineering, Vol: 124, No: 9, pp. 846-856.

Mair, R. J. (1982). "Ground Movement around Shallow Tunnels in Soft Clay". Tunnels and Tunnelling, Vol.: 14, No.: 5, pp 45-48. U.K.

Meguid, M.A., Saada, O., Nunes, M.A., and Mattar, J. (2007). "Physical Modeling of Tunnels in Soft Ground: A Review". Tunnelling and Underground Space Technology, Vol: 23, No: 2, pp 185-198.

Morton, J.D., and King, K.H. (1979). "Effect of Tunnelling on the Bearing Capacity of and Settlement of Piled Foundations". Proceedings of Tunnelling 1979, London, pp 57-58.

Mroueh, H., and Shahrour, I. (1999). "Three-Dimensional Analysis of the Interaction between Tunnelling and Pile Foundations". Proceedings of the $7^{\text {th }}$ Conference on Numerical Models in Geomechanics, Austria, and The Netherlands, pp 397-402.

Mroueh, H., and Shahrour, I. (2002). "Three-Dimensional Finite Element Analysis of the Interaction between Tunnelling and Pile Foundations". International Journal for Numerical and Analytical Methods in Geomechanics, Vol: 26, pp 217-230.

Muir Wood, A.M. (1975). "The Circular Tunnel in Elastic Ground". Geotechnique, Vol: 25, No: 1, pp 115-127. 
Murayama, S. (1968). "Earth Pressure on Vertically Yielding Section in Sand Layer" [in Japanese]. Disaster Prevention Research Institute Annuals, Kyoto University, Vol: 11B, pp. 123-138.

Murayama, S., and Matsuoka, H. (1971). "Earth Pressure on Tunnels in Sandy Ground" [in Japanese]. Journal of Geotechnical Engineering, JSCE 187, pp. 95-108.

Nakai T., Shahin H.M., Hinokio M., and Sada T. (2000). "Tunnel Excavations Considering Building Loads: 2D Model Tests and Numerical Analysis". Nagoya Institute of Technology, Japan.

Nomoto, T., Imamura, S., Hagiwara, T., Kusakabe, O., and Fujii, N. (1999). "Shield Tunnel Construction in Centrifuge". Journal of Geotechnical and Geoenvironmental Engineering, Vol.: 125, No.: 4, pp 289-300. Japan.

Peck, R.B. (1969). "Deep Excavations and Tunneling in Soft Ground", Proceedings, Seventh International Conference on Soil Mechanics and Foundation Engineering, Mexico City, State of the Art Volume, pp. 225-290.

PLAXIS B.V. (2004). "PLAXIS 2D Version 8.2 - Finite element code for soil and rock analysis", A.A. Balkema Publishers, Delft, The Netherlands.

Poulos, H.G., and Davis, E.H. (1974). "Elastic Solutions for Soil and Rock Mechanics". John Wiley \& Sons Inc.

Potts, D.M., and Addenbrooke, T.I. (1997). "A Structure's Influence on TunnellingInduced Ground Movements". Proceedings of the Institute of Civil Engineers, Geotechnical Engineering, Vol: 125, April, pp 109-125.

Potts, D.M., and Bond, A.J. (1994). "Calculation of Structural Forces for Propped Retaining Walls". Proceedings $13^{\text {th }}$ International Conference of Soil Mechanics and Foundations Engineering, New Delhi, Vol: 2, pp 823-826.

Rankin, W.J. (1988). "Ground Movements Resulting From Urban Tunnelling". Proceedings of the Conference of Engineering Geological Underground Movements, Nottingham, pp 79-92.

Sakai, T. (1996). "A Study of a Particle Size Effect of a Trap Door Problem with Glass Beads". Faculty of Agricullture, Ehime University, Japan, pp. 145.

Schanz, T. (1998). "Zur Modellierung des Mechanischen Verhaltens von Reibungsmaterialien". Habilitation, University of Stuttgart, Germany.

Schanz, T., Vermeer, P.A., and Bonnier, P.G (1999). "The Hardening Soil Model: Formulation and Verification". Brinkgreve (ed) Beyond 2000 in Computational Geotechnics. Balkema, Rotterdam, pp 281-296.

Sharma, Bolton and Boyle, R.E. (2001). "A New Technique for Simulation of Tunnel Excavation in a Centrifuge". Geotechnical Testing Journal, Vol.: 24 No.: 4, pp. 343349.

Stimpson, B. (1970). "Modeling Materials for Engineering Rock Mechanics". International Journal of Rock Mechanics and Mining Sciences, Vol: 7, pp 77-121.

StrainBook 616, and WaveBook Software (2005). "Ethernet-Based Strain Gauge Measurement System". IOtech Inc., Cleveland, OH. U.S.A. 
Vermeer, P.A., and Bonnier, P.G. (1991). "Pile Settlements due to Tunnelling". Proceedings of the $10^{\text {th }}$ European Conference on Soil Mechanics and Foundation Engineering, Italy, and The Netherlands, Vol: 2, pp 869-872.

Vermeer, P.A., Marcher, T., and Ruse, N. (2002). “On the Ground Response Curve". Felsbau. Rock and Soil Engineering. Vol: 20, No.: 6, pp 19-24

Xu, L.M., Nakai, T., and Yamazaki, H. (1995). "Three Dimensional Model Tests and Analyses of Lowering Basement" [in Japanese]. Proceedings of the $30^{\text {th }}$ Japanese National Conference on Geotechnical Engineering, pp. 504-505.

Zurabov, G.T., and Bugaeva, O.E. (1962). "Water Tunnels in Hydroelectric Stations". Gosenérgoizdat, Moscow. 


\section{APPENDICES}

\section{A - AutoCad Drawing of Steel Box Structure and Flange Components}

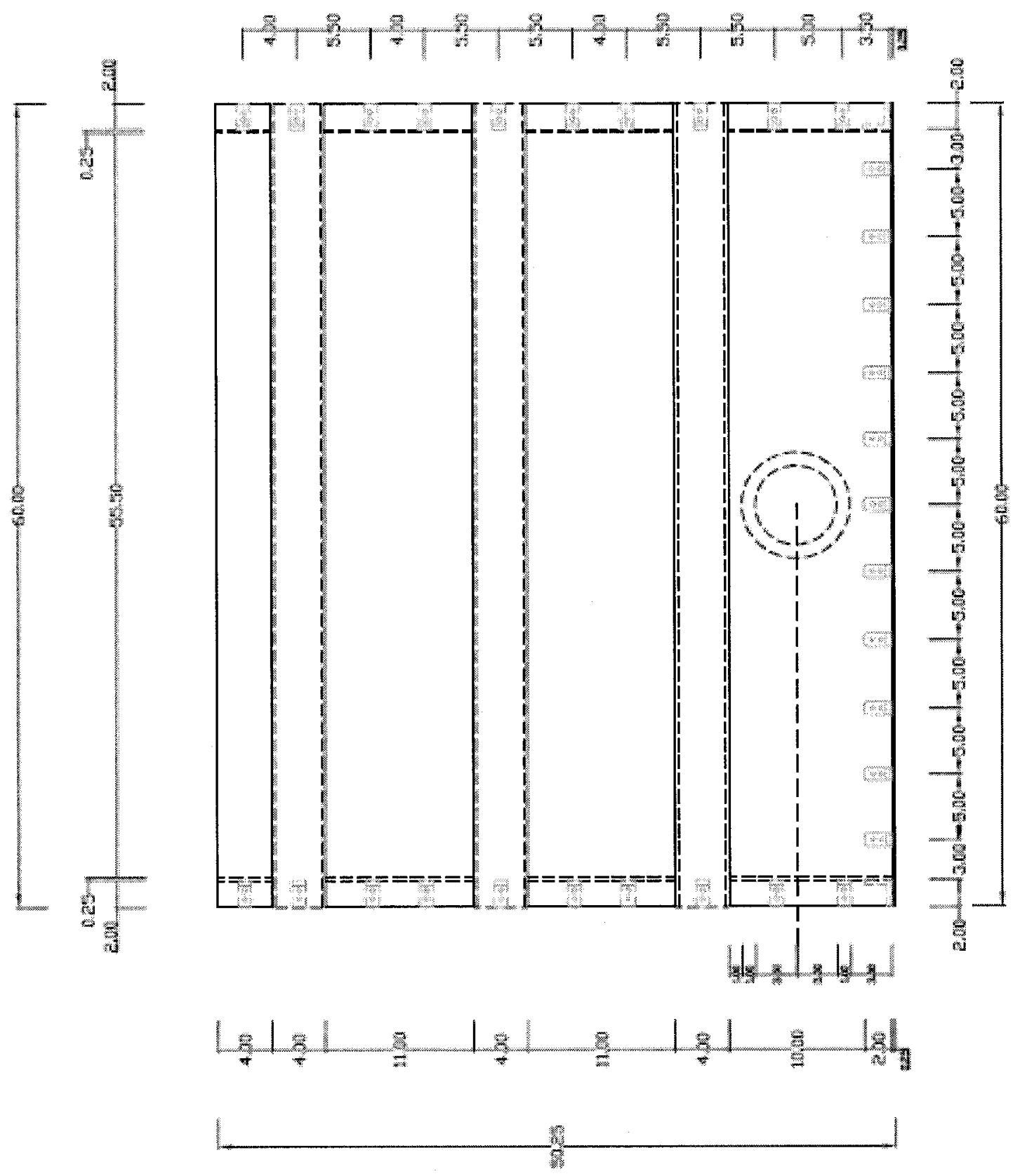



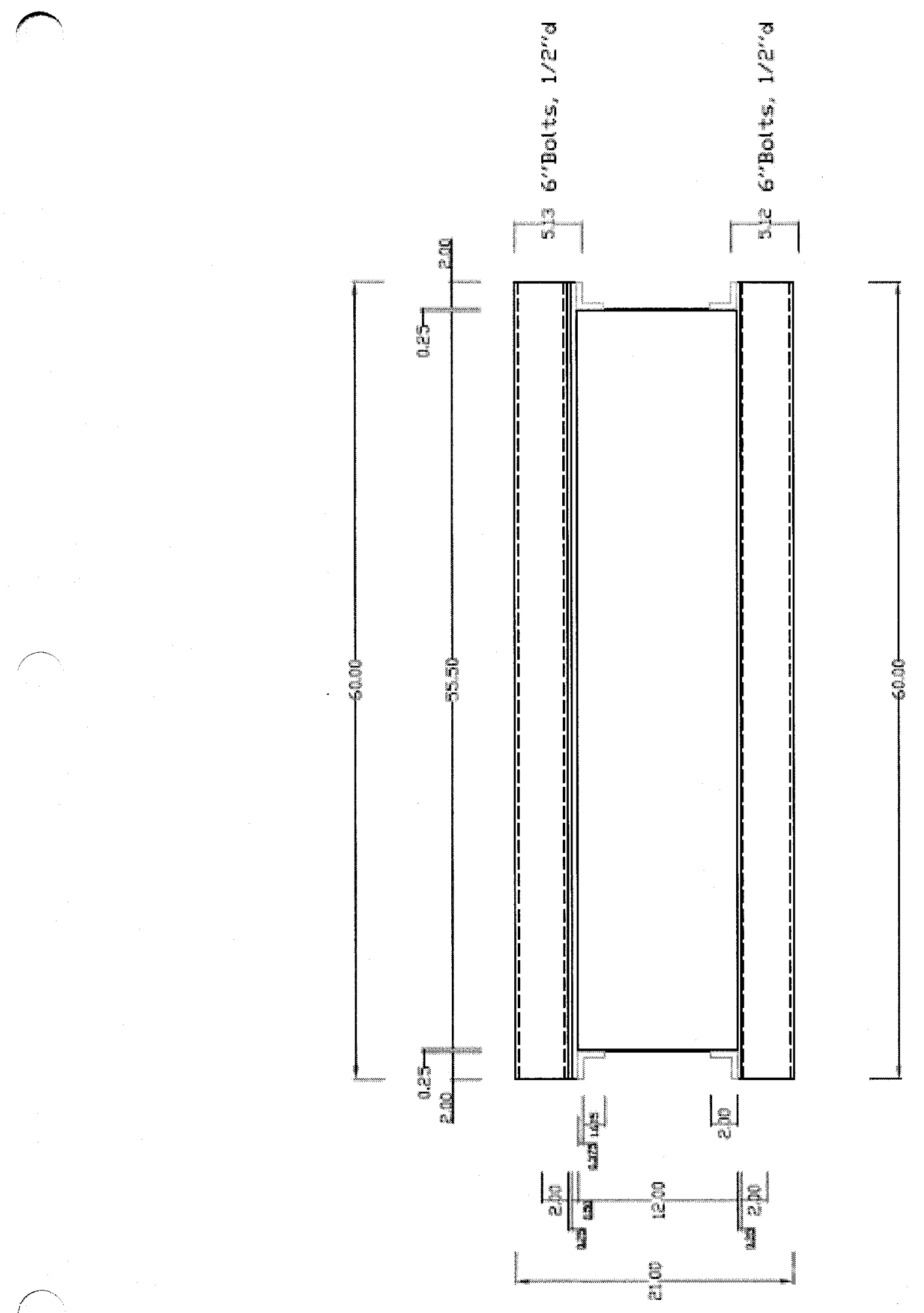


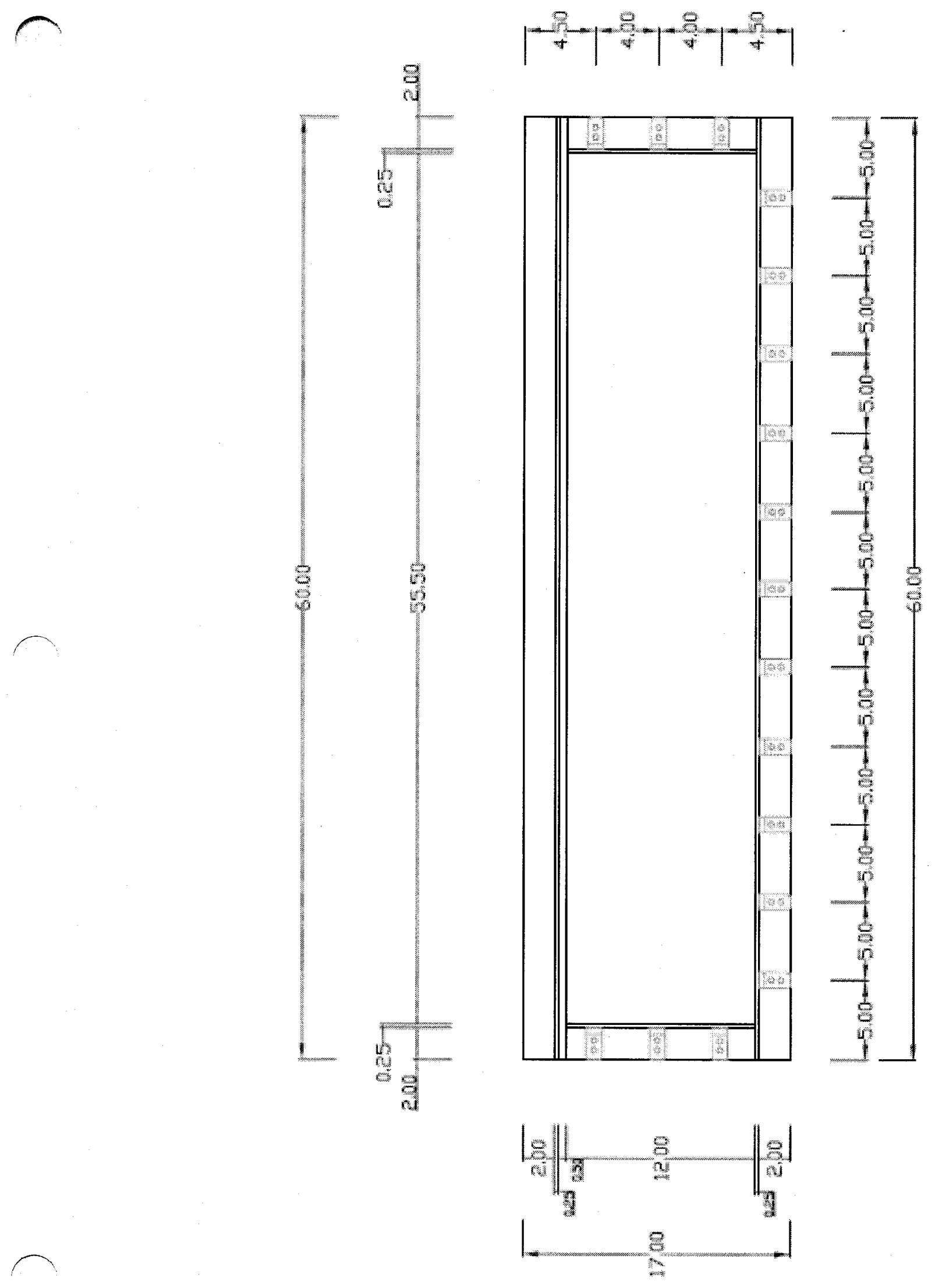


$\frown$
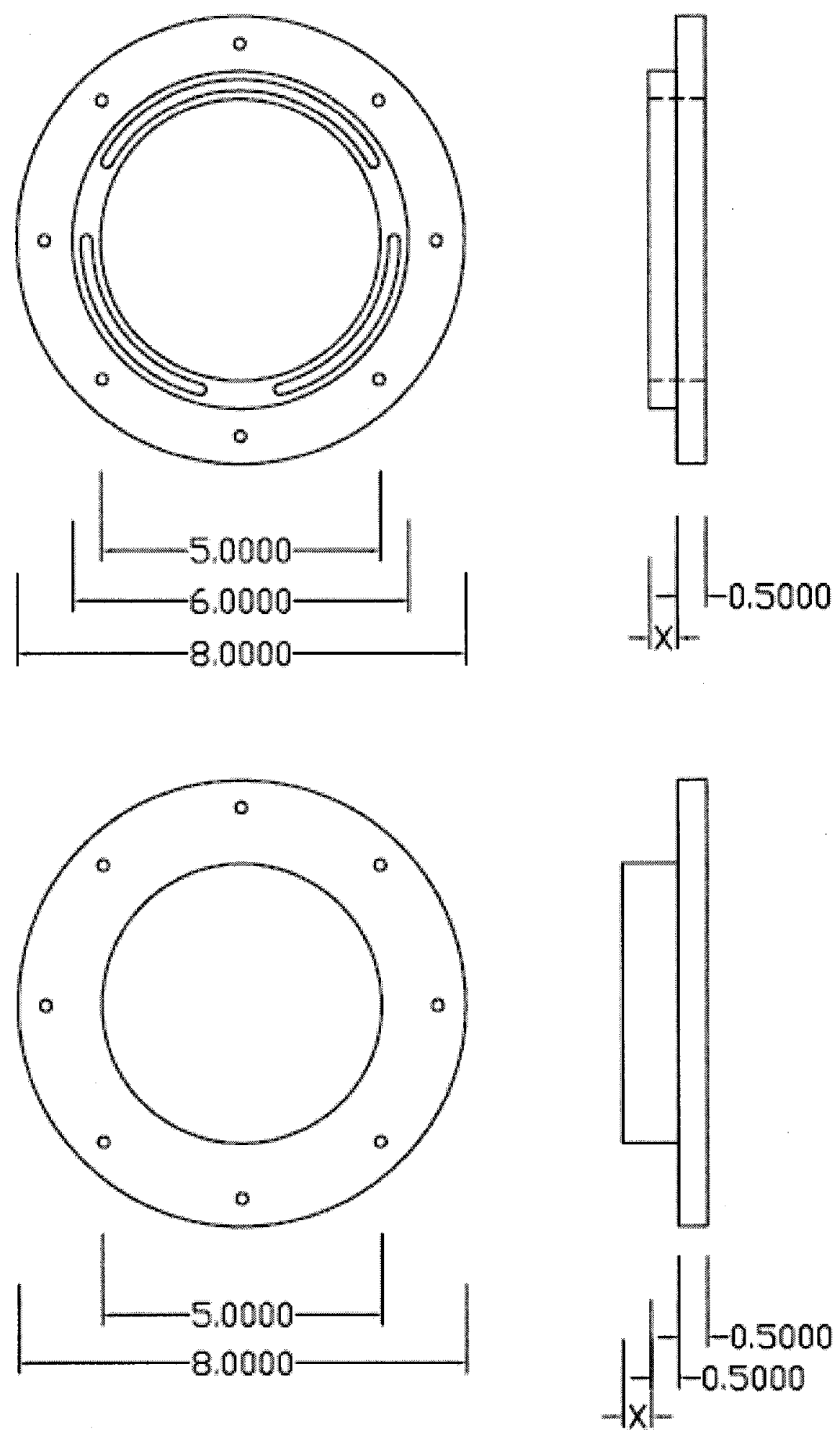

Dimensions are in inches. $\mathrm{X}$ represents the thickness of the respective side of the box where the flange is applied on: $1 / 4$ inch $(0.006 \mathrm{~m})$ for the steel face, $1 / 2$ inch $(0.013 \mathrm{~m})$ for the plexiglas face. 


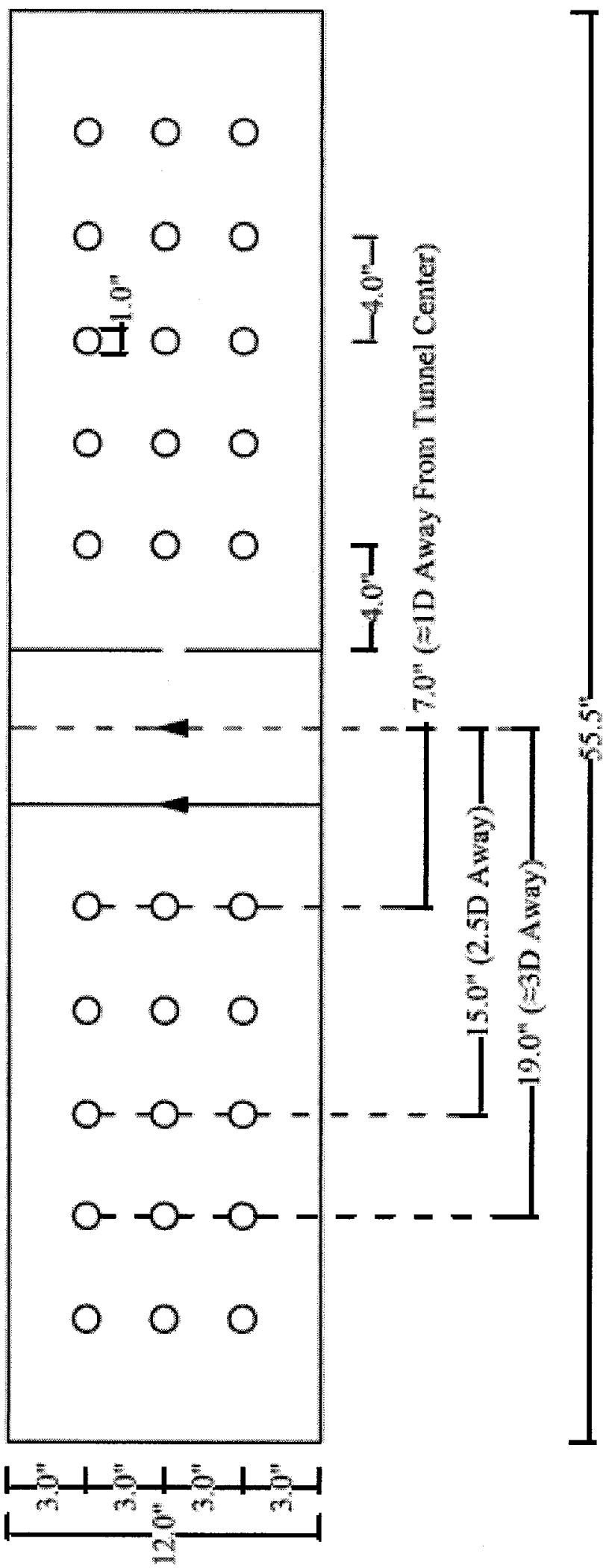

